\title{
ANALYSIS OF THE EXPERIMENTAL LICENSES OF THE FEDERAL COMMUNICATIONS COMMISSION (FCC)
}

\author{
by \\ Pedro J. Bustamante
}

Electronics Engineer, Universidad del Azuay, 2010

\author{
Submitted to the Graduate Faculty of \\ the School of Information Sciences in partial fulfillment \\ of the requirements for the degree of \\ Master of Sciences
}

University of Pittsburgh

2017 


\section{UNIVERSITY OF PITTSBURGH \\ SCHOOL OF INFORMATION SCIENCES}

This thesis was presented

by

Pedro J. Bustamante

It was defended on

December 15th 2016

and approved by

Martin Weiss, Professor

Phrashant Krishnamurthy, School of Information Sciences Associate Professor Douglas Sicker, Carnegie Mellon University Head of the Engineering and Public Policy Department

Thesis Advisor: Martin Weiss, Professor 


\title{
ANALYSIS OF THE EXPERIMENTAL LICENSES OF THE FEDERAL COMMUNICATIONS COMMISSION (FCC)
}

\author{
Pedro J. Bustamante, M.S. \\ University of Pittsburgh, 2017
}

Experimental licenses have been awarded by the Federal Communications Commission for more than thirty years as a means to promote research and innovation. In this work, we present a comprehensive analysis of the details pertaining to the assignment of these licenses during the past ten years. For this purpose, utilizing publicly available information in the Commissions website, we have built a general database. This has permitted us to differentiate among the existing types of Experimental Licenses and, subsequently, analyze the multiple technical and non-technical details of these licenses. We pay particular attention to the evolution, over time, of various parameters such as duration of licenses, frequency of assignment, processing times, operational parameters, applications, among others. We conclude this work by delving into license details that permit us to map their application to efforts toward the development of next generation cellular technologies. 


\section{TABLE OF CONTENTS}

1.0 INTRODUCTION . . . . . . . . . . . . . . . . . . . . . . 1

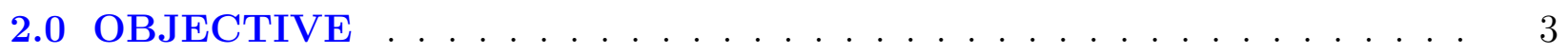

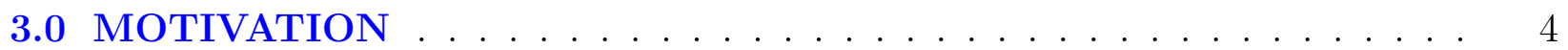

4.0 BACKGROUND . . . . . . . . . . . . . . . . . . . . 6

4.1 Regulation ............................ 6

4.1.1 Types of Licenses . . . . . . . . . . . . . . . . . . . 7

4.1.1.1 Conventional Experimental: . . . . . . . . . . . . 7

4.1.1.2 Broadcast Experimental: . . . . . . . . . . . . . . . 8

4.1.1.3 Program experimental: . . . . . . . . . . . . 8

4.1.1.4 Medical Testing Experimental: . . . . . . . . . . . . . 8

4.1.1.5 Compliance Testing Experimental . . . . . . . . . . . . 9

4.1 .2 Technical Limitations . . . . . . . . . . . . . . . . . . . . . . . . 9

4.1.2.1 Frequency ................... 9

4.1.2.2 Power . . . . . . . . . . . . . . . . 10

4.1.2.3 Non-interference Criterion . . . . . . . . . . . . . . . 10

4.2 Application Process . . . . . . . . . . . . . . . . . . 10

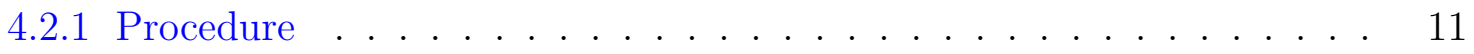

4.2 .2 License Period . . . . . . . . . . . . . . . . . 11

4.2.2.1 Special Temporary Authorization . . . . . . . . . . . . 11

4.2.2.2 Broadcast Experimental . . . . . . . . . . . . . 11

4.2 .3 Experimental Report . . . . . . . . . . . . . . . 13

4.2 .4 Confidential Applications . . . . . . . . . . . . . . . 13 
4.3 Impact of Experimental Radio Service . . . . . . . . . . . . . . . . . 13

4.3 .1 Amateur Radio . . . . . . . . . . . . . . . . . . . . . . . . . 13

4.3 .2 Demonstrations . . . . . . . . . . . . . . . . . . . . 14

4.3 .3 Testbeds . . . . . . . . . . . . . . . . . . . . . . 14

4.3 .4 Future Technologies . . . . . . . . . . . . . . . . . . . . 15

5.0 METHODOLOGY . . . . . . . . . . . . . . . . . . . . 16

5.1 Information Organization $\ldots \ldots \ldots \ldots$

5.2 Database . . . . . . . . . . . . . . . . . . . . 17

5.2 .1 Scraping Interface $\ldots \ldots \ldots \ldots$

5.2 .2 Ten-year Database . . . . . . . . . . . . . . . . . . . 18

5.3 Analysis . . . . . . . . . . . . . . . . . . . . . . 21

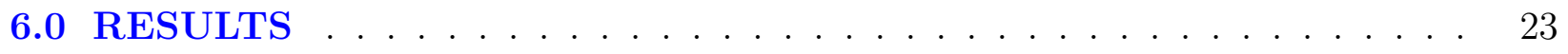

6.1 General Assignment Process . . . . . . . . . . . . . . . . . . . . . . 23

6.1 .1 License Type . . . . . . . . . . . . . . . . . . . . . . . . 24

6.1 .2 General Processing Time . . . . . . . . . . . . . . . . . 25

6.2 Conventional Licenses . . . . . . . . . . . . . . . . . . . . . . 28

6.2 .1 General Information . . . . . . . . . . . . . . . . . 28

6.2 .2 Licensee Details . . . . . . . . . . . . . . . . . . . . . . . . . 29

6.2 .3 Technical Characteristics . . . . . . . . . . . . . . . 33

6.2 .3 .1 Equipment . . . . . . . . . . . . . . . . 33

6.2.3.2 Frequency Assignment . . . . . . . . . . . . . . . . 34

6.2.3.3 Authorized Power . . . . . . . . . . . . . . . . . . . 39

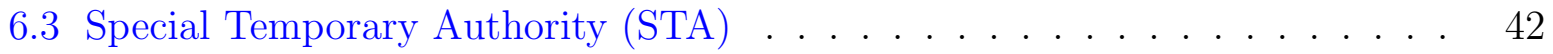

6.3 .1 General Information . . . . . . . . . . . . . . . . . . 42

6.3 .2 Technical Details . . . . . . . . . . . . . . . . . . 44

6.3.2.1 Equipment. . . . . . . . . . . . . . . . . . . 44

6.3.2.2 Assigned Frequencies . . . . . . . . . . . . . . . . 44

6.3.2.3 Authorized Power . . . . . . . . . . . . . . . . . . 48

6.3 .3 Purpose of Operation . . . . . . . . . . . . . . . . . . . 50

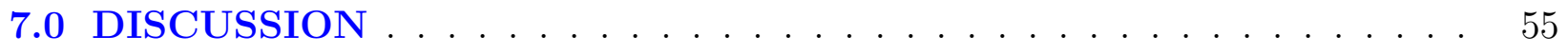


7.1 Findings . . . . . . . . . . . . . . . . . . . 55

7.1 .1 General Assignment Process . . . . . . . . . . . . . . . 55

7.1 .2 Conventional Licenses . . . . . . . . . . . . . . . . . 56

7.1.3 Special Temporal Authorizations . . . . . . . . . . . . . . 60

7.2 Experimental Licenses and Future Technologies . . . . . . . . . . . . . 61

7.2 .1 Experimental Authorizations . . . . . . . . . . . . . . . . 62

7.2.1.1 Experimental Coverage: . . . . . . . . . . . . . . 63

7.2.1.2 Equipment Testing . . . . . . . . . . . . . 63

7.2.1.3 Design and Development . . . . . . . . . . . . . 65

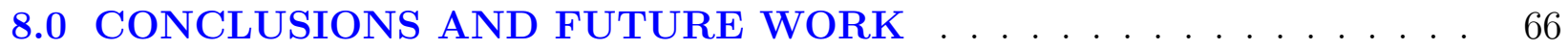

APPENDIX A. SUMMARY PURPOSE OF OPERATION STAS . . . . . 68

APPENDIX B. UHF BAND DISTRIBUTION . . . . . . . . . . . . . . . 77

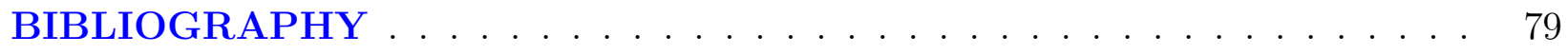




\section{LIST OF TABLES}

1 Evolution in the Number of Experimental Licenses from 2007 to 2016 . . . . 25

2 Application Processing Time . . . . . . . . . . . . . . . . . 27

3 Licensee Identification (FCC Form 442) . . . . . . . . . . . . . . . 31

4 Frequency Distribution by Radio Band (FCC Form 442 ) . . . . . . . . . 37

5 Power Distribution (FCC Form 442) . . . . . . . . . . . . . . 40

6 STA Frequency Distribution by Radio Band . . . . . . . . . . . . . . . . 45

7 STA Power Distribution . . . . . . . . . . . . . . . . . . . . . . . 49

8 Applicants with the greatest number of granted STAs _ . . . . . . . . 51

9 Average Processing Time by Type of License . . . . . . . . . . . . . . 57

10 Distribution of Frequencies in the UHF Band . . . . . . . . . . . . . . 60

11 Authorized Frequencies License Number 0040-EX-ML-2012 (University of Texas) 64

12 Authorized Frequencies STA WK9XII(AT\&T) . . . . . . . . . . . 65

13 Authorized Equipment STA WK9XII(AT\&T) . . . . . . . . . . . . . 65

14 Authorized Frequencies License 0494-EX-PL-2016 (Keysight Technologies, Inc.) 65 


\section{LIST OF FIGURES}

1 FCC Experimental Licenses Classification . . . . . . . . . . . . . . . 8

2 FCC Standard Forms . . . . . . . . . . . . . . . . . . . . . 12

3 Scraping Code Structure (Java Code) … . . . . . . . . . . . . . . 19

4 Number of Granted and Denied Licenses by the FCC for the past 30 years . . 20

5 Distribution of Number of Licenses per year . . . . . . . . . . . . . . . 21

6 Evolution in the Number of Experimental Licenses Granted by the FCC . . . 24

7 Distribution of Number of Licenses by Type . . . . . . . . . . . . . . 26

8 Processing Time Metrics . . . . . . . . . . . . . . . . . . 27

9 Distribution processing times by elapsed months . . . . . . . . . . . . 28

10 New Licenses vs. Modification of Licenses . . . . . . . . . . . . . . . . . . 29

11 Distribution of Requested Times (FCC Form 442) $\ldots \ldots$. . . . . . . 30

12 Requested Periods in the past 10 years (FCC Form 442) . . . . . . . . . 30

13 Licensee Identification (FCC Form 442) … . . . . . . . . . . 31

14 Additional Identification Parameters (FCC Form 442) . . . . . . . . . . 33

15 Equipment Classification (FCC Form 442) . . . . . . . . . . . . . . . 34

16 Equipment Classification Distribution (FCC Form 442) . . . . . . . . . 34

17 Global Station Classification(FCC Form 442) . . . . . . . . . . . . . 35

18 Frequency Distribution by Radio Band (FCC Form 442) . . . . . . . . . . 36

19 Frequency Distribution Conventional Licenses (Lower Bands) . . . . . . . . . 38

20 Frequency Distribution Conventional Licenses (Middle Bands) . . . . . . . . . 39

21 Frequency Distribution Conventional Licenses (Higher Bands) . . . . . . . . . 39

22 FCC Form 442 Power Distribution by Power Level . . . . . . . . . . . . . . . 41 
23 FCC Form 442 Power Distribution by Year . . . . . . . . . . . . . . 42

24 STA License Duration Distribution . . . . . . . . . . . . . . . . . . 43

25 STA License Duration Distribution for licenses of 30 days or less . . . . . . . 43

26 STA Equipment Classification . . . . . . . . . . . . . . . . 44

27 STA Frequency Distribution by Radio Band . . . . . . . . . . . . . . 46

28 STA Frequency Distribution (Lower Bands) . . . . . . . . . . . . . . 47

29 STA Frequency Distribution (Middle Bands) . . . . . . . . . . . . . . 48

30 STA Frequency Distribution (Higher Bands) $\ldots \ldots \ldots$. . . . . . . . 48

31 STA Power Distribution by Power Level . . . . . . . . . . . . . . . . 50

32 STA Power Distribution by Year . . . . . . . . . . . . . . . 50

33 Purpose of Operation among companies with the greatest number of STAs. . 52

34 Classification Purpose of Operation STAs . . . . . . . . . . . . . . 54

35 Processing Delay by Type of License . . . . . . . . . . . . . . . . . 57

36 Distribution of Frequencies in the UHF Band . . . . . . . . . . . . . 59

37 Number of Licenses Assigned in the 3 to $300 \mathrm{GHz}$ bands . . . . . . . . . . . 62 


\subsection{INTRODUCTION}

For innovation to be successful, it is necessary for the adequate resources to be readily available. Commonly, resource availability results from significant technical, regulatory and scientific investments. Regulatory bodies, like the Federal Communications Commission, have made significant efforts in order to promote innovation. Innovation comes from entities of different sizes and areas of impact, as well as from commercial to academic objectives.

The licensing plan of the Federal Communications Commission is rather broad and it aims at targeting different types of spectrum uses. It is important to note that many of these licenses not only focus on promoting innovative uses of spectrum, but also on giving access to this resource to parties with limited access to general, commercial spectrum auctions. The objective of the Commissions Experimental Licensing system is precisely to provide spectrum to different types of users, while promoting innovation. When a licensing system is implemented, it is interesting to observe what is its impact. The impact of commercial licenses is quite evident. Indeed, we can pay attention to multiple indicators which allow us to infer how valuable the auctioned spectrum is and which are the uses which merit higher investments. Nevertheless, in other cases, such as that of experimental licenses, those indicators tend to not be that clear.

There is a significant amount of public information regarding these licenses; however, a deeper analysis is required to draw conclusions. The analysis in question can provide us with metrics to evaluate how onerous the process to obtain a license is, but more importantly, it can allow us to find out whether and how an experimental licensing system has contributed to the development and improvement of the myriad technologies that have arisen. It is for

this reason that in this work we tackle the task of delving deeper into the experimental licensing world. 
Our first task is to obtain all the relevant information, organize it and then process it taking into account metrics that we consider appropriate for our evaluation. For this purpose, we build a general experimental license database by scraping information from the FCCs website under the "Generic Search Platform". Having all the information in one database under a single repository, allows us to determine which are the parameters that can be studied in more detail, including technical and non-technical details of not only the licenses itself, but also the applicants. Ultimately, these parameters permit us to explore the actual applicability of experimental licenses in technologies such as $5 \mathrm{G}$ and lay the ground for future analyses and studies regarding other areas of impact. 


\subsection{OBJECTIVE}

The main goal of this thesis is to explore and analyze the evolution in the assignment of experimental licenses (Experimental Radio Service) by the Federal Communications Commission in the past 10 years (2007-2016). Furthermore, this thesis aims to explore not only the technical, but also the non-technical characteristics associated with the different experimental licenses that have been assigned.

In order to achieve the aforementioned goal, this work seeks to:

- Build a parallel database that combines technical and non-technical information under a single data repository using the publicly available information of the FCC. ${ }^{1}$

- Analyze the evolution in the assignment of experimental licenses in terms of the number of licenses granted and denied each year and the type distribution.

- Explore different non-technical features of the granted licenses, such as: processing times, requested times, type of licensee, etc.

- Explore the frequency and power characteristic of the different licenses that have been granted by the FCC in the past ten years.

- Discuss particular examples of the application of experimental licenses in the development of next generation cellular technologies.

\footnotetext{
${ }^{1}$ The FCC details information by licensee, but it does not display all applicants under a single database.
} 


\subsection{MOTIVATION}

In the past ten years, the fast evolution of wireless technologies and the innovation surrounding them is undeniable. Nowadays, for instance, the proportion of users that have an LTE signal in countries such as South Korea, United States or Japan is greater than $81 \%$ [15]. Furthermore, several efforts are being done to start deploying the Fifth Generation of Cellular Networks (5G) by the first quarter of 2018 [18]. A critical part of these efforts constitute the spectrum bands where $5 \mathrm{G}$ will be deployed, as this represents one of the most innovative and effective characteristics of $5 \mathrm{G}$. Indeed, the initial experiments in $5 \mathrm{G}$ have proposed the use of large chunks of underutilized spectrum in very high frequencies such as millimeter-wave (mmWave) $[10,17,19]$. It is in this manner that several experimental licenses granted by the FCC have been utilized for testing these new concepts in very high frequencies $[12,20,2,11]$.

Nonetheless, we consider that a key factor in comprehending the relationship between experimental licenses and future wireless technologies, as an example, is to first study their basis. To the best of our knowledge, no analysis has been done to explore the fundamental characteristics of the Experimental Radio Service licenses that have been issued by the Federal Communications Commission. As the first step this requires finding a method that allows us to extract, aggregate and process the information that the FCC has made publicly available $^{1}$. To this end, we deem appropriate to build and consolidate a database with this information, which would allow us to perform a deeper analysis on relevant metrics and parameters. We expect such an analysis to represent a useful tool for current and

\footnotetext{
${ }^{1}$ Non-confidential information regarding license assignment can be accessed through the FCC's webpage. Nevertheless, there is no access to a complete database including technical and non-technical details for massive consultations of the users under a single repository.
} 
future exploratory activities around the relationship between experimental licenses and the development of new technologies. 


\subsection{BACKGROUND}

We begin this work by exploring the basic characteristics of the Experimental Radio Service (ERS) of the FCC. In this light, the following section starts with an overview of the

legal documents that constitute the basis for the assignment of experimental licenses. This overview includes an analysis of the current regulation of the ERS, which focuses on the types of licenses and the different technical limitations related to them. In addition, this section reports on an analysis of the established procedure by the FCC to obtain an experimental license and its relationship to the different types of applications for licenses. We conclude this section by discussing some examples of experimental licenses being used in fields of the wireless environment.

\subsection{REGULATION}

The Federal Communications Commission (FCC) is authorized to provide experimental use of frequencies as amended in the Section 303(g) of the Communications Act of 1934. This amendment charges the FCC with the responsibility of encouraging larger and more effective use of radio spectrum in the public interest. Thus, spectrum licenses may be used for purposes of experimentation, product development and market trials, which are not otherwise permitted under existing service rules[5]. This experimental radio service is administered by the FCC's Office of Engineering and Technology (OET) and its Experimental Licensing Branch.

In its 2013 Report \& Order (R\&O) (FCC 13-15), the Commission adopted numerous changes to its Experimental Radio Service (Part 5), revising and streamlining its rules. 
With the new rules, the FCC states that the Experimental Radio Service (ERS) will have "a more flexible framework to keep pace with the speed of modern technological change, while continuing to provide an environment where creativity can thrive"[6]. These changes were initiated in 2010 when the FCC issued a Notice of Proposed Rulemaking (NPRM) that sought to implement portions of the National Broadband Plan. In the NPRM, the FCC solicited comments on several proposed changes to the ERS rules "to provide additional flexibility to innovators, so that they can more quickly transform their ideas to fully functional new products and services that meet consumer needs." Modifications that have already been included in the Part 5 of the Commission's Rules since January 31, $2013^{1}$.

\subsubsection{Types of Licenses}

The Experimental Radio Service licenses are classified in five categories ${ }^{2}$, which are shown in Fig. 1. According to the FCC, this new license structure will "benefit the development of new technologies, expedite their introduction to the marketplace and unleash the full power of innovators to keep the United States at the forefront of the communications industry." [6]

4.1.1.1 Conventional Experimental: The first type of experimental license is issued for a specific research or experimentation project or a series of closely-related projects. In this way, if the series of projects are widely divergent and unrelated, experiments must be conducted under separate licenses. In addition, a conventional license could be issued for a product development trial, or a market trial.

The Special Temporary Authorization (STA) is a subcategory of the conventional experiment licenses. An STA applies to cases where applicants need to operate transmitting equipment in circumstances where it is not possible to wait for a license to be issued. Further, STA applications can either be associated with an existing license or not. This permission is issued when the program is expected to last no more than six months; thus, its operation is considered temporary.

\footnotetext{
${ }^{1}$ Report \& Order (R\&O) FCC 13-15 released by the FCC on February 4, 2013.

${ }^{2}$ This new license scheme was implemented by the FCC in 2013, where three new types of Experimental Radio Service licenses were included: Program, Medical Testing and Compliance Testing.
} 


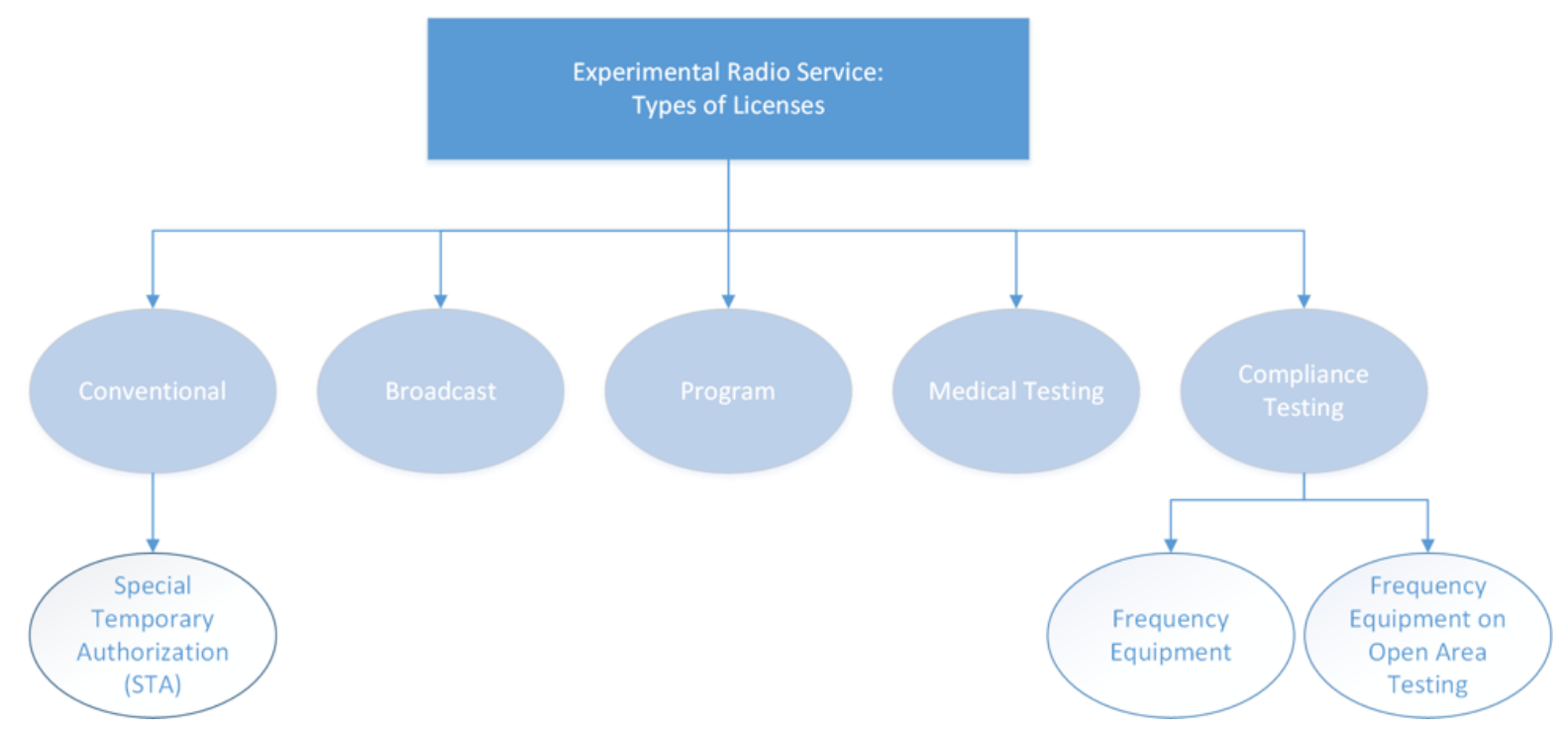

Figure 1: FCC Experimental Licenses Classification

4.1.1.2 Broadcast Experimental: These licenses were introduced in 2013 as part of the modifications of the Commission's Rules. The corresponding authorization is granted for research and experimentation projects, which focus on the development and advancement of new broadcast technologies, equipment, systems or services. This authorization is limited to use by the general public and stations intended for reception.

4.1.1.3 Program experimental: Intended for qualified institutions wishing to conduct an ongoing program of research and experimentation under a single experimental authorization. These institutions include: colleges, universities, research laboratories, manufacturers and medical research institutions that integrate radio frequency equipment into their end products.

4.1.1.4 Medical Testing Experimental: Program experimental licenses are generally issued for medical research institutions. Nevertheless, a medical testing license is intended for hospitals and health care institutions that demonstrate expertise in testing and operating experimental medical devices that use wireless telecommunications technology or communi- 
cations functions in clinical trials for diagnosis, treatment, or patient monitoring.

4.1.1.5 Compliance Testing Experimental This type of license is specific for laboratories recognized by the FCC to perform the following:

- Product testing of radio frequency equipment.

- Testing of radio frequency equipment in an Open Area Test Site ${ }^{3}$.

\subsubsection{Technical Limitations}

The rules of the Experimental Radio Service provide great flexibility with regards to the technical parameters of the petitions: allowable frequency range, transmitted irradiated power, and emission. Nonetheless, the FCC, as the enforcement agency, clearly mandates that: "radiations of the transmitter shall be suspended immediately upon detection or notification of a deviation from the technical requirements of the station authorization until such deviation is corrected." [5]

4.1.2.1 Frequency Frequencies are assigned on a shared basis and not for the exclusive use of any one licensee. All licensees shall ensure that transmitted emissions remain within the authorized frequency band and bandwidth. Under normal operating conditions, licensees could be allowed to utilize any Federal or non-Federal frequency, except for those exclusively allocated to passive services (e.g., radio astronomy and space research services) ${ }^{4}$. Moreover, the FCC advises to avoid the use of public safety frequencies except when their utilization is in the public interest. Otherwise, coordination is required with the appropriate frequency coordinator or all of the public safety experimenters in the proposed area of operation.

In the case of Broadcast experimental radio stations, the assigned frequencies should be the most suitable for the purpose of the experimentation and those which are the least

\footnotetext{
${ }^{3}$ Tests are normally performed in an RF shielded room or anechoic chamber so that the radio signals used to illuminate the product do not radiate over the airwaves. Open area test sites refer to locations where the signals may radiate over the airwaves and pose a significant risk of interference to communications services.[4]

${ }^{4}$ On July 6, 2015, the Commission adopted a Memorandum Opinion and Order modifying its rules covering Experimental Radio Service. The FCC modified its rules to permit certain licenses to use bands exclusively allocated to the passive services in some circumstances for testing medical devices.[1]
} 
likely to cause interference to established stations. Furthermore, only frequencies allocated to broadcasting service are assigned. If an experiment cannot be feasibly conducted on frequencies allocated to a broadcasting service, an experimental station may be authorized to operate on other frequencies showing that the proposed operation can be conducted without causing harmful interference to established services.

4.1.2.2 Power Since experimental licenses are meant to share spectrum, the transmitting radiated power is understood to be limited to the minimum practical radiated power necessary for the success of the experiment. Furthermore, in the case of broadcast experimental radio stations, the power shall not exceed the maximum power specified by more than five percent.

The efficiency factor should be guided by values normally utilized for similar equipment operated within the authorized frequency range.

4.1.2.3 Non-interference Criterion The FCC mandates that the operation of an experimental radio station is permitted only on the condition that harmful interference is not caused to any station operating on the frequency allocation. Furthermore, the Commission requires that if harmful interference to an established radio service occurs, the licensee should cease transmissions immediately upon becoming aware of such harmful interference. In addition, the radio operator is not allowed to resume transmissions until the licensee establishes, to the satisfaction of the Commission, that further harmful interference will not be caused to any existing radio service.

\subsection{APPLICATION PROCESS}

Even though the FCC rules provide great flexibility regarding the technical parameters, any authorization for stations in the ERS are issued only to entities qualified to conduct those operations. Consequently, it is mandated by the FCC that no experimental radio transmitter within the United States could start operations before a proper authorization 
has been granted. Nonetheless, one special case is considered under this restriction: an experimental license is not required when the device is fully contained within an anechoic chamber or a Faraday cage.

\subsubsection{Procedure}

One key element in the procedure to obtain an experimental license is the usage of FCC Standard Forms for all the petitions managed by the Commission. In this manner, the FCC seeks to expedite the emitting process of experimental licenses, and aims to assure that only the necessary information is supplied in a consistent manner by the different applicants.

Each application should be specific and complete with regards to the information required such as location, proposed equipment, power, antenna height, and operating frequencies. All applications are submitted electronically through the OET website. These standardized forms have been included in Fig. 2 .

\subsubsection{License Period}

The license period is another very flexible aspect of the Commission's ERS program. For Conventional, Program, Medical and Compliance licenses, the regular term assigned by the FCC is 24 months (2 years). However, the applicant can request a license term up to 5 years. Additionally, any license can be renewed for an additional term (no longer than 5 years) upon applicant's request.

4.2.2.1 Special Temporary Authorization STAs represent a special case in terms of license duration. The program to be authorized is expected to last no more than six months. Nevertheless, in order to obtain an STA, the Commission requires applications to be submitted electronically at least ten days prior to the start of the proposed operation.

4.2.2.2 Broadcast Experimental Broadcast experimental radio licenses are issued for 12 month-periods (1 year). Nevertheless, any broadcast license could be renewed for an additional term not exceeding 5 years. 


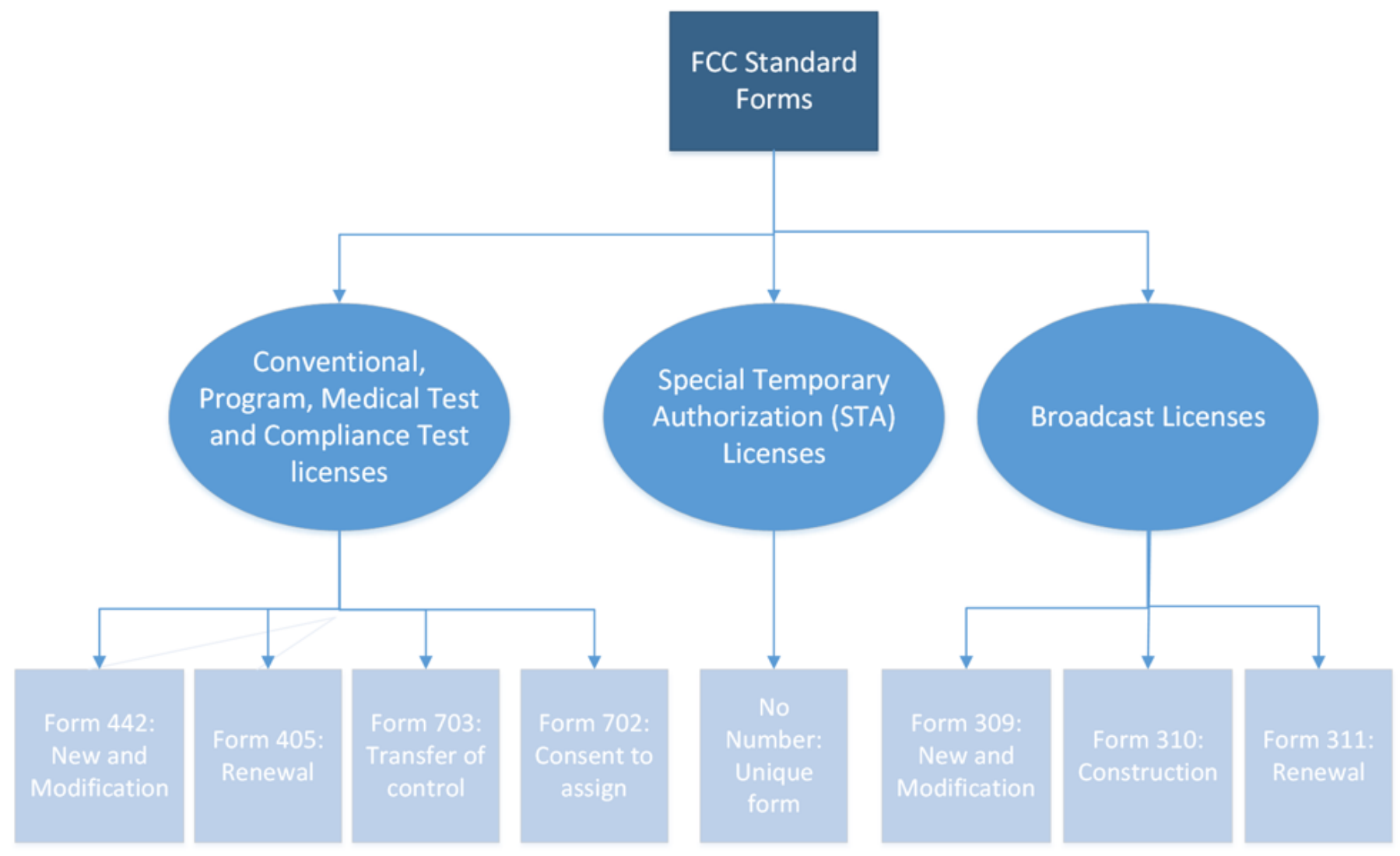

Figure 2: FCC Standard Forms 


\subsubsection{Experimental Report}

It is necessary to point out that for conventional and medical testing licenses, the FCC may require the submission of periodic reports in order to evaluate the progress of the experimental program. However, an applicant may request that the Commission withholds from the public certain reports and associated material.

\subsubsection{Confidential Applications}

An application, or part of it, could be treated as confidential by the FCC upon demand of the applicant. However, the Commission requires an exhibit stating why confidentiality is requested in reference to rule sections 0.457 and 0.459 .

\subsection{IMPACT OF EXPERIMENTAL RADIO SERVICE}

The present work explores not only the different characteristics of the authorized licenses over the past 10 years, but also their impact in various sectors of the wireless community. In this light, we believe that it is possible to trace its impact into several fields that range from amateur experiences to the development of future technologies. We illustrate this through the examples that follow.

\subsubsection{Amateur Radio}

As exhibited by the International Telecommunications Union (ITU) in [21], several countries, including the United States, have authorized the use of various parts of the band from 415 to $526.5 \mathrm{kHz}$ to amateur service operators. Many of these amateur operators have been assigned temporary authorizations with different allowed frequencies and power limits. Furthermore, the ITU recognizes that "Experimental use of these frequencies by amateurs during the past

few years has demonstrated that interesting technical investigations, as well as local and international communications activities, can be conducted successfully" 
This is not the only example of the relationship between amateur radio and experimental licenses. In fact, after the release of the FCC-13-15 Report and Order, the American Radio Relay League (ARRL) was one of the organizations who recognized the value of experimental licenses. The ARRL stated that "...The current Part 5 rules provide a very flexible, well-administered and robust venue for the development of new technologies and products. The ARRL and individual Amateur Radio operators have applied for and been granted Experimental licenses and STAs from time to time..." [7]

\subsubsection{Demonstrations}

Fields of application of experimental licenses also include demonstrations of equipment, standards, protocols, performance, of wireless systems. For instance, during the IEEE International Symposium on Dynamic Spectrum Access Networks (DySPAN) 2008, held in Chicago, IL, 13 live demonstrations of Cognitive Radios comprising transmission, reception and solely reception systems could be showed thanks to the assignation of different $\mathrm{STAs}^{5}$ issued by the FCC for the 482-500 MHz frequency range. Further, this allowed several spectrum sharing actors to utilize this band and interfere with each other for the duration of the event. [16]

\subsubsection{Testbeds}

In the same manner as demonstrations, testing is a key element in the innovation of wireless technologies. Therefore, we can observe that an experimental license issued by the FCC $^{6}$ allowed the Microsoft Research team to deploy a wireless network that operates in the white spaces of the TV band spectrum and covers most of Microsoft campus in Redmond, WA. The FCC authorized the team to operate on all the TV band white spaces in the UHF (512 to $698 \mathrm{MHz}$ ) and VHF (174 to $216 \mathrm{MHz}$ ) bands. [2]

\footnotetext{
${ }^{5}$ Special Temporary Authorizations emitted: Philips Research NA, a division of Philips Electronics North America Corp. (Callsign: WD9XMD), Virginia Tech (Callsign: WD9XMF) and Trinity College Dublin (Callsign: WD9XIB)

${ }^{6}$ Conventional Experimental License to Microsoft Corporation. File Number: 0190-EX-ML-2011
} 


\subsubsection{Future Technologies}

It is also necessary to explore the current efforts that will allow the development of future wireless technologies. In this light, the FCC has issued two licenses ${ }^{7}$ that have been utilized by the Polytechnic Institute of New York University to obtain measurements for future outdoor cellular systems (5G) at $28 \mathrm{GHz}$ and $38 \mathrm{GHz}$. These tests were conducted in urban microcellular environments in New York City and Austin, Texas. [11]

\footnotetext{
${ }^{7}$ Experimental Licenses Number: 0548-EX-PL-2010 and 0040-EX-ML -2012.
} 


\subsection{METHODOLOGY}

After exploring the general guidelines for the assignment of experimental licenses, this chapter focuses on the specific details and steps related to the analysis performed in this thesis. To this end, we first expose the structure of how the information has been made publicly available by the FCC and the implications to this work. Then, we explore the process followed to extract the information from the Commission's webpage and to create the database used in this work.

This chapter concludes by providing a brief analysis of the past 30 years of experimental licenses, which constitutes the basics for the future investigation of the Experimental Radio Service presented in this work. In addition, we exhibit a brief overview of the analysis to be performed in this thesis.

\subsection{INFORMATION ORGANIZATION}

Non-confidential information regarding the experimental licenses, granted and denied, since the year 1987, have been made publicly available by the Office of Engineering and Technology's web page. Nevertheless, since the electronic filing of applications for experimental licenses started in 1995, for the period corresponding from 1987 to 1995, most of the application registers do not contain details about the licenses besides the licensee name and the license identification numbers[13].

All the information about the experimental licenses that have been issued by the FCC are available through the "Generic Search" web page created by the OET. This tool al- 
lows any user $^{1}$ to perform searches in the Experimental Licensing Branch database of the Commission[14].

A query to the Experimental Licensing Branch Database of the Commission through the "Generic Search Platform" will result in a table of contents of all the applications with the following details:

- General Information:

- File Number

- Call Sign

- Applicant Name

- Status of the License

- Dates:

- Receipt Date

- Status Date (Corresponds to the date when the license was issued)

- Detailed Information (For each of the applications):

- Applicant Information

- License Details

- Technical Information

\subsection{DATABASE}

As previously mentioned, all the information about experimental licenses is only available through the use of the "Generic Search" platform of the FCC, as no Application Program Interface (API) is available to directly query the Experimental Licensing Branch database in an automated manner. The results of each query are presented using HyperText Markup Language (HTML). Consequently, the best suitable alternative, and first step in this work, is to extract and compile all the required information about the experimental licenses through the implementation of a scraping (i.e., web harvesting or web data extraction) interface.

\footnotetext{
${ }^{1}$ This includes users that have been granted licenses, and generic users of the application.
} 


\subsubsection{Scraping Interface}

The objective of the scraping interface is to create automatic processes that are able to search, analyze and transform the unstructured data generated through the OET web search platform. In other words, this tool permits to convert raw data in HTML format to structured data that can be stored in a database or a spreadsheet.

To fulfill this goal, a Java code ${ }^{2}$ as an scraping interface was developed ${ }^{3}$. For a complete automatic web extracting process ${ }^{4}$, the code developed comprises the following sections:

1. Connection Setup: Initiates a TCP/IP connection between the Java compiler and the Generic Search Platform of the OET.

2. Classification of Licenses by Form Number: New and Modification, STAs and Renewals.

3. Web Scraping: Extraction of the Information by license.

4. Database Construction: Transform the unstructured data in plain text files for future analysis (8 files per year).

5. Connection Close: Closes the initiated TCP/IP connection.

The tool was designed to process any search performed through the FCC's platform. In this manner, it is flexible enough that it served for building a database for the scope of this project, and it can be also utilized under any search condition placed on the generic platform of the FCC and subsequent database construction.

\subsubsection{Ten-year Database}

The public information on experimental licenses dates from $1987^{5}$. During this period the FCC has granted 24,757 licenses ${ }^{6}$, while the number of dismissed applications reaches 3,750. As it can be observed in Fig.4, the number of granted licenses has continuously grown for

\footnotetext{
${ }^{2}$ Code developed using the Eclipse IDE for Java Developers compiler. Version: Mars.1 Release (4.5.1).

${ }^{3}$ The structure of the resulting code is presented in Fig. 3

${ }^{4}$ The scraping interface still have a limitation of 200 applications at a time, due to the restrictions of visualization in the Generic Search Platform of the FCC.

${ }^{5}$ Between 1987 and 1995 only general information is listed about the licenses. Further, no additional details are provided for each license (Technical Details, Licensee Information, etc.).

${ }^{6}$ Information gathered through the FCC's "OET Generic Search" platform on October 2016. The number of granted licenses include: New, Modification, Renewal, Expired, STAs and Expired due to new licenses.
} 
Connection Setup:

TCP/IP socket connection with the Generic Search Platform

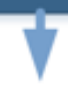

Applications: Identification Information, Dates and Status

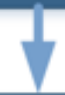

Classification of Licenses by Form (Type of License)

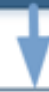

General Information per License

Equipment Information per License

Transmission Technical Details per License

Web Scraping

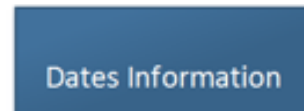

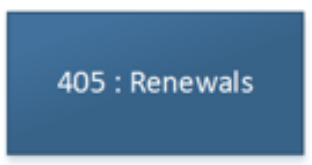

442 (New and

Modification):

General Information

STA:

General Information
STA:

Equipment
442 (New and

Modification):

Equipment

$$
\text { STA: }
$$

Frequencies

Modification):

Frequencies
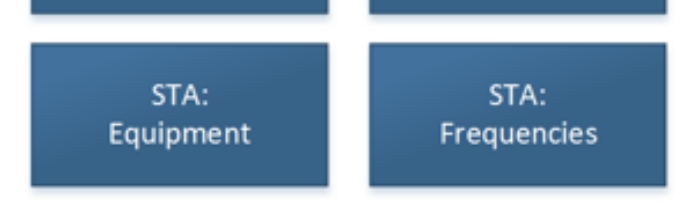

Database Generation

Figure 3: Scraping Code Structure (Java Code) 
the past 30 years. Further, while the number of denied licenses remains relatively constant, the number of issued licenses goes from less than 500 per year in the first 10 years to more than 2000 licenses per year in the last three years. We can also observe that $61 \%$ of the total licenses have been issued by the Commission during the past 10 years (including 2016). Additionally, 39\% of the total number of licenses were emitted in the period between 2012 and 2016 (Fig. 5). It is for this reason that, in this work, we focus on the experimental licensing activity occurring in the last ten years, from 2007 to $2016 .^{7}$

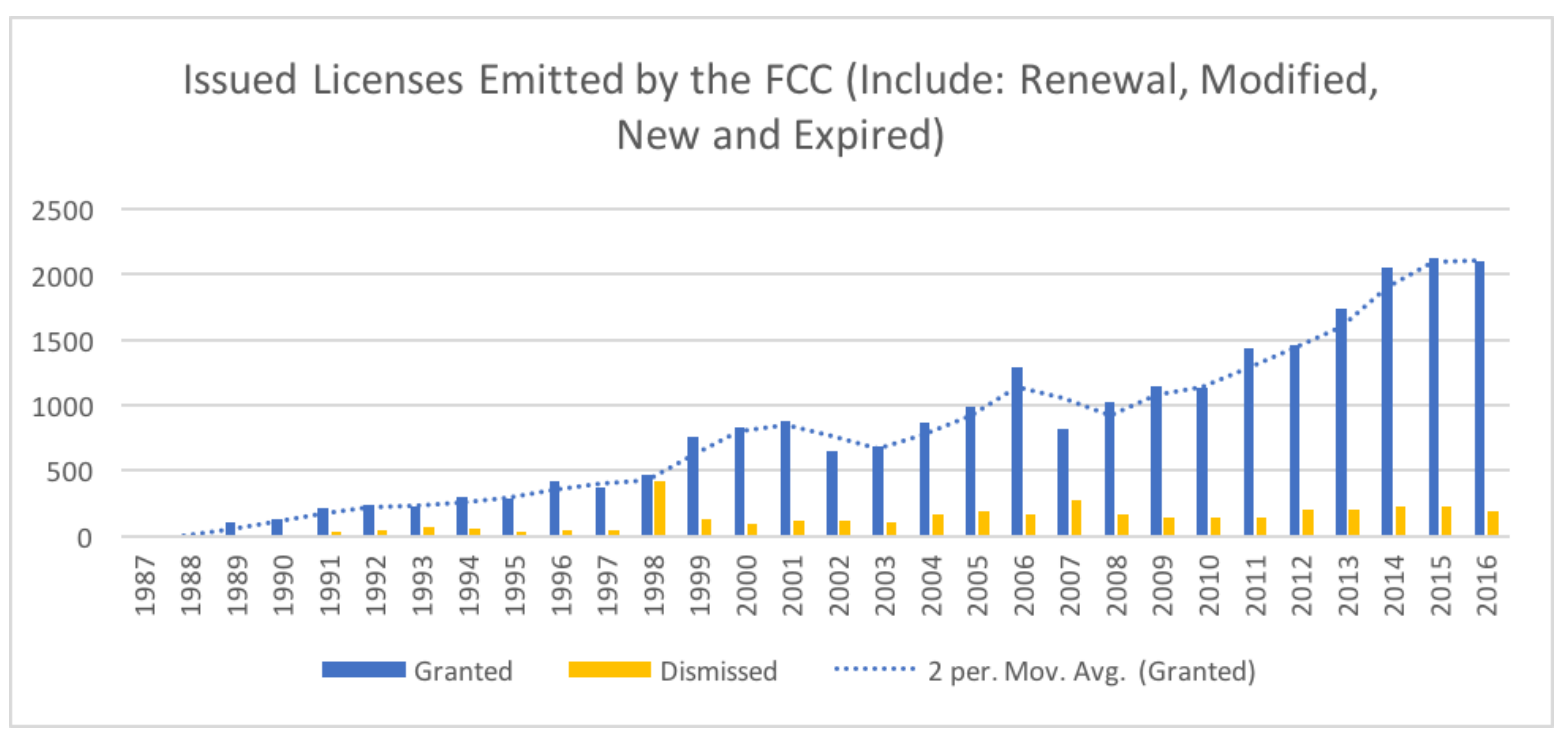

Figure 4: Number of Granted and Denied Licenses by the FCC for the past 30 years

\footnotetext{
${ }^{7}$ Note that given that broadcast licenses (Form 702 and 703) were included by the FCC in 2013, this analysis includes only Forms 442 (New and Modification), 405 (Renewal of Licenses) and Special Temporary Authorization (STA).
} 


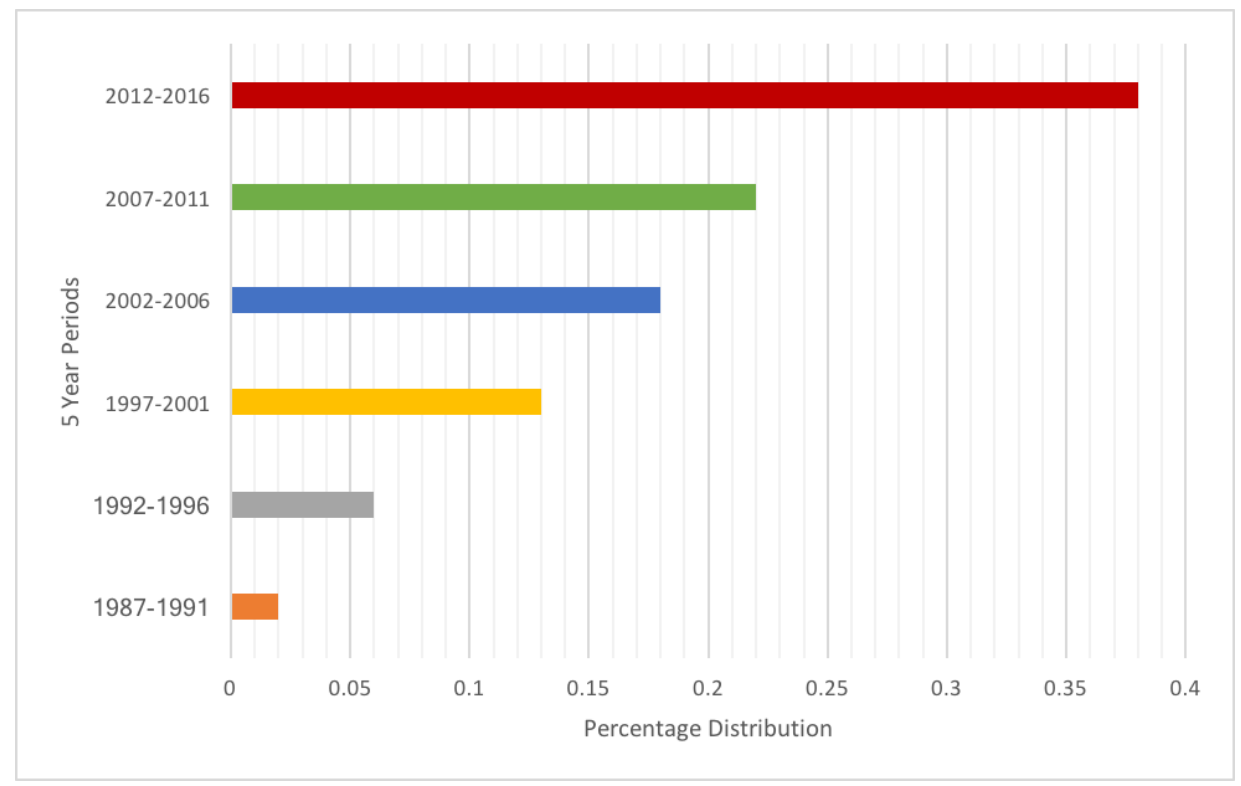

Figure 5: Distribution of Number of Licenses per year

\section{$5.3 \quad$ ANALYSIS}

Since the construction of the database is only one part of the present work, this section concludes by discussing the different characteristics that will be analyzed in this thesis. The information obtained through the scraping process (see Section 5.1) will be statistically analyzed and processed according to the following parameters:

1. Assignment Process

- Type of License

- Processing Time

2. New and Modification Licenses (Form 442)

- Licensee Characteristics

- Requested Times

- Location Distribution

- Technical Features: Frequency and Power 
3. Special Temporary Authority (STA)

- Licensee Characteristics

- Requested Times

- Location Distribution

- Technical Features: Frequency and Power

- Purpose of the Experiment ${ }^{8}$

The processing tools include Microsoft Excel 2016 and MATLAB.

${ }^{8}$ This item will be only analyzed in the STAs section, because only for this form the FCC includes the details of purpose of the experiment under the Generic Search Platform licenses. 


\subsection{RESULTS}

This chapter explores the results of the analysis of the different details and characteristics

of the experimental licenses that have been issued in the past ten years. In this manner, the first items to be exposed are the general characteristics related to the assignment of licenses by the FCC. This first analysis points out the total number of licenses and its classification in addition to the processing times required to obtain a license since 2007. Additionally, this chapter presents an analysis of Conventional Licenses (New and Modification) and Special Temporary Authorizations. For this purpose, the results are classified in general details, licensee information and technical specifications for both types of licenses.

\subsection{GENERAL ASSIGNMENT PROCESS}

We consider necessary to first explore the characteristics that are transversal to all licenses irrespective of their type. For this purpose, we first explore the distribution of the number of licenses since 2007. Thus, we group the licenses according to the FCC form being used and the relationship among them. In addition, we explore the distribution of the elapsed time since a license application was received until the license was granted, for all types of licenses. 


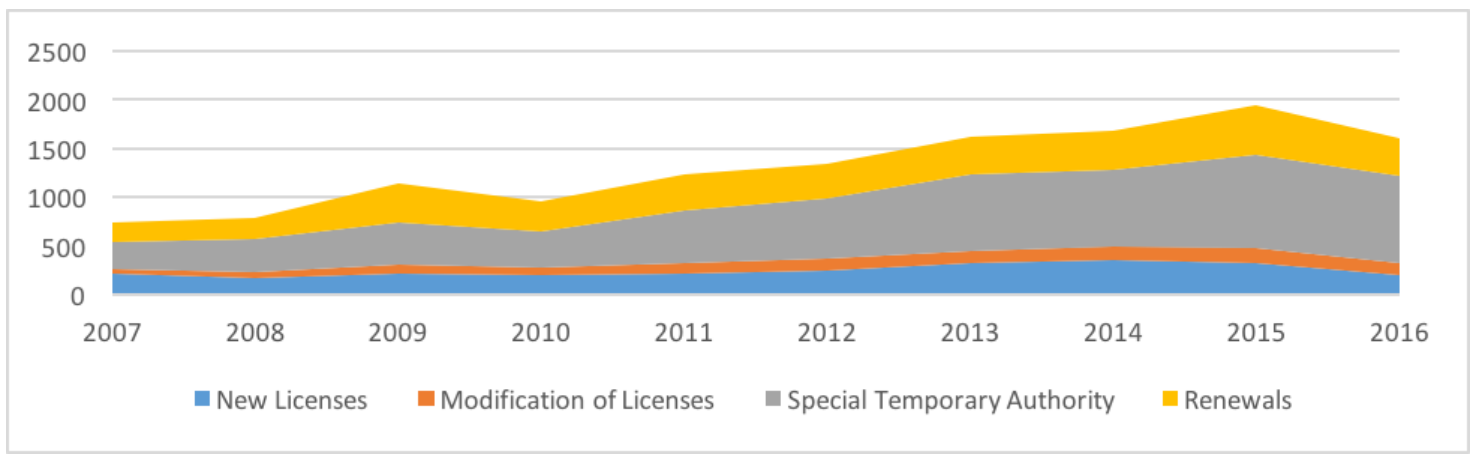

Figure 6: Evolution in the Number of Experimental Licenses Granted by the FCC

\subsubsection{License Type}

In the past 10 years, 13,077 experimental licenses have been granted by the FCC in the United States ${ }^{1}$. It is also shown that the number of experimental licenses have had an average increase of $11 \%$ per year during this period, going from 743 in 2007 to almost 2000 licenses by 2015. This increase is especially evident in the number of Special Temporary Authorizations, which present the most significant growth. Indeed, the number of STAs has increased $15 \%$ per year, on average, while other types of licenses have lower growth rates: New (2\%), Modification (10\%) and Renewal (11\%). The number of licenses issued each year, per category, is presented in Table 1 and Fig. 6. It is also shown that the percentage of the type of licenses issued has changed in this past ten years. In the years from 2007 to 2010 the ratio of conventional licenses ${ }^{2}$ to STAs was approximately $62 \%$ to $38 \%$. However, since 2011, the percentage of STAs increased to a $54 \%$ of the total number of issued licenses.

As shown, in the past 6 years there has been a change in the distribution of the total number of issued licenses, with a clear increase in the number of STAs compared to the number of conventional licenses. Consequently, we can observe that in the past 10 years, $46 \%$ of the total assigned licenses correspond to Special Temporary Authorization (Fig. 7) with a little bit less than 6,000 licenses in ten years. On the other hand, 27\% were assigned

\footnotetext{
${ }^{1}$ For the year 2016, the data correspond to the period between 01/01/2016 to 10/30/2016.

${ }^{2}$ Includes New, Modification and Renewals of License.
} 
Table 1: Evolution in the Number of Experimental Licenses from 2007 to 2016

\begin{tabular}{|l|l|l|l|l|l|l|l|l|l|l|l|}
\hline License & $\mathbf{2 0 0 7}$ & $\mathbf{2 0 0 8}$ & $\mathbf{2 0 0 9}$ & $\mathbf{2 0 1 0}$ & $\mathbf{2 0 1 1}$ & $\mathbf{2 0 1 2}$ & $\mathbf{2 0 1 3}$ & $\mathbf{2 0 1 4}$ & $\mathbf{2 0 1 5}$ & $\mathbf{2 0 1 6}$ & Total \\
\hline New & 221 & 174 & 225 & 207 & 214 & 241 & 319 & 354 & 325 & 204 & 2484 \\
\hline Modification & 38 & 62 & 80 & 74 & 108 & 130 & 126 & 142 & 156 & 115 & 1031 \\
\hline STA & 281 & 337 & 431 & 365 & 544 & 620 & 796 & 779 & 962 & 895 & 6010 \\
\hline Renewals & 203 & 220 & 413 & 320 & 363 & 354 & 376 & 404 & 506 & 393 & 3552 \\
\hline Total & 743 & 793 & 1149 & 966 & 1229 & 1345 & 1617 & 1679 & 1949 & 1607 & $\mathbf{1 3 0 7 7}$ \\
\hline
\end{tabular}

as conventional experimental licenses ${ }^{3}$. It is important to point out that part of these licenses were renewed by the FCC. Indeed, the Commission has processed and issued 3,552 (27\%) renewals during the past ten years.

\subsubsection{General Processing Time}

The time elapsed from the date an application is received to the date a license is issued (status date) is considered as the processing time of an application. According to the Report of the Unlicensed Devices and Experimental Licenses Working Group of the FCC, "Experimental applications that are solely within the FCC's jurisdiction are usually approved in less than a month". Nevertheless, as also exposed by the Federal Communications Commission Spectrum Policy Task Force "The principal concern of these parties appeared to be the delays involved in obtaining an experimental authorization due to NTIA coordination..." $4[8]$

In this light, from the constructed database, we were able to process and analyze the time required to obtain an experimental license from the FCC. We have observed that the average processing time has been reduced from over 50 days $^{5}$, from 2007 to 2009 , to less

\footnotetext{
${ }^{3}$ New Licenses $19 \%$ and Modification of Licenses $8 \%$

${ }^{4}$ The information related to the coordination with the NTIA is not publicly available through the Generic Search of the FCC. Therefore, the periods analyzed in this work do not discriminate between licenses processed only by the FCC and the ones that require coordination with the NTIA.

${ }^{5}$ Calendar days, includes weekends and holidays.
} 


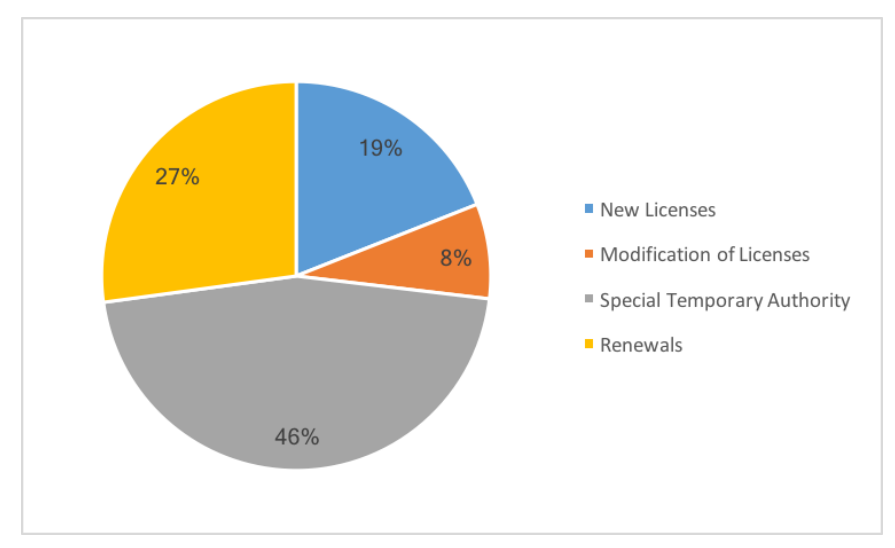

Figure 7: Distribution of Number of Licenses by Type

than 40 days in the past three years. However, due to the sensitivity to the outliers of the average metric, we consider necessary to also explore other statistical measurements in this analysis. Thus, if we observe the median value for the processing times, it is shown that effectively $50 \%$ of the total applications have been resolved in less than forty days, except for the year 2007. Furthermore, in most years, the median solving time is around 20 days. Note that $75 \%$ of applications ${ }^{6}$ have been resolved in less than 53 days since 2010 (Table 2 and Fig. 8), which is a clear improvement from previous years such as 2007 and 2009, where the $75 \%$ of the applications were resolved in 162 and 71.25 days, respectively. It is also worth to mention that $25 \%$ of the applications have very small processing times. Thus, we can see for example that in this past nine years these times are below two weeks. ${ }^{7}$

\footnotetext{
${ }^{6}$ Third Quartile of Table 2

${ }^{7}$ Only in the year 2007 the $25 \%$ of the processing times was below 21 days
} 


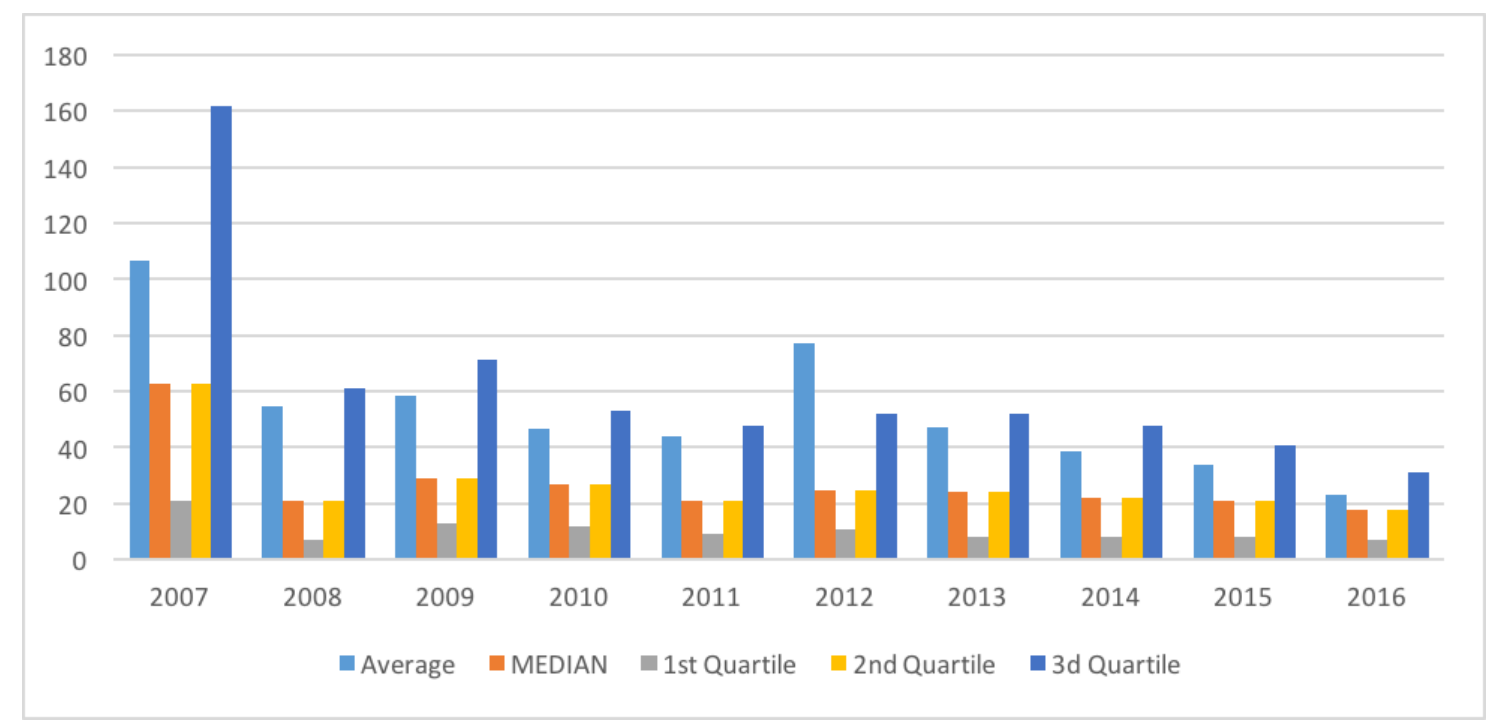

Figure 8: Processing Time Metrics

Table 2: Application Processing Time

\begin{tabular}{|c|r|r|r|r|r|r|r|r|r|r|}
\hline Metrics & $\mathbf{2 0 0 7}$ & $\mathbf{2 0 0 8}$ & $\mathbf{2 0 0 9}$ & $\mathbf{2 0 1 0}$ & $\mathbf{2 0 1 1}$ & $\mathbf{2 0 1 2}$ & $\mathbf{2 0 1 3}$ & $\mathbf{2 0 1 4}$ & $\mathbf{2 0 1 5}$ & $\mathbf{2 0 1 6}$ \\
\hline Average & 106.41 & 54.76 & 58.33 & 46.90 & 44.07 & 77.21 & 47.48 & 38.65 & 33.68 & 23.31 \\
\hline Median & 63 & 21 & 29 & 27 & 21 & 25 & 24 & 22 & 21 & 18 \\
\hline 1st Quartile & 21 & 7 & 13 & 11.75 & 9 & 11 & 8 & 8 & 8 & 7 \\
\hline 2nd Quartile & 63 & 21 & 29 & 27 & 21 & 25 & 24 & 22 & 21 & 18 \\
\hline 3d Quartile & 162 & 61 & 71.25 & 53 & 48 & 52 & 52 & 48 & 41 & 31 \\
\hline
\end{tabular}

To conclude the analysis of the assignment process of licenses and to achieve a deeper understanding of the time associated with obtaining experimental licenses, we can also observe the distribution of the processing delays, shown in Fig. 9. From this distribution it should be pointed out that most of the applications are resolved in less than 3 months by the FCC. Indeed, for the past 7 years most of the applications obtained a license after 1 or 2 months. Indeed, since 2014 the processing delays of more than 3 months is almost zero. 


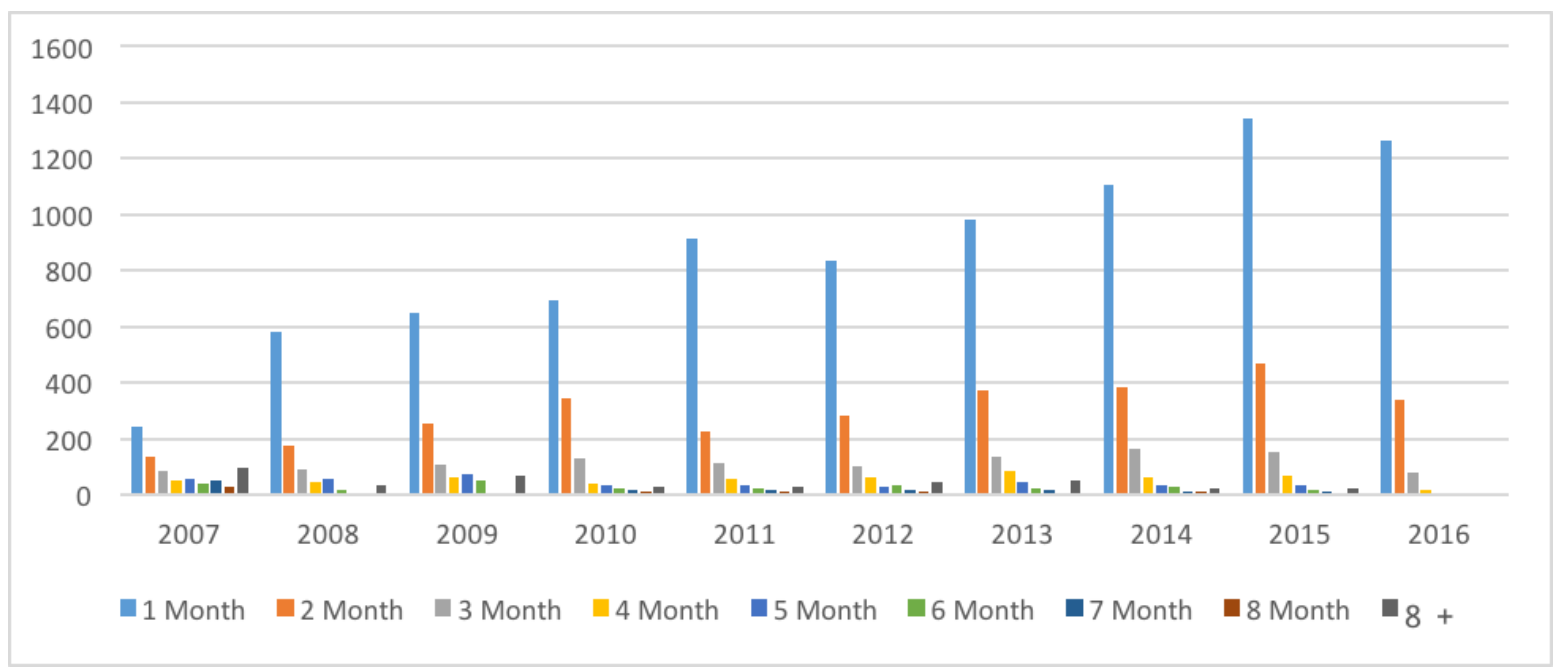

Figure 9: Distribution processing times by elapsed months

\subsection{CONVENTIONAL LICENSES}

This section analyzes the characteristics of the applications categorized by the FCC as conventional new licenses and their corresponding modifications ${ }^{8}$. The analysis will be divided in three parts: General Information, Licensees Details, Technical Characteristics.

\subsubsection{General Information}

Since the FCC Form 442 is utilized for both, New Licenses and Modifications on existing licenses, the first step in the analysis is to differentiate them. In this manner, we can observe that over the past 10 years most of the applications correspond to new licenses. From these applications, $60 \%$ of issued authorizations match to new applications and the remaining $40 \%$ to modifications (Fig. 10). In addition, we can observe that this distribution of new and modifications changed from around $85 \%$ in 2007 to $60 \%$ in this last year.

\footnotetext{
${ }^{8}$ As mentioned in previous sections in order to obtain a new license for experiments that last six months, or more, an standard FCC 442 form should be utilized. This form also applies for modifications to the original license.
} 


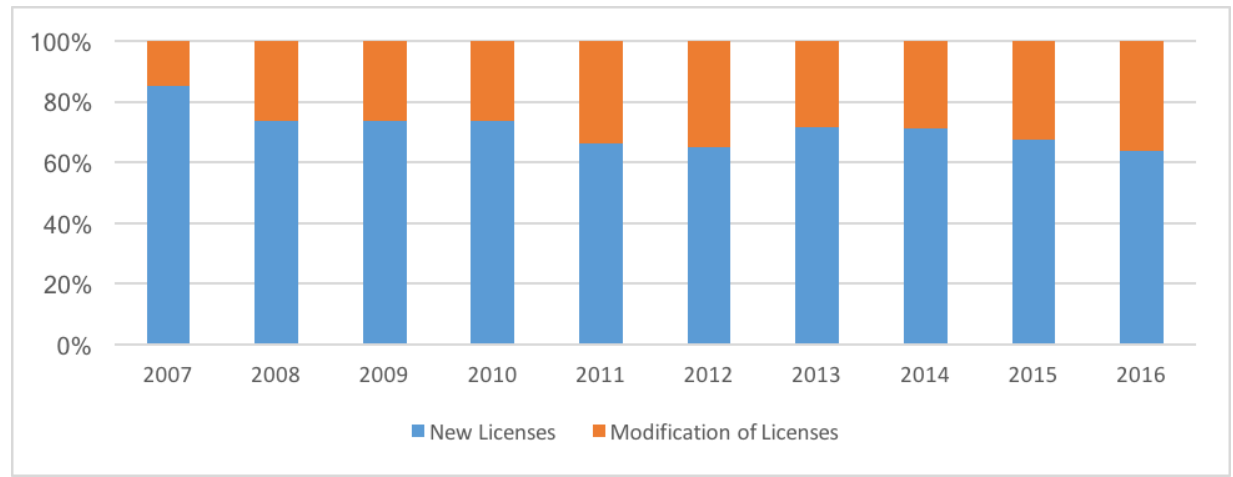

Figure 10: New Licenses vs. Modification of Licenses

In Section 4.2.2 we mentioned that a conventional experimental license could be issued for any period between 6 months and 5 years. Further, the FCC exposed in [5] that the regular assigned term is 24 months (2 years) for most applications. Therefore, we can observe that this is indeed the case for the licenses issued between 2007 and 2016, where, in average, $69 \%$ of the total licenses per year are issued for 2 years (Fig. 11). Indeed, we can observe that the number of licenses with requested times of 24 months went from 209 in 2007 to 370 in 370, an increase of $77 \%$. However, as also shown licenses for 12 months or less also had a relevant increase passing from 16 to 63 in the same period.

Finally if we analyze this past ten years as a whole it is shown that $89 \%$ of the total conventional licenses have been issued for periods between 1 and 24 months (2 years): 14\% for less than year and $75 \%$ for 12 to 24 month-periods, (Fig. 12). It is also important to point out that $7 \%$ of the total licenses are granted for the longest allowed period, i.e., 5 years (60 months), which is generally required for bigger research projects. Finally, it is shown that only $5 \%$ of the total licenses are granted for periods between 24 months and 5 years.

\subsubsection{Licensee Details}

The FCC requires all applicants to identify themselves. Thus, a licensee could be classified into one of these four categories: Individual, Association, Partnership and Corporation. As we can observe in Table 3, for the past 10 years most of the licenses have been issued for applicants identified as corporations, corresponding to an $86 \%$ of the total licenses (Fig. 13), 


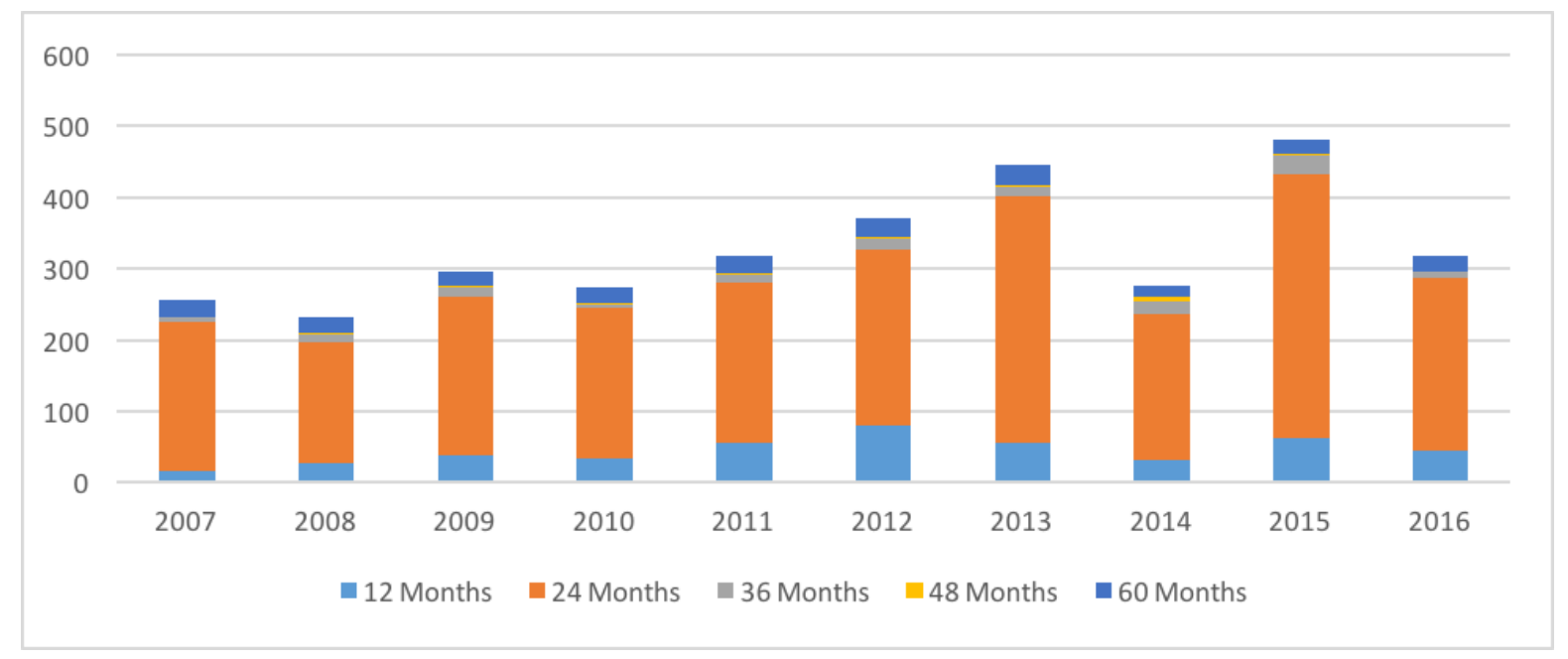

Figure 11: Distribution of Requested Times (FCC Form 442)

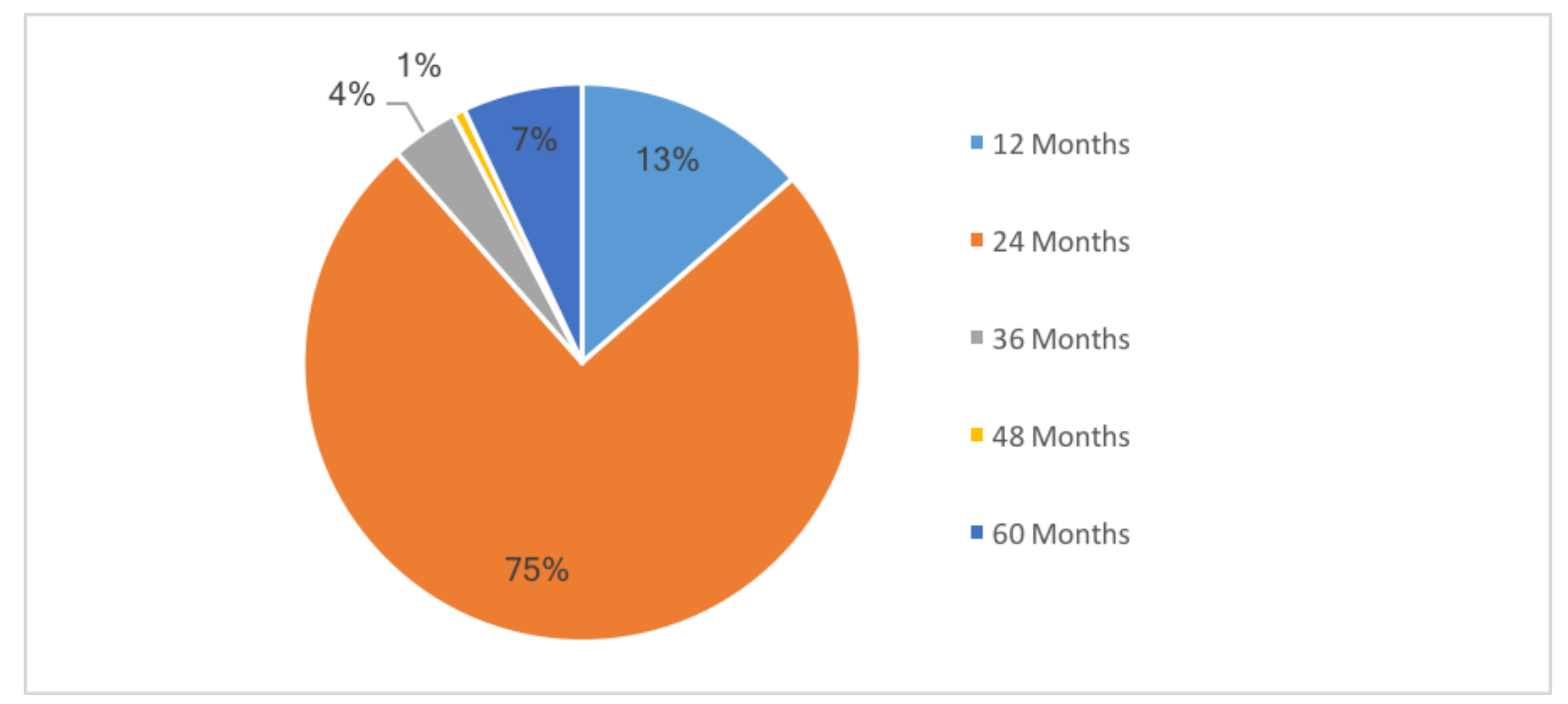

Figure 12: Requested Periods in the past 10 years (FCC Form 442) 
while the percentage of applicants identified as individuals and partnerships correspond to $3 \%$ and $2 \%$, respectively.

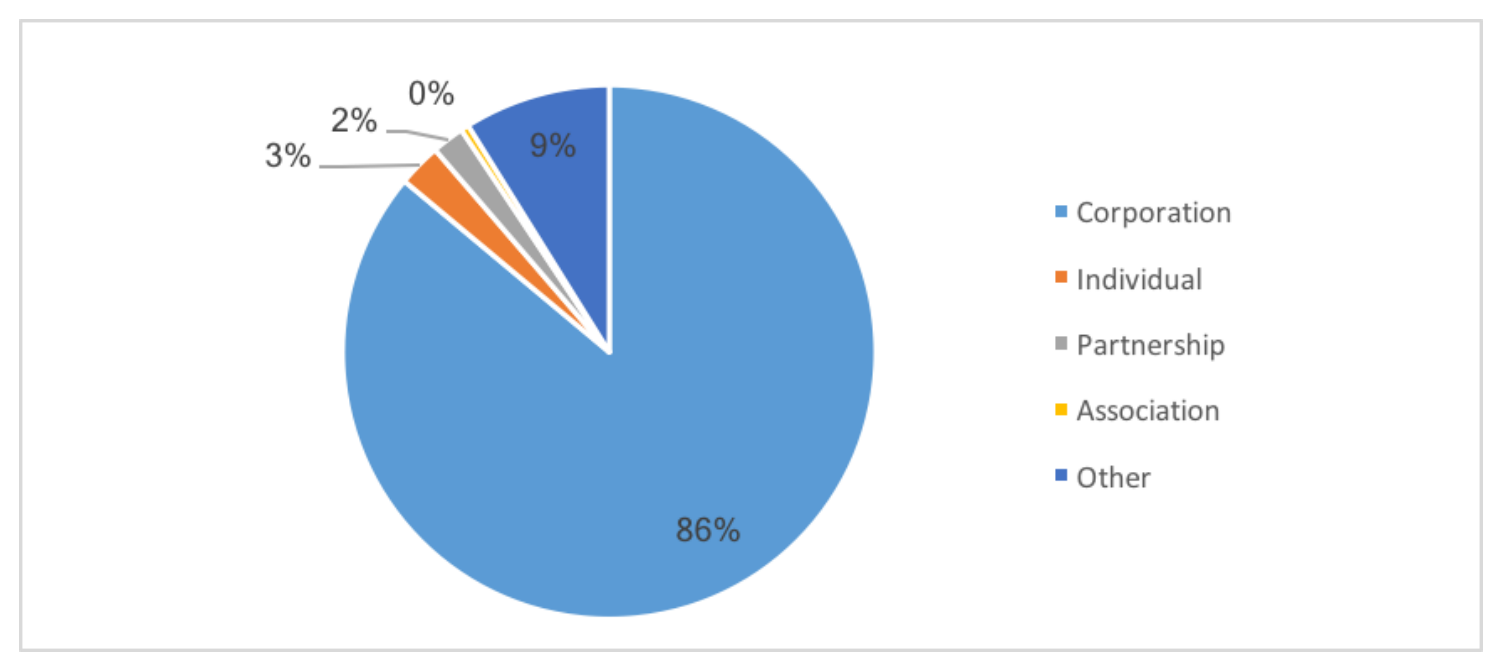

Figure 13: Licensee Identification (FCC Form 442)

Table 3: Licensee Identification (FCC Form 442)

\begin{tabular}{|c|r|r|r|r|r|r|r|r|r|r|}
\hline Identification & $\mathbf{2 0 0 7}$ & $\mathbf{2 0 0 8}$ & $\mathbf{2 0 0 9}$ & $\mathbf{2 0 1 0}$ & $\mathbf{2 0 1 1}$ & $\mathbf{2 0 1 2}$ & $\mathbf{2 0 1 3}$ & $\mathbf{2 0 1 4}$ & $\mathbf{2 0 1 5}$ & $\mathbf{2 0 1 6}$ \\
\hline Corporation & 224 & 203 & 260 & 232 & 285 & 324 & 380 & 418 & 425 & 274 \\
\hline Individual & 2 & 3 & 3 & 3 & 5 & 8 & 12 & 25 & 14 & 17 \\
\hline Partnership & 5 & 8 & 7 & 7 & 8 & 7 & 8 & 10 & 4 & 5 \\
\hline Association & 0 & 1 & 0 & 5 & 1 & 2 & 1 & 3 & 3 & 1 \\
\hline Other & 28 & 21 & 35 & 34 & 23 & 30 & 44 & 40 & 35 & 22 \\
\hline
\end{tabular}

Nevertheless, as also shown in Fig. 13, the FCC's identity classification does not include all the licensee's types. Thus, the Commission has included an "other" option in all the 
applications. This selection allows the applicant to describe what best fits its identity [14]. In fact, $9 \%$ of the licensees identify themselves as "other", where the most common utilized descriptors are:

- Governmental Institutions:

- City Agencies

- State Agencies

- Port Authority

- Colleges and Universities

- Research Organizations and Laboratories

To conclude this section about licensee's information, we will explore additional identification characteristics imposed by the FCC on the different applications for conventional experimental licenses that utilize the FCC Form 442 [14]:

- Government Contract: The license is used for fulfilling the requirement of a government contract with an agency of the United States Government.

- Foreign Government Use: The authorization is used for the exclusive purpose of developing radio equipment for export to be employed by stations under the jurisdiction of a foreign government.

- Research Project: To be used for providing communications essential to a research project. (The radio communication is not the objective of the research project).

We can observe in Fig.14 that only $32 \%$ of the total number of applicants in the past 10 years was identified under these characteristics: Government contract:19\%, Research Project: $11 \%$ and Foreign Government Use: $2 \%$. In fact, $68 \%$ of all applications are categorized as none of the aforementioned types. For these cases, the Commission requires the applicant to submit additional information about the purpose of the experiment that will allow a deeper understanding of the applicant. ${ }^{9}$

\footnotetext{
${ }^{9}$ This additional information is not exposed as part of the license in the "Generic Search" tool of the FCC; in consequence, this details are not included in this work
} 


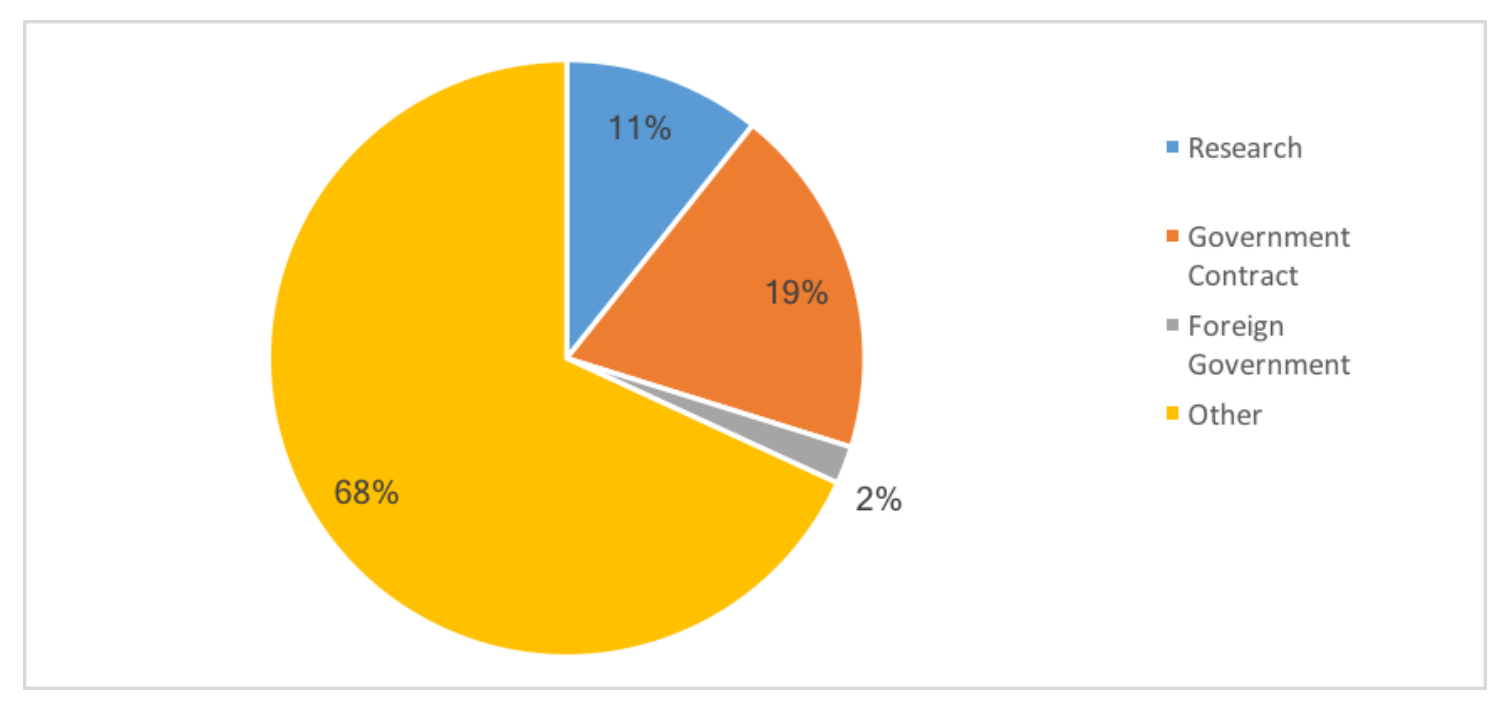

Figure 14: Additional Identification Parameters (FCC Form 442)

\subsubsection{Technical Characteristics}

It is well known that in the core of any FCC license lies its authorized technical parameters, and this is not the exception for experimental radio service licenses. Therefore, for a better understanding of this key element, this section will analyze the technical parameters of the conventional licenses classifying them into three categories: Equipment, Frequency Assignment and Authorized Power.

6.2.3.1 Equipment The Commission requires all applicants to list all the radio equipment to be used in the experiment. This list includes the manufacturer of the transmitter, model number, ${ }^{10}$ and the total amount of units, for each piece of equipment to be utilized. As part of the requirements, the FCC also mandates the inclusion of the experimental identification of the equipment. In this manner, we can observe that for the past 8 years the number of experimental equipment being used is around $40 \%$ of the total instrumentation (Fig. 15), which is a clear increase from 2007 and 2008 when it was only around the $20 \%$.

\footnotetext{
${ }^{10}$ Only non-required field in this section of the FCC Form 442
} 


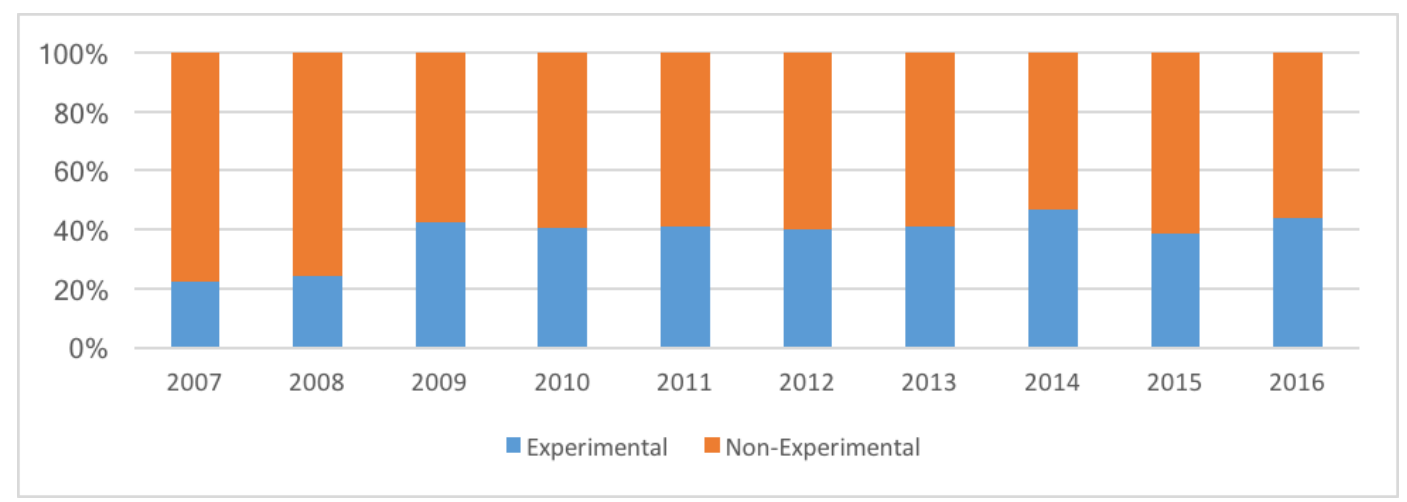

Figure 15: Equipment Classification (FCC Form 442)

In addition, it can be seen that for the past 10 years $61 \%$ of the utilized equipment is classified as conventional ${ }^{11}$ (Fig. 16), which means that since 2007 to this date only $39 \%$ of the total equipment that has been implemented in these experiments was indeed experimental.

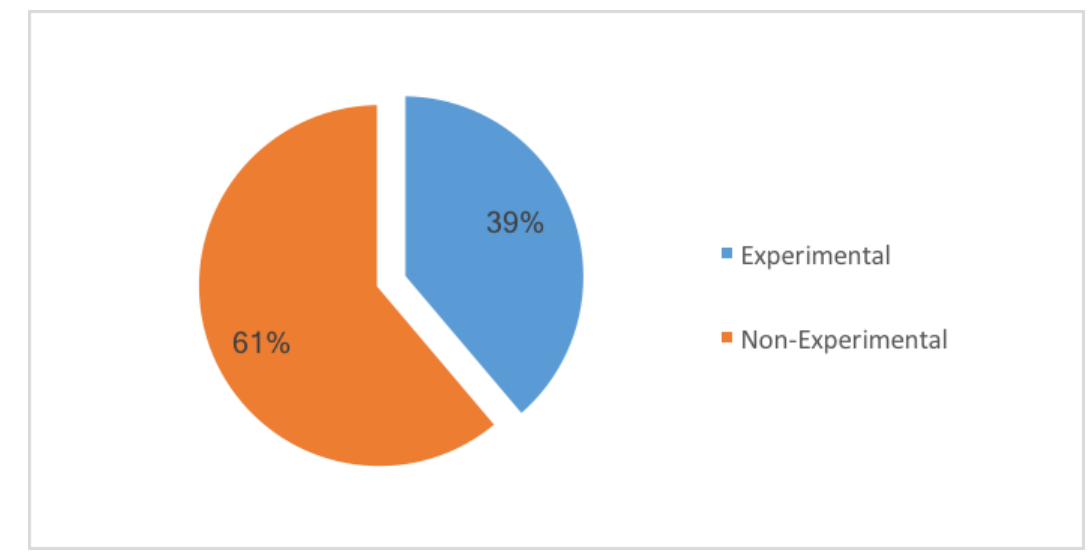

Figure 16: Equipment Classification Distribution (FCC Form 442)

6.2.3.2 Frequency Assignment The first technical required field on the FCC form is the nature of the stations that will be using the assigned frequencies. These stations are

\footnotetext{
${ }^{11}$ Classified by the FCC as non-experimental
} 


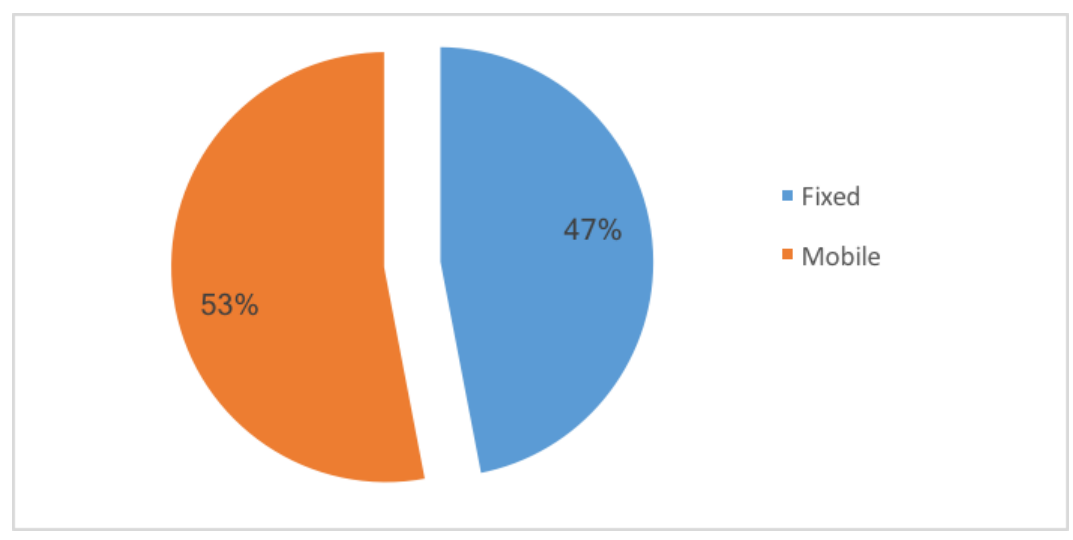

Figure 17: Global Station Classification(FCC Form 442)

classified into two categories "Fixed" or "Mobile". From the gathered information we see that there is almost an equal number of fixed and mobile stations (Fig. 17) since 2007. In fact, $53 \%$ of the total authorized stations are mobile and the other $43 \%$ of are fixed.

As mentioned in previous sections, the experimental licenses have great flexibility in terms of authorized frequencies and transmission power. This is true for the past 10 years of authorized licenses, where we can observe that frequencies have been assigned in almost every radio band defined by the ITU [9] with a total of 74,932 frequencies assigned since 2007. Indeed, as shown in Fig. 18, the only radio band where no frequencies have been assigned for conventional licenses is the Tremendously High Frequency (THF) band, which ranges from 300 to $3000 \mathrm{GHz}$. (Table 4). On the other hand, as also depicted in Fig. 18 the bands with the higher number of frequencies assigned are the Ultra High Frequency (UHF) and the Super High Frequency (SHF) with 34,251 and 15,010 assignations, respectively.

To perform a better analysis of this key element, the assigned frequencies will be divided in three groups from lower to higher frequency bands, as follows:

Lower Bands (ELF, SLF, ULF, VLF and LF): As we can observe in Fig. 19, on average, there are only 44 frequencies assigned in this bands per year. Indeed, only in 2014, the number of assigned licenses was of 140 for this lower bands. As shown, the Low Frequency (LF) band has the most frequencies assigned reaching $84 \%$ among the lower bands. However, 


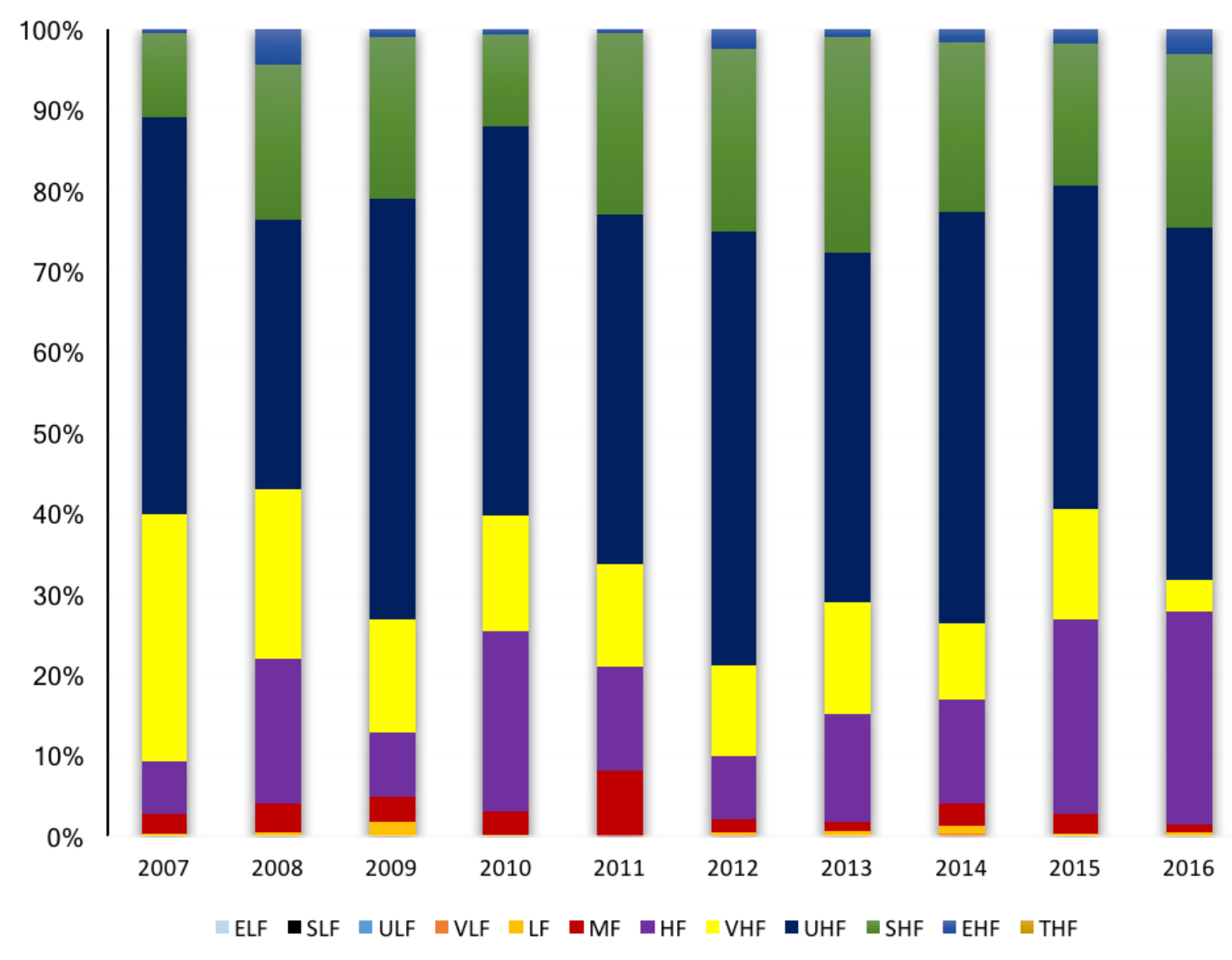

Figure 18: Frequency Distribution by Radio Band (FCC Form 442) 
Table 4: Frequency Distribution by Radio Band (FCC Form 442 )

\begin{tabular}{|c|r|r|r|r|r|r|r|r|r|r|}
\hline Band & $\mathbf{2 0 0 7}$ & $\mathbf{2 0 0 8}$ & $\mathbf{2 0 0 9}$ & $\mathbf{2 0 1 0}$ & $\mathbf{2 0 1 1}$ & $\mathbf{2 0 1 2}$ & $\mathbf{2 0 1 3}$ & $\mathbf{2 0 1 4}$ & $\mathbf{2 0 1 5}$ & $\mathbf{2 0 1 6}$ \\
\hline $\mathbf{E L F}$ & 0 & 2 & 0 & 0 & 0 & 0 & 0 & 0 & 0 & 0 \\
\hline SLF & 0 & 1 & 0 & 0 & 0 & 0 & 0 & 0 & 0 & 0 \\
\hline $\mathbf{U L F}$ & 0 & 0 & 0 & 0 & 0 & 1 & 0 & 1 & 0 & 1 \\
\hline $\mathbf{V L F}$ & 1 & 0 & 2 & 5 & 0 & 9 & 1 & 41 & 6 & 1 \\
\hline $\mathbf{L F}$ & 11 & 14 & 79 & 8 & 7 & 19 & 56 & 99 & 37 & 41 \\
\hline $\mathbf{M F}$ & 113 & 118 & 137 & 177 & 684 & 112 & 111 & 306 & 269 & 95 \\
\hline $\mathbf{H F}$ & 294 & 581 & 359 & 1387 & 1098 & 497 & 1249 & 1433 & 2752 & 2553 \\
\hline $\mathbf{V H F}$ & 1395 & 678 & 627 & 893 & 1091 & 730 & 1276 & 1057 & 1563 & 384 \\
\hline $\mathbf{U H F}$ & 2229 & 1084 & 2330 & 2984 & 3701 & 3457 & 4027 & 5678 & 4559 & 4205 \\
\hline SHF & 472 & 625 & 898 & 713 & 1918 & 1459 & 2482 & 2348 & 2016 & 2079 \\
\hline $\mathbf{E H F}$ & 23 & 140 & 42 & 39 & 46 & 153 & 97 & 175 & 194 & 297 \\
\hline THF & 0 & 0 & 0 & 0 & 0 & 0 & 0 & 0 & 0 & 0 \\
\hline
\end{tabular}


we can observe that less than $0.5 \%$ of the total licenses are assigned for frequencies lower than $300 \mathrm{KHz}$. Indeed, for the most part of this 20 years less than 50 frequencies have been assigned in this range.

Middle Bands (MF, HF, VHF, UHF): As expected, since most of the wireless services are contained between these bands $(300 \mathrm{KHz}-3000 \mathrm{MHz})$, most of the experimental licenses have been assigned in this range. From the 74,932 total frequencies, 58,273 (77,8\%) have been assigned within these limits. In addition, as already aforementioned, in average, $58 \%$ of the frequencies per year are requested for the UHF band (Fig. 20), which is actually the most common band for experimental licenses. Additionally, the High Frequency (HF) Band has also become "popular" since 2007. Thus, it has gone from only 274 in 2007, to 2752 frequencies by the end of 2015 .

Higher Bands (SHF, EHF and THF): Finally, the higher bands, which represent the $21.64 \%$ of the total authorized frequencies (16,216 assignments), are the only bands with continuous increase in the past 4 years. It increased from less than 1000 to more than 2000 licenses per year since 2013 (Fig. 21). Additionally, we can observe that most of the assigned frequencies are located in the SHF band (3-30 GHz) with an average of $92 \%$ of the total frequencies assigned in these bands.

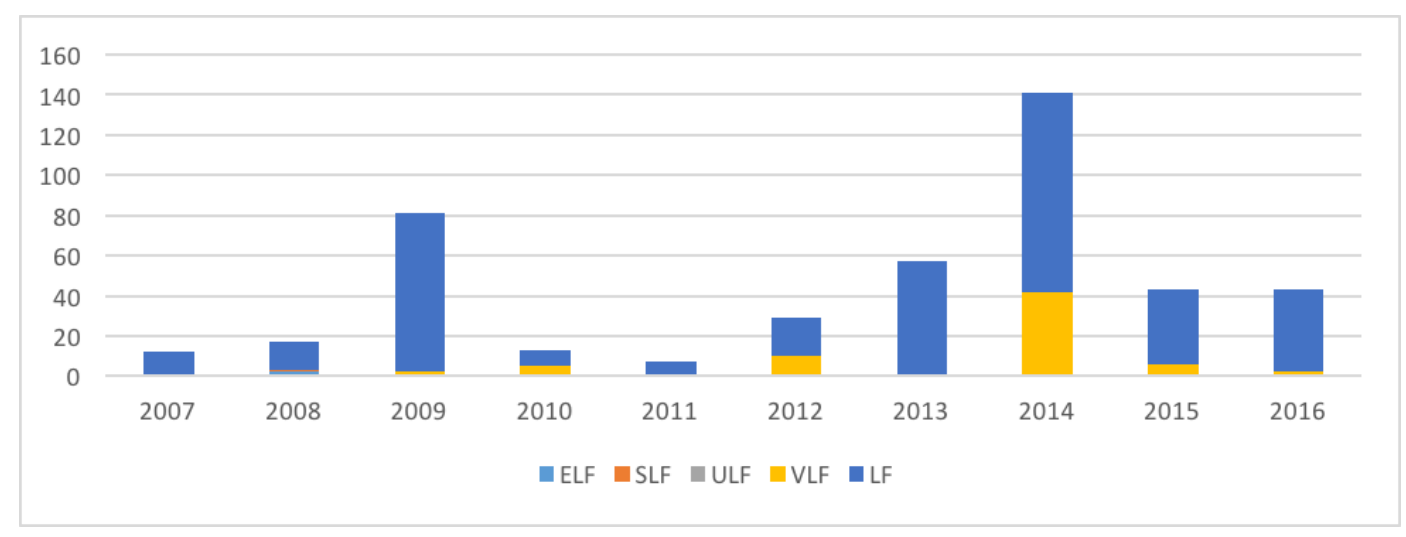

Figure 19: Frequency Distribution Conventional Licenses (Lower Bands) 


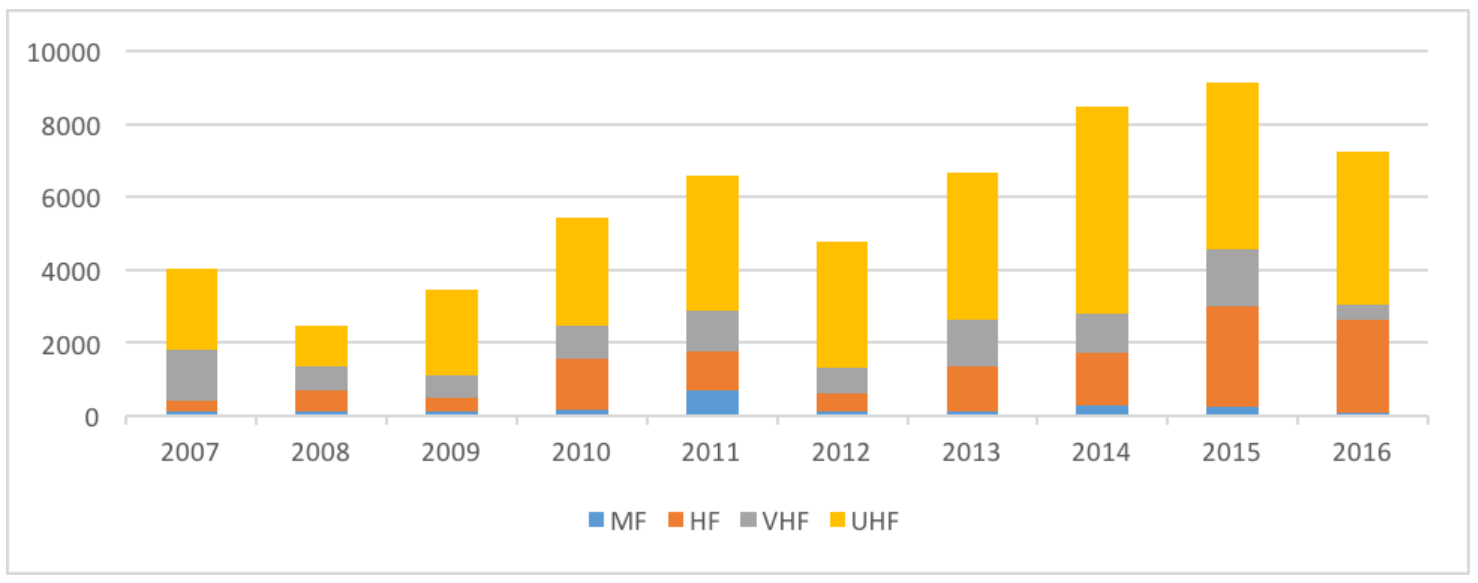

Figure 20: Frequency Distribution Conventional Licenses (Middle Bands)

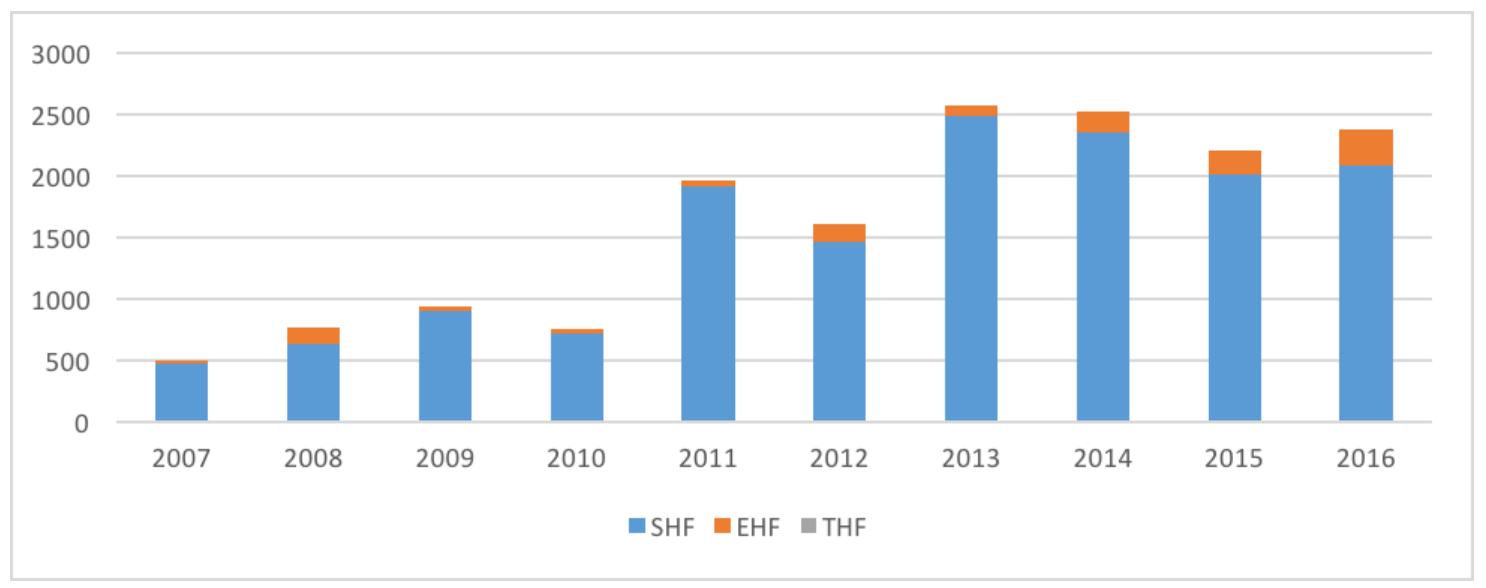

Figure 21: Frequency Distribution Conventional Licenses (Higher Bands)

6.2.3.3 Authorized Power To conclude the analysis of the technical characteristics of the conventional experimental radio service we will explore the authorized power of the different licenses. In the same way as the frequency, power authorizations are also very flexible. We can observe in Table 5 that the transmitted power varies from very low (less than $1 \mathrm{~mW}$ ) to very high power levels (more than $1 \mathrm{GW}$ ).

Indeed, as we can observe in Fig. 22 most of the authorized power limits have been less than $1 \mathrm{~mW}$ in the past ten years $(24 \%)$. Nonetheless, this is not a continuous trend over 
Table 5: Power Distribution (FCC Form 442)

\begin{tabular}{|c|r|r|r|r|r|r|r|r|r|r|}
\hline Power & $\mathbf{2 0 0 7}$ & $\mathbf{2 0 0 8}$ & $\mathbf{2 0 0 9}$ & $\mathbf{2 0 1 0}$ & $\mathbf{2 0 1 1}$ & $\mathbf{2 0 1 2}$ & $\mathbf{2 0 1 3}$ & $\mathbf{2 0 1 4}$ & $\mathbf{2 0 1 5}$ & $\mathbf{2 0 1 6}$ \\
\hline Less than 1mW & 85 & 123 & 204 & 179 & 1773 & 193 & 2599 & 5094 & 4692 & 2907 \\
\hline 1mW - 10mW & 50 & 107 & 12 & 25 & 29 & 266 & 217 & 113 & 46 & 33 \\
\hline 10mW-100mW & 230 & 95 & 40 & 53 & 93 & 163 & 348 & 167 & 89 & 39 \\
\hline 100mW-1W & 1470 & 365 & 410 & 945 & 549 & 793 & 648 & 941 & 448 & 707 \\
\hline 1W-10W & 392 & 310 & 499 & 603 & 647 & 1512 & 1910 & 1655 & 1460 & 1280 \\
\hline 10W-100W & 713 & 617 & 1167 & 1363 & 1524 & 1370 & 1620 & 1578 & 1449 & 1497 \\
\hline 100W-1kW & 909 & 729 & 1416 & 2380 & 2756 & 953 & 1179 & 831 & 1811 & 1189 \\
\hline 1kW-10kW & 277 & 196 & 235 & 164 & 305 & 175 & 282 & 289 & 227 & 1502 \\
\hline 10kW-100kW & 145 & 290 & 182 & 149 & 320 & 596 & 113 & 110 & 875 & 181 \\
\hline 100kW-1MW & 28 & 178 & 82 & 88 & 33 & 135 & 123 & 134 & 123 & 89 \\
\hline 1MW-10MW & 0 & 36 & 57 & 73 & 221 & 74 & 85 & 57 & 56 & 0 \\
\hline 10MW-100MW & 35 & 90 & 80 & 65 & 114 & 69 & 60 & 49 & 18 & 51 \\
\hline 100MW-1GW & 10 & 11 & 37 & 28 & 11 & 37 & 30 & 30 & 45 & 65 \\
\hline More than 1GW & 2 & 1 & 10 & 18 & 6 & 74 & 20 & 10 & 11 & 80 \\
\hline
\end{tabular}




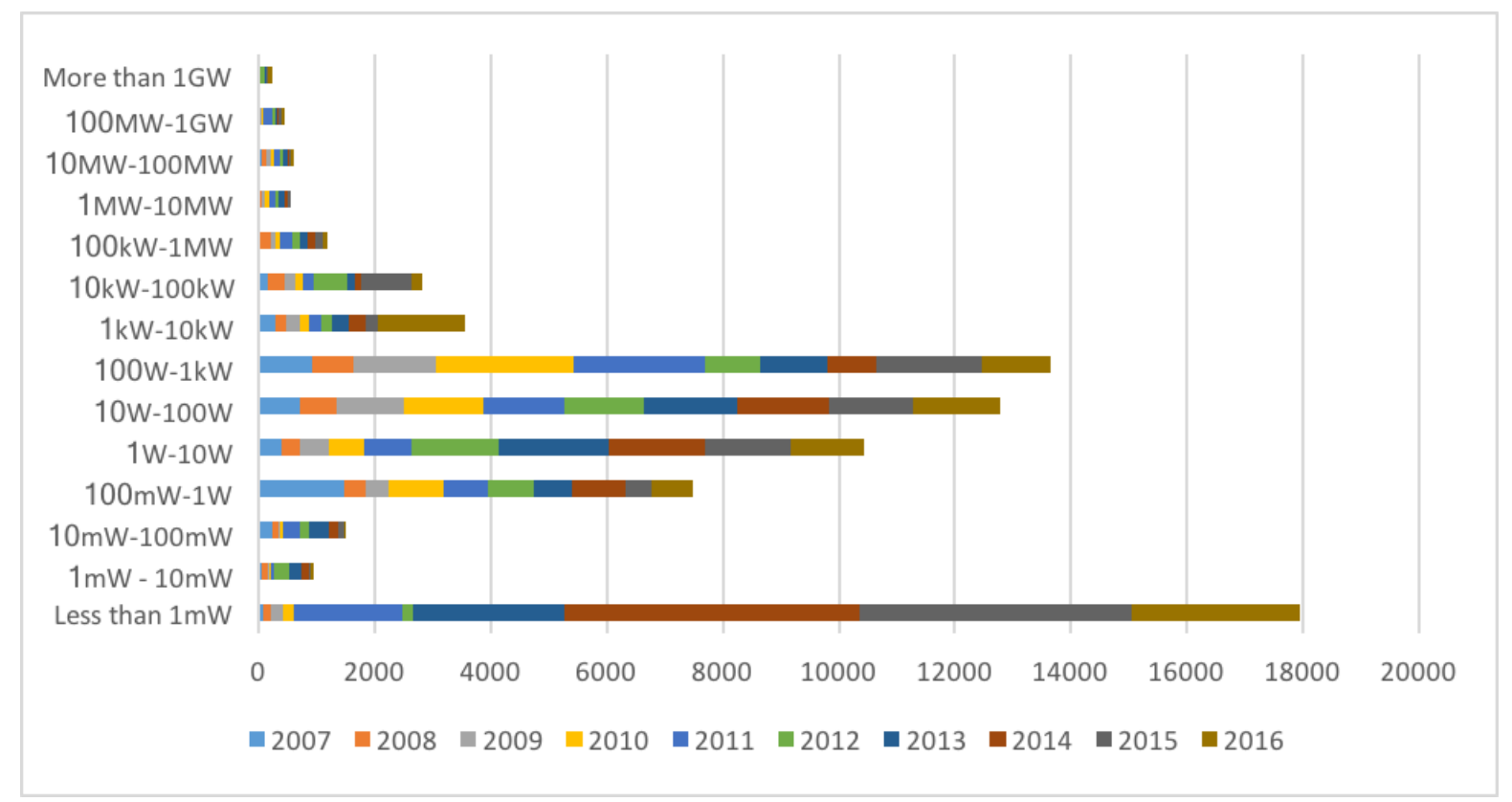

Figure 22: FCC Form 442 Power Distribution by Power Level

the period of analysis. Indeed, we can observe that most of these low power levels have been assigned since 2011 (Fig. 23). In addition, it is possible to observe that the highest concentration of power levels is located between $100 \mathrm{~mW}$ to $1 \mathrm{KW}$ corresponding to $65 \%$ of assignments. As presented in Fig. 23 this has been a trend since the year 2007. Additionally, we can observe that more applications are granted smaller power levels than high powers. In fact, the number of stations operation with low power levels, less than $100 \mathrm{~mW}$, doubles the stations with high power authorizations of 10KW or more. 


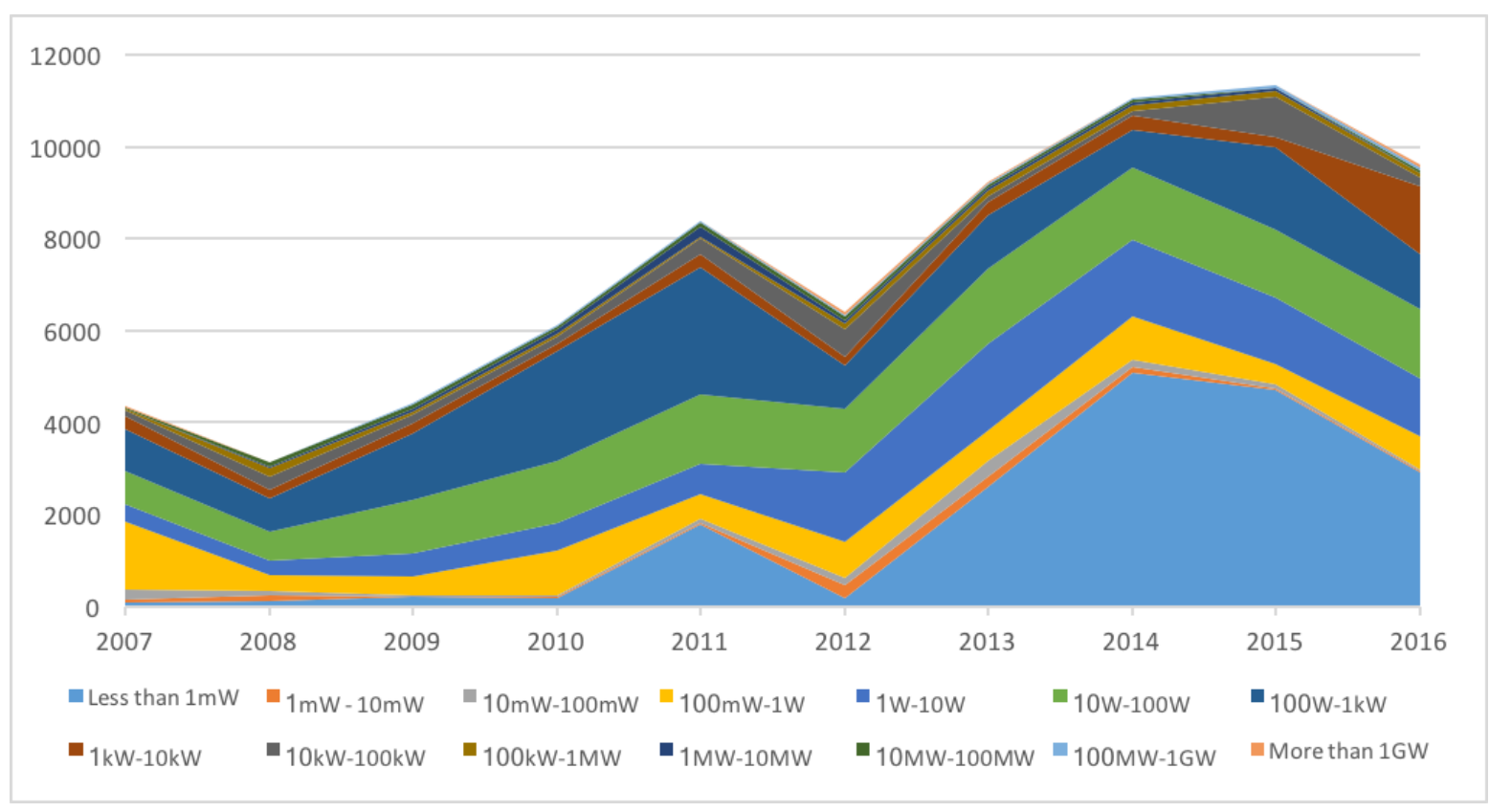

Figure 23: FCC Form 442 Power Distribution by Year

\subsection{SPECIAL TEMPORARY AUTHORITY (STA)}

According to the FCC, an STA applies in cases where applicants need to operate transmitting equipment in special circumstances, when it is not feasible to wait for a license to be issued. Further, STA applications can either be associated with or without an existing license and cannot last more than 6 months [14]. The following section explores this special type of license and its main characteristics. For this purpose, the analysis will be divided in three parts: General Information, Technical Details and Purpose of Operation.

\subsubsection{General Information}

In the past 10 years 5,582 Special Temporary Authorizations have been issued by the Commission. Since 2007 the number of STAs has continuously increased an $18 \%$ per year in average, going from only 272 in 2007 to almost 1000 by the end of 2015 . 
Without a doubt what most significantly differentiates an STA from a conventional license is its duration. In Fig. 24 this characteristic is evident. In fact, most of the STA licenses are authorized for less than a month (30 days) with $47 \%$ of the total number of STAs issued from 2007 to 2016. Moreover, as shown in Fig. 25 the majority of these licenses are either authorized for less than 3 days, 10\%, or less than a week, $52 \%$.

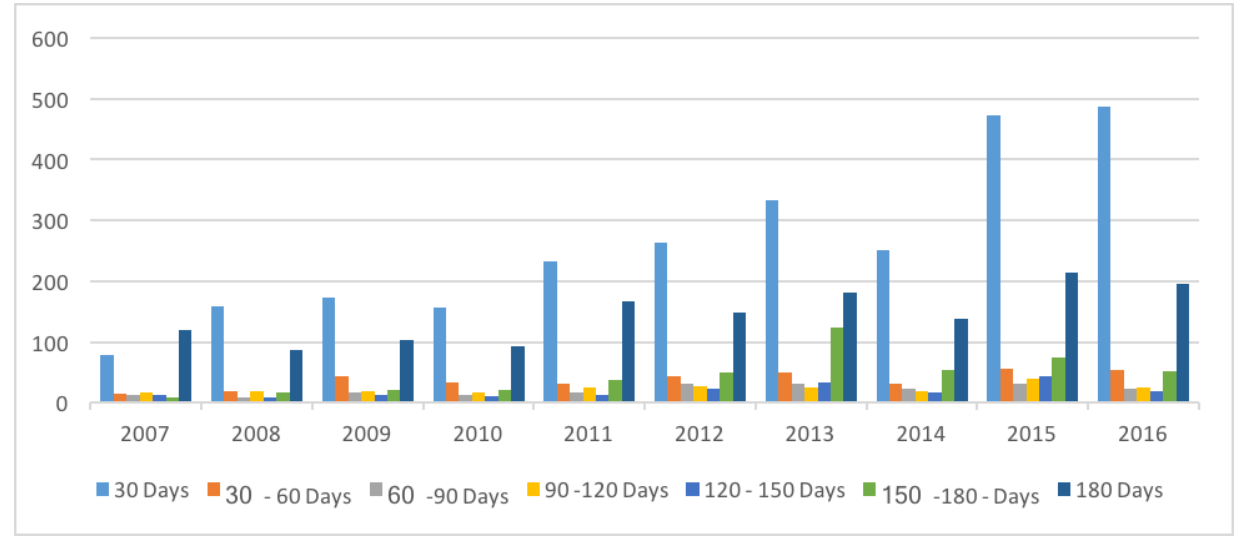

Figure 24: STA License Duration Distribution

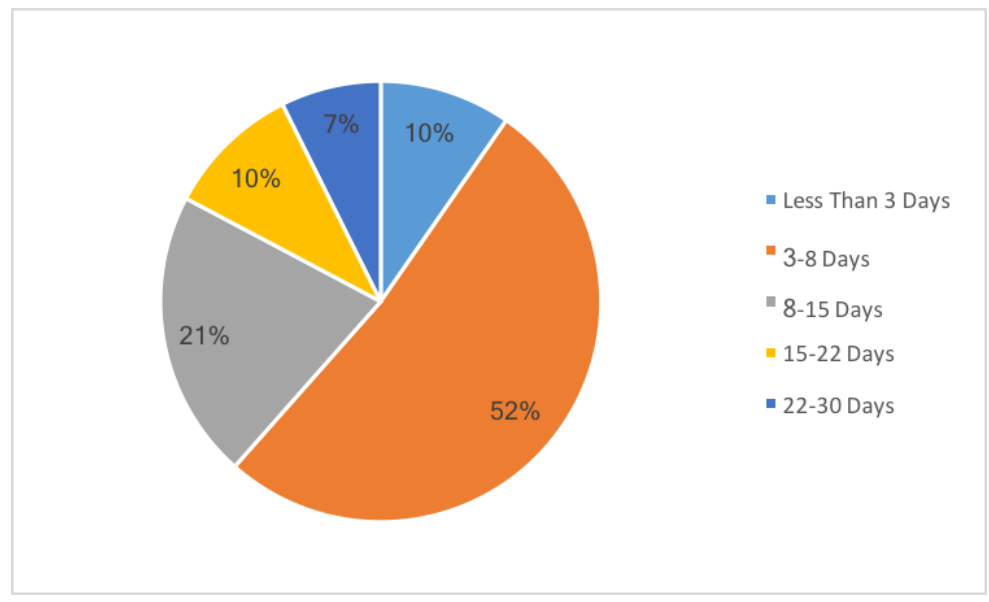

Figure 25: STA License Duration Distribution for licenses of 30 days or less 


\subsubsection{Technical Details}

6.3.2.1 Equipment In the same manner as the conventional experimental licenses, all STAs are required to list all the radio equipment to be used in the experiment as part of the application. The list also includes the manufacturer, the model ${ }^{12}$, and the total number of units to be used. In addition, the FCC requires the experimental identification of the equipment. For this requirement we can observe that only $23 \%$ of the total utilized equipment is experimental (Fig. 26).

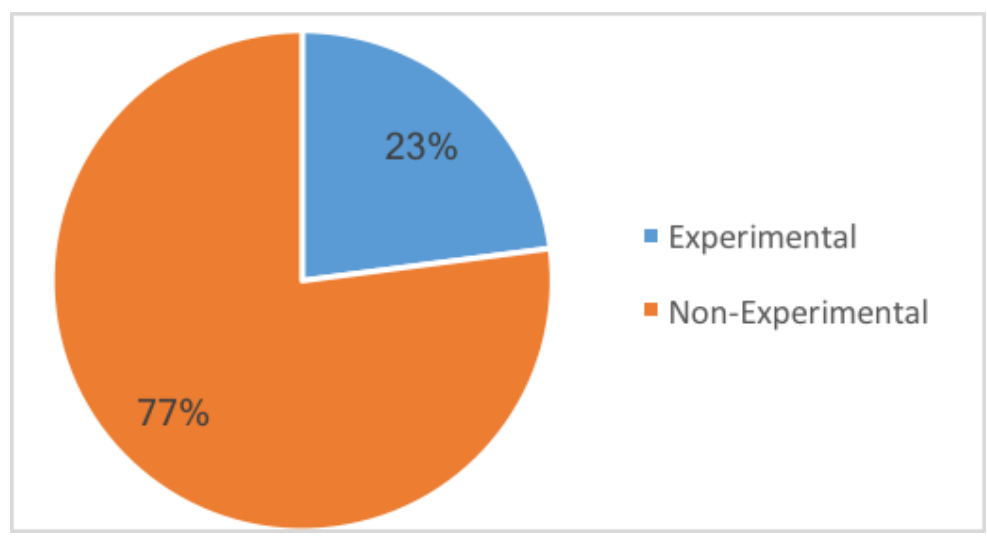

Figure 26: STA Equipment Classification

6.3.2.2 Assigned Frequencies The Special Temporary Authorizations also have great flexibility in terms of frequencies and transmission power. This is true for the past 10 years of assignments, where we can observe that frequencies span across the majority of Radio Bands [9] with a total of 52,601 frequencies assigned since 2007. Indeed, the only radio band where zero frequencies have been assigned is the ULF band (Ultra Low Frequency), which ranges from 0.3 to $3 \mathrm{KHz}$. (Table 4). Moreover, in the same way as the conventional licenses, we can observe that most of the assigned frequencies correspond to the band of 300-3000

\footnotetext{
${ }^{12}$ Only non-required field in this section of the application
} 
MHz. Indeed, in the UHF band 35,555 frequencies have been assigned in this past ten years as it is shown in Fig. 27.

Table 6: STA Frequency Distribution by Radio Band

\begin{tabular}{|c|r|r|r|r|r|r|r|r|r|r|}
\hline Band & $\mathbf{2 0 0 7}$ & $\mathbf{2 0 0 8}$ & $\mathbf{2 0 0 9}$ & $\mathbf{2 0 1 0}$ & $\mathbf{2 0 1 1}$ & $\mathbf{2 0 1 2}$ & $\mathbf{2 0 1 3}$ & $\mathbf{2 0 1 4}$ & $\mathbf{2 0 1 5}$ & $\mathbf{2 0 1 6}$ \\
\hline $\mathbf{E L F}$ & 0 & 2 & 0 & 0 & 0 & 0 & 0 & 0 & 0 & 0 \\
\hline SLF & 1 & 0 & 0 & 0 & 0 & 0 & 0 & 0 & 0 & 0 \\
\hline $\mathbf{U L F}$ & 0 & 0 & 0 & 0 & 0 & 0 & 0 & 0 & 0 & 0 \\
\hline $\mathbf{V L F}$ & 0 & 0 & 0 & 0 & 0 & 0 & 1 & 0 & 1 & 1 \\
\hline $\mathbf{L F}$ & 0 & 0 & 0 & 1 & 2 & 0 & 0 & 11 & 13 & 8 \\
\hline $\mathbf{M F}$ & 60 & 21 & 15 & 6 & 12 & 17 & 49 & 20 & 84 & 18 \\
\hline $\mathbf{H F}$ & 268 & 62 & 121 & 435 & 34 & 69 & 450 & 774 & 436 & 343 \\
\hline $\mathbf{V H F}$ & 621 & 461 & 245 & 438 & 308 & 197 & 809 & 427 & 615 & 268 \\
\hline $\mathbf{U H F}$ & 1583 & 2021 & 2649 & 2510 & 3007 & 3668 & 4399 & 4492 & 5841 & 5385 \\
\hline SHF & 412 & 252 & 414 & 440 & 682 & 796 & 1277 & 909 & 1409 & 1963 \\
\hline $\mathbf{E H F}$ & 18 & 7 & 14 & 16 & 14 & 27 & 31 & 82 & 287 & 263 \\
\hline THF & 0 & 0 & 0 & 0 & 0 & 0 & 1 & 0 & 0 & 8 \\
\hline
\end{tabular}

For a deeper understanding of the frequencies that have been assigned to the applicants in the past ten years for Special Temporary Authorizations, we will group the frequencies in three groups as explained below.

Lower Bands (ELF, SLF, ULF, VLF and LF): As we can observe in Fig. 28 there are only 10 frequencies assigned in this bands per year, in average. Furthermore, less than $0.1 \%$ of the total frequencies have been assigned in bands below $300 \mathrm{KHz}$. These values follow the same pattern of the conventional experimental licenses presented in the previous section. Furthermore, we can observe that before 2014 less than two licenses per year were assigned in this range of frequencies. Indeed, for the years 2009 and 2012 no assignments are registered among these bands. 


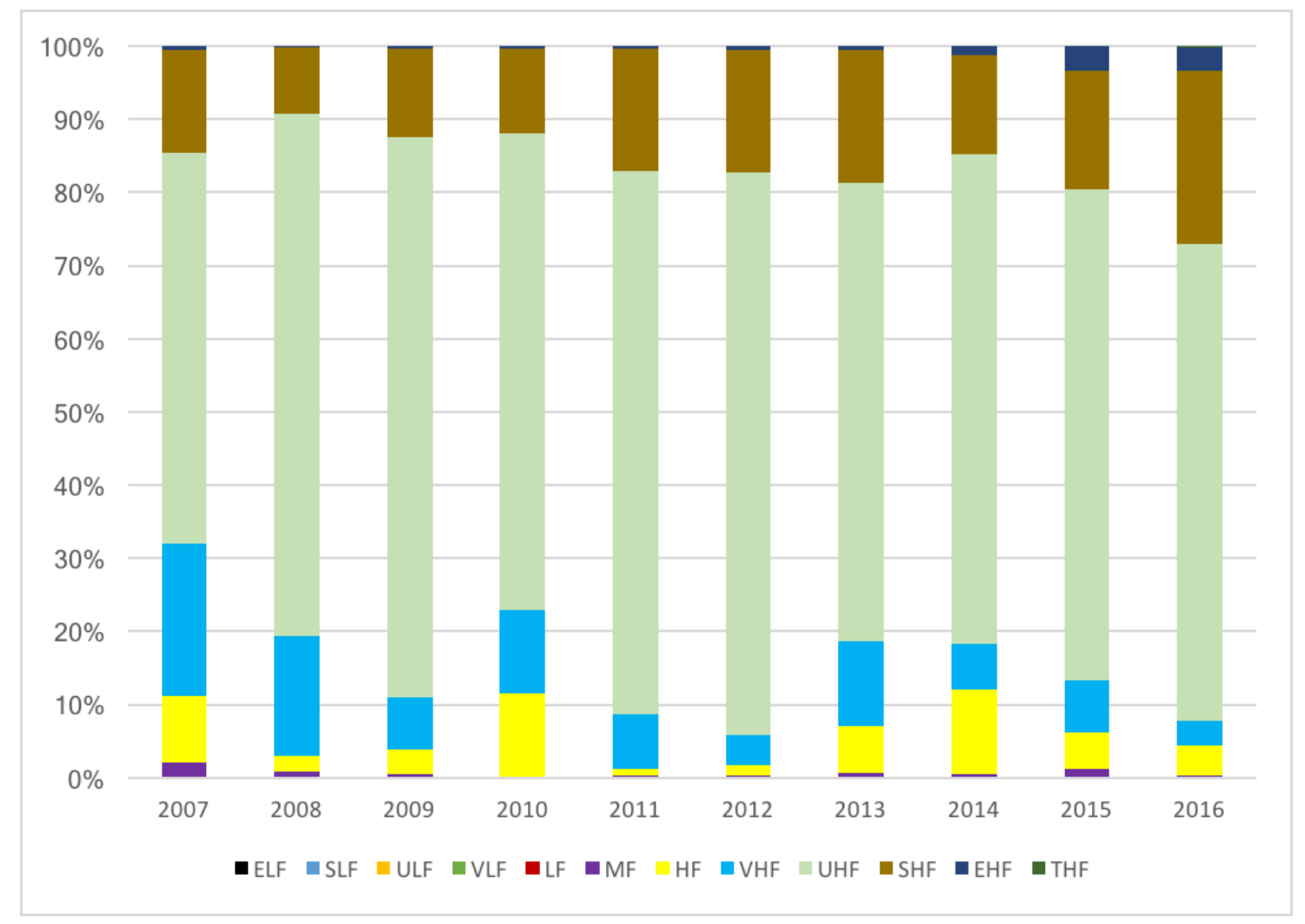

Figure 27: STA Frequency Distribution by Radio Band 
Middle Bands (MF, HF, VHF, UHF): As expected, since most of the wireless services are contained within these bands $(300 \mathrm{KHz}-3000 \mathrm{MHz})$, most of the STAs' frequencies have been assigned in this range. Further, 43,238 out of the 52,601 total frequencies (83.34\%), have been assigned within these limits. In addition, it is possible to observe that, in average, $68 \%$ of the requested frequencies each year belong to the UHF band (Figure 29). This characteristic has also a deep relationship with the purpose of operation in the STAs. Further, as exposed in the following section, among the companies with the greatest number of authorized STAs per year, most of them correspond to companies whose services include the transmission and support of televised events.

Higher Bands (SHF, EHF and THF): Finally, the higher bands, which represent the $17.72 \%$ of the total frequencies (9,322 assignments), are the only group with a continuous increase in the past four years. The annual assignment of these licenses has increased from less than 500 in 2007 to more than 2000 by 2016 (Fig. 30). Note that most of the assigned frequencies are located in the SHF band (3-30 GHz) with an average of $92 \%$ of the total frequencies assigned in this group. Moreover, we can observe that this band presents the biggest increase in number of frequencies among these bands, going from less than 500 in the period between 2007 and 2010 to almost 2000 in 2016.

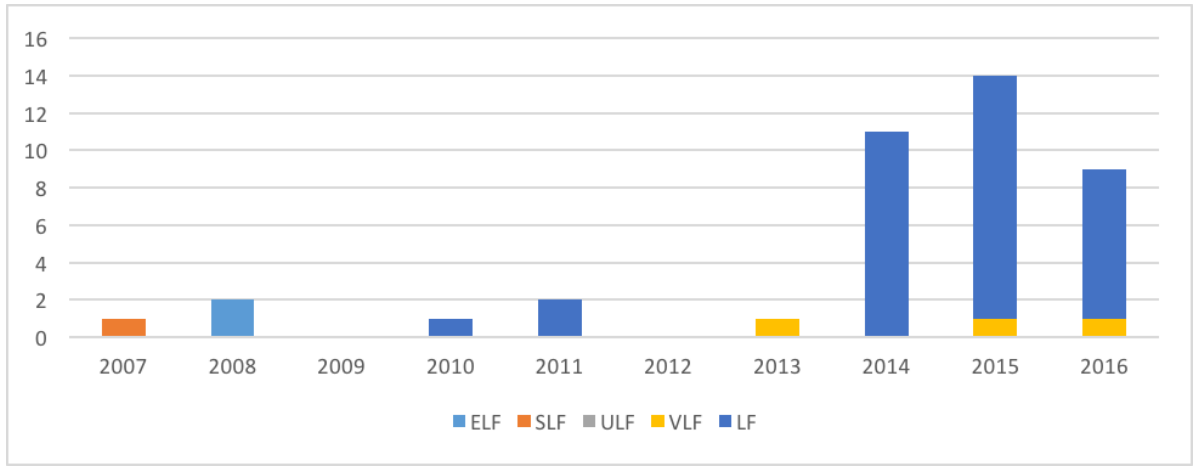

Figure 28: STA Frequency Distribution (Lower Bands) 


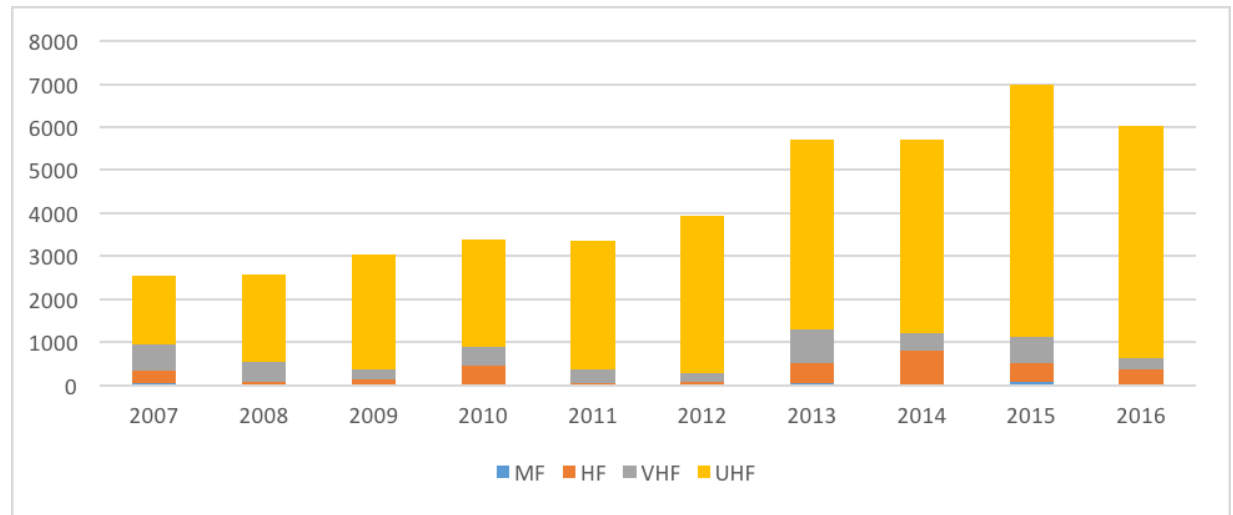

Figure 29: STA Frequency Distribution (Middle Bands)

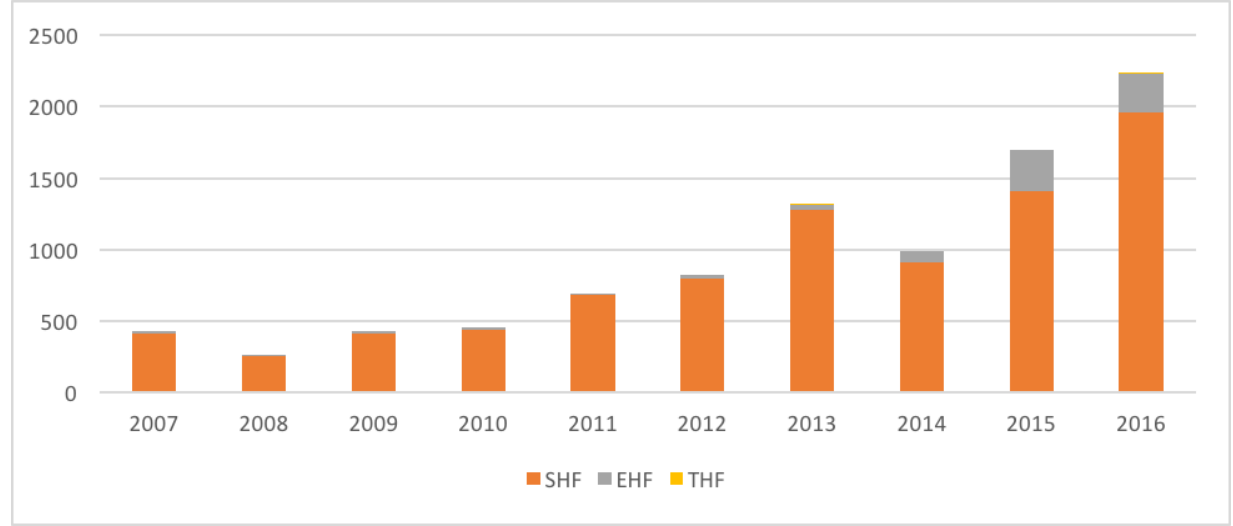

Figure 30: STA Frequency Distribution (Higher Bands)

6.3.2.3 Authorized Power Finally, to conclude this section of technical details of the Special Temporal Authorizations, we will discuss the authorized power to the different licensees. In this manner, we can also observe a great flexibility in all the authorizations. Thus, as shown in Table 7 the transmitted power varies from very low (less than $1 \mathrm{~mW}$ ) to very high levels (more than $1 \mathrm{GW}$ ) throughout the past 10 years. Furthermore, as shown in Fig. 32 this has been true for the complete period of this analysis (From 2007 to 2016) without exceptions.

Within this distribution, it is interesting to see that the highest concentration of power 
levels is also located between $100 \mathrm{~mW}$ to $1 \mathrm{KW}^{13}$ corresponding to $78 \%$ of the assignments in the past ten years. And, as shown in Fig. 32, this has also been a trend since 2007. In addition, we can observe that in the case of STAs there is a greater number of stations operating with smaller levels of power,less than $100 \mathrm{~mW}$, than others with high power levels, more than $1 \mathrm{KW}$. Indeed, low power almost double the number of high power stations as it is shown in Fig. 31.

Table 7: STA Power Distribution

\begin{tabular}{|c|r|r|r|r|r|r|r|r|r|r|}
\hline Power & $\mathbf{2 0 0 7}$ & $\mathbf{2 0 0 8}$ & $\mathbf{2 0 0 9}$ & $\mathbf{2 0 1 0}$ & $\mathbf{2 0 1 1}$ & $\mathbf{2 0 1 2}$ & $\mathbf{2 0 1 3}$ & $\mathbf{2 0 1 4}$ & $\mathbf{2 0 1 5}$ & $\mathbf{2 0 1 6}$ \\
\hline Less than 1mW & 113 & 164 & 126 & 61 & 60 & 118 & 145 & 28 & 1487 & 1249 \\
\hline 1mW - 10mW & 118 & 12 & 24 & 3 & 3 & 78 & 67 & 21 & 35 & 63 \\
\hline $\mathbf{1 0 m W - 1 0 0 m W}$ & 28 & 102 & 130 & 192 & 208 & 290 & 553 & 210 & 448 & 603 \\
\hline $\mathbf{1 0 0 m W - 1 W}$ & 322 & 629 & 903 & 1001 & 918 & 1284 & 1342 & 1738 & 1893 & 1924 \\
\hline 1W-10W & 623 & 650 & 1151 & 793 & 1043 & 984 & 1636 & 1602 & 1856 & 1253 \\
\hline 10W-100W & 928 & 813 & 600 & 1039 & 723 & 1310 & 1616 & 1225 & 1381 & 1604 \\
\hline 100W-1kW & 574 & 200 & 157 & 468 & 673 & 369 & 1195 & 1195 & 449 & 579 \\
\hline 1kW-10kW & 67 & 101 & 193 & 144 & 203 & 189 & 285 & 190 & 65 & 320 \\
\hline 10kW-100kW & 120 & 20 & 28 & 30 & 74 & 40 & 41 & 82 & 207 & 188 \\
\hline 100kW-1MW & 17 & 21 & 3 & 46 & 26 & 22 & 29 & 35 & 89 & 146 \\
\hline 1MW-10MW & 11 & 2 & 14 & 3 & 32 & 7 & 9 & 10 & 4 & 19 \\
\hline 10MW-100MW & 14 & 42 & 9 & 9 & 6 & 31 & 11 & 17 & 65 & 18 \\
\hline 100MW-1GW & 3 & 4 & 17 & 14 & 19 & 11 & 8 & 9 & 41 & 3 \\
\hline More than 1GW & 1 & 0 & 2 & 6 & 57 & 11 & 3 & 22 & 0 & 3 \\
\hline
\end{tabular}

\footnotetext{
${ }^{13}$ Same as the conventional experimental licenses
} 


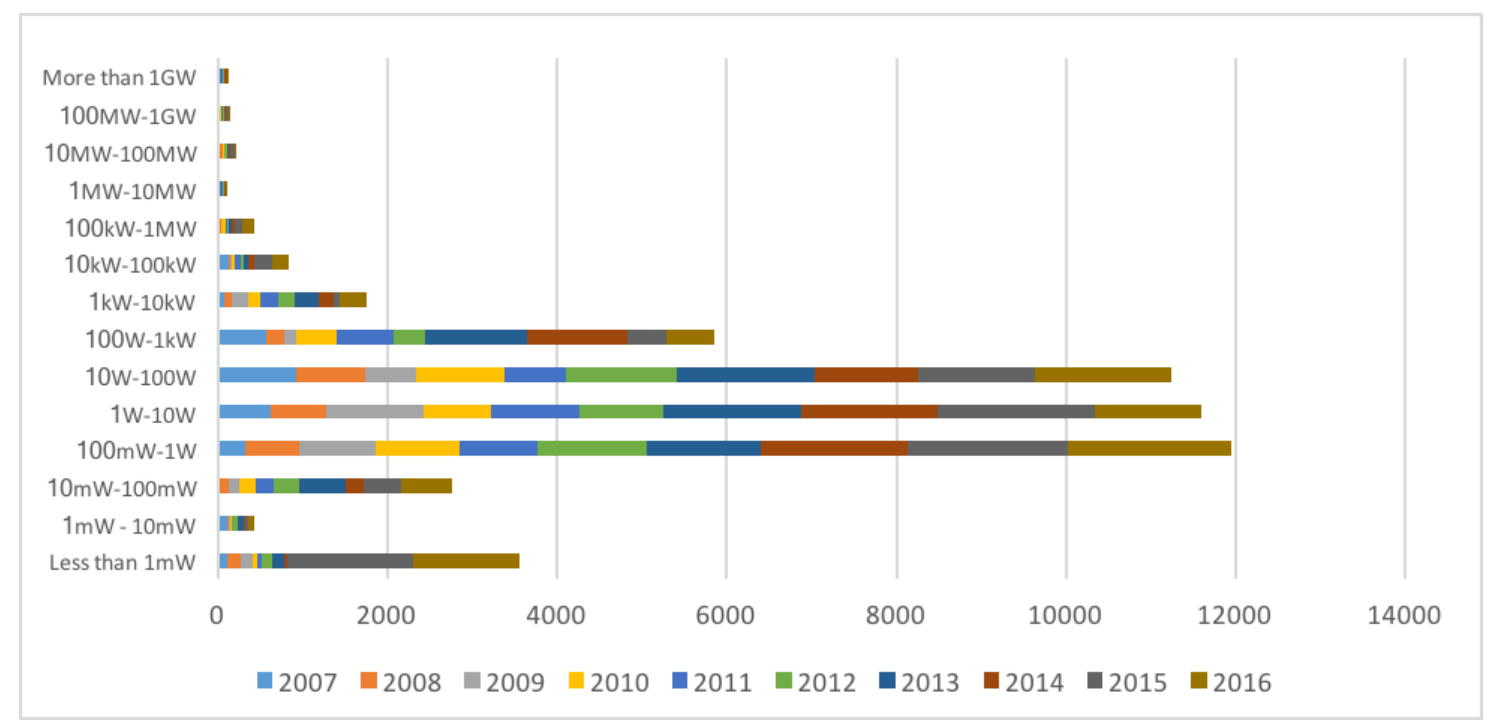

Figure 31: STA Power Distribution by Power Level

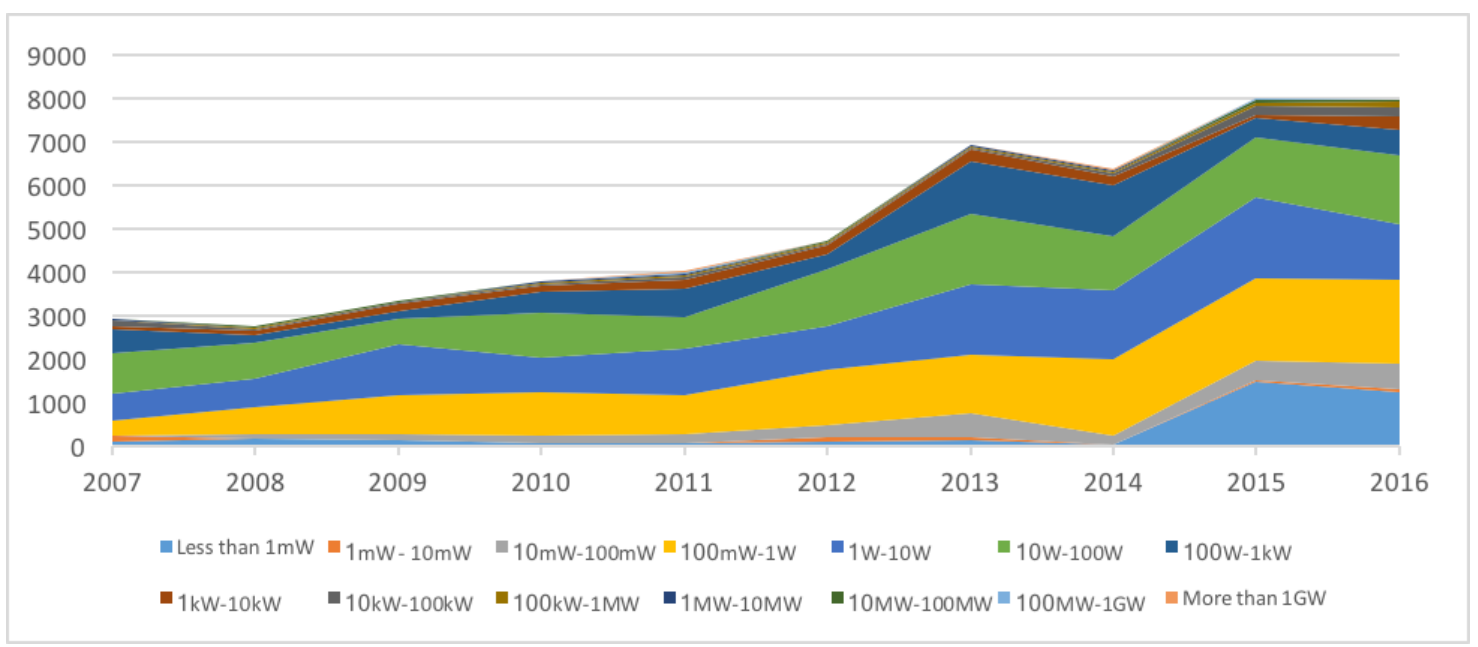

Figure 32: STA Power Distribution by Year

\subsubsection{Purpose of Operation}

As previously mentioned, one interesting characteristic of the STAs is its purpose of operation. The purpose of operation is defined as a detailed explanation of the type of operation 
that will be performed with the experimental license [14]. Due to the large number of authorized STAs, 6,000 since 2007, the analysis of this section will focus only on the companies with the greatest number license assignments per year (Table 8) in the period comprehended between 2007 and 2016 .

Appendix A shows the summary of the purpose of operation of the top 5 companies with the greatest number of STAs per year from 2007 to 2016. As we can observe, wellknown companies such as Broadcast Sports, Inc. CP Communications, Lockheed Martin Corporation, Ericsson Inc., Alcatel Lucent, among others, are part of the applicants with the most number of STA assignments in the past ten years.

Table 8: Applicants with the greatest number of granted STAs

\begin{tabular}{|l|c|}
\hline \multicolumn{1}{|c|}{ Applicant } & Number of STAs \\
\hline QUALCOMM INC. & 13 \\
\hline NORTHROP GRUMMAN SYSTEMS CORPORATION & 16 \\
\hline RAYTHEON NETWORK CENTRIC SYSTEMS & 18 \\
\hline SCREENED IMAGES, INC & 18 \\
\hline TOTALRF PRODUCTIONS & 18 \\
\hline BAE SYSTEMS & 24 \\
\hline ALCATEL-LUCENT & 26 \\
\hline HARRIS CORPORATION & 29 \\
\hline IROBOT CORPORATION & 30 \\
\hline ERICSSON INC & 47 \\
\hline LOCKHEED MARTIN CORPORATION & 57 \\
\hline BROADCOMM INC. & 136 \\
\hline 3G WIRELESS, LLC & 139 \\
\hline THE BOEING COMPANY & 140 \\
\hline BROADCAST SPORTS INTERNATIONAL & 330 \\
\hline CP COMMUNICATIONS & 336 \\
\hline BROADCAST SPORTS INC. & 758 \\
\hline
\end{tabular}


Furthermore, after analyzing the purpose of operation of the different STAs, it is shown that there is a wide variety of applications for this especial type of licenses. In fact, applications range from very specific deployments and demonstrations for military equipment to large complex tests of aircraft systems. Nevertheless, from the companies with the largest number of authorized STAs, it is shown that most licenses are authorized for the coverage and support of televised events nationwide. Indeed, as shown in Fig. 33, $73 \%$ of these licenses are assigned for this purpose. ${ }^{14}$

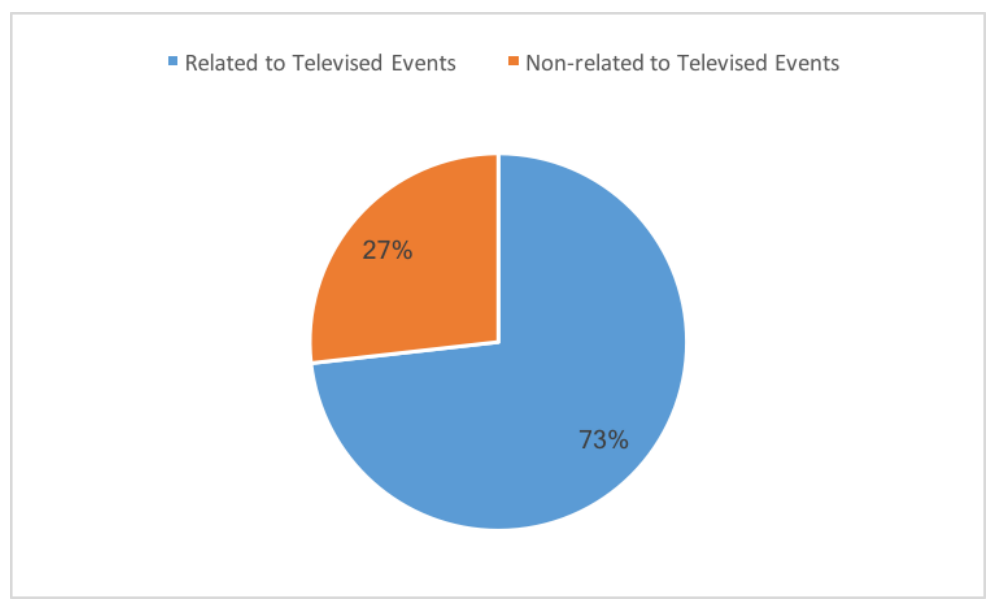

Figure 33: Purpose of Operation among companies with the greatest number of STAs.

We can observe that the licenses related to televised events are not solely utilized for transmission purposes. In fact, several activities are performed using these STAs. For instance, we have: equipment testing, support and coordination of transmissions, personal communications, etc. (Fig 34). Even though most of the covered events are sports-related, other types of events such as presidential debates ${ }^{15}$ or awards ceremonies ${ }^{16}$ also rely on STAs for transmission and support.

\footnotetext{
${ }^{14}$ Licenses assigned to: Broadcast Sports Inc., CP Communications, Broadcast Sports International, 3G Wireless, LLC and Broadcomm Inc.

${ }^{15}$ Classified as Political in Fig. 34.

${ }^{16}$ Classified as Cultural in Fig. 34.
} 
On the other hand, STAs that are not related to televised coverage of events also have a wide range of purposes of operation. As also shown in Fig. 34, we can observe that these authorizations are mainly used for Military, Government and Research projects. Moreover, based on the activities detailed in the applications for these STAs, we can further classify them in: Demonstrations, Developing, Analysis, and Testing of equipment, wireless technologies or security characteristics. 


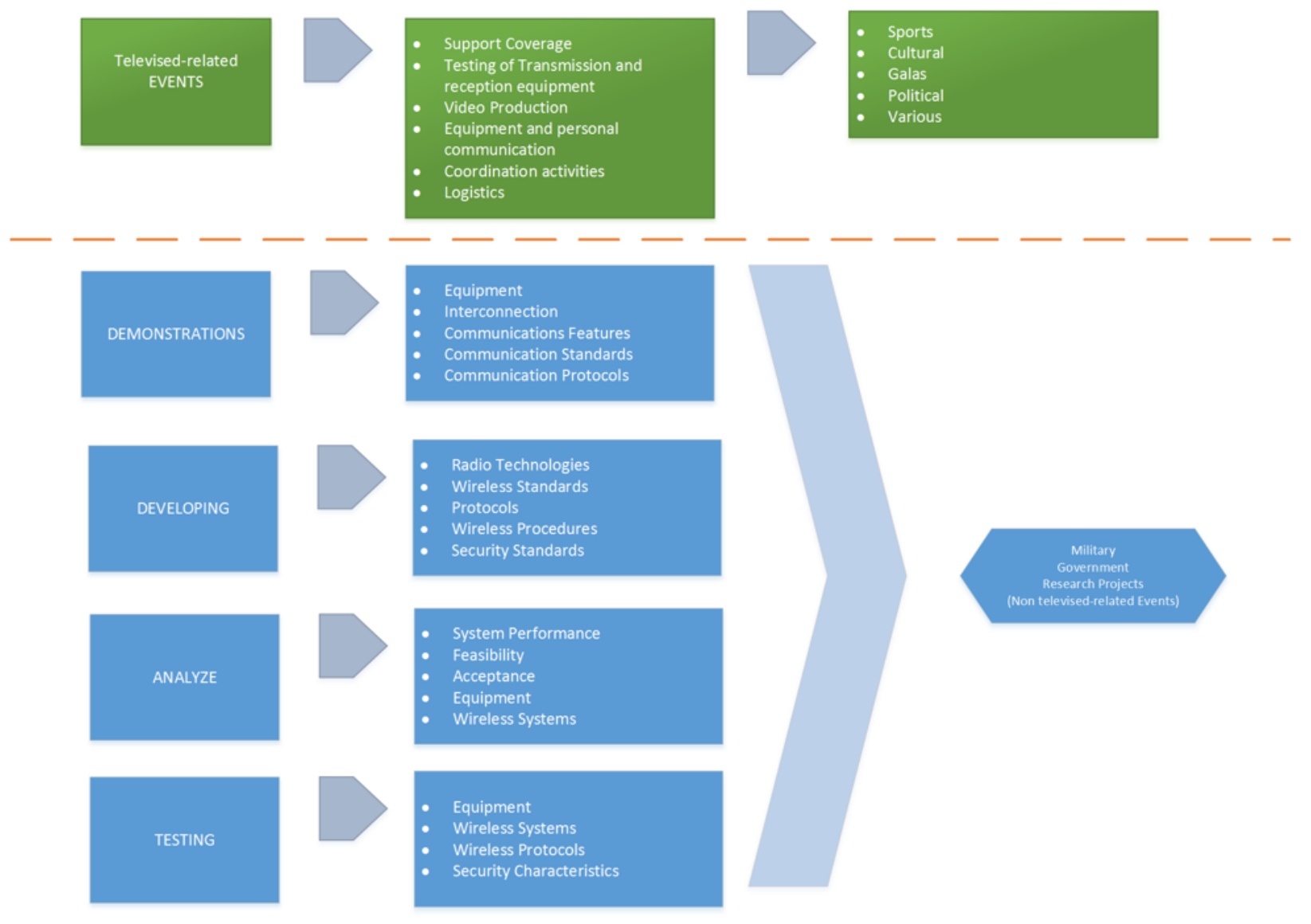

Figure 34: Classification Purpose of Operation STAs 


\subsection{DISCUSSION}

We conclude this work by highlighting some of the results that were detailed in the previous chapters with regards to: the general process of obtaining a license, the conventional licenses and the Special Temporary Authorizations. Additionally, topics such as processing time of licenses and assigned frequencies will be analyzed in more detail than exposed in the previous chapters. We finish by exploring the connection between the experimental radio service and the development of future technologies. For this purpose, we explore the implementation of some authorizations in the development of coverage models, equipment and design of next generation of cellular networks, 5G.

\section{$7.1 \quad$ FINDINGS}

\subsubsection{General Assignment Process}

The Experimental radio service of the FCC presents a great opportunity for innovation in the wireless world, where we can observe that 24,757 have been granted by the FCC over the past 30 years. Moreover, $61 \%^{1}$ of these licenses have been issued in the past 10 years, 2007-2016, with an average increase of $11 \%$ per year, going from 743 in 2007 to almost 2000 licenses by 2015 . In addition, we observed that $46 \%$ of the total licenses correspond to STAs and the other $27 \%$ were assigned as conventional experimental licenses ${ }^{2}$.

With regards to the processing delay between the application and the actual assignment of a license, we observed that the average processing time has been reduced from over 50

\footnotetext{
${ }^{1} 13,077$ licenses.

${ }^{2}$ This includes New and Modification of Licenses
} 
days, from 2007 to 2009, to less than 40 days in the past three years. Furthermore, $50 \%$ of the total applications have been resolved in less than forty days, except for the year 2007 and $75 \%$ of applications have been resolved in less than 53 days since 2010. Indeed, most of the applications are resolved in less than 3 months by the FCC. Furthermore, for the past 7 years most of the applications obtained a license after 1 or 2 months.

To expand on what was exposed in section 6.1 .2 we can further classify the processing delay by type of license. As shown in Table 9 the processing delays for all types of licenses have been reduced from 2007 to (Fig. 35). For instance, the average time for a new license has gone from 168 to 42 days, a reduction of $74 \%$ of the processing time. We can see that the biggest reduction in processing time correspond to Renewals with a decrease of $82 \%$. In addition, we can observe that the least processing time correspond to the Special with an average of 26.62 days over this past ten years. While, new licenses are the ones that require the most processing time with an average of 87.74 days. Nevertheless, as we can observe this high average value is a consequence of the biggest peaks of the average processing time in new licenses, which took place on 2007, 167.28 days, and in 2008 with 128.80 days. In fact, in 2016 all types have processing times below 45 days.

\subsubsection{Conventional Licenses}

From the conventional licenses issued by the FCC since 2007, we observed that $60 \%$ were authorizations for new applications and the remaining $40 \%$ to modifications, which has changed from around $85 \%$ in 2007 to $60 \%$ in this last year. In addition, as aforementioned in this past ten years $89 \%$ of the total conventional licenses have been issued for periods between 1 and 24 months (2 years): 14\% for less than year and $75 \%$ for 12 to 24 month-periods.

With regards to the applicants that obtained conventional licenses we can point out that $86 \%$ of them correspond to corporations, $3 \%$ to individuals and $2 \%$ to partnerships. Nevertheless, it is also necessary to expose that $9 \%$ of the licensees identify themselves as other, where the most common utilized descriptors are: Governmental Institutions, Universities and Research Organizations. Furthermore, it was also shown that from all applications only $32 \%$ was identified under the following: Government contract:19\%, Research Project: 11\% 


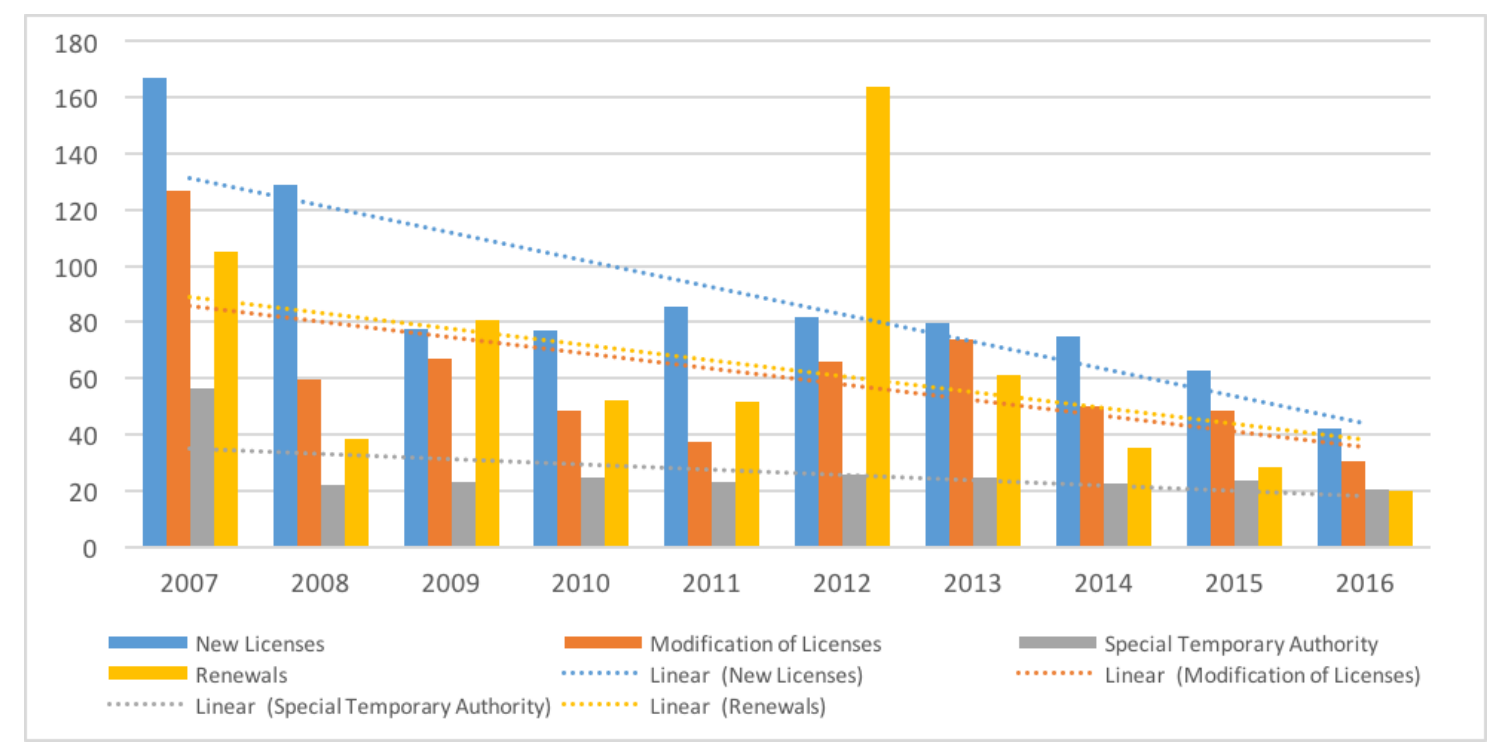

Figure 35: Processing Delay by Type of License

Table 9: Average Processing Time by Type of License

\begin{tabular}{|c|c|c|c|c|c|c|c|c|c|c|}
\hline License Type & $\mathbf{2 0 0 7}$ & $\mathbf{2 0 0 8}$ & $\mathbf{2 0 0 9}$ & $\mathbf{2 0 1 0}$ & $\mathbf{2 0 1 1}$ & $\mathbf{2 0 1 2}$ & $\mathbf{2 0 1 3}$ & $\mathbf{2 0 1 4}$ & $\mathbf{2 0 1 5}$ & $\mathbf{2 0 1 6}$ \\
\hline New Licenses & 167.28 & 128.80 & 77.58 & 76.90 & 85.50 & 81.88 & 79.69 & 75.03 & 62.79 & 41.92 \\
\hline Modification & 126.62 & 59.74 & 67.13 & 48.58 & 37.23 & 65.74 & 73.81 & 49.87 & 48.57 & 30.28 \\
\hline STA & 56.51 & 21.83 & 22.93 & 24.90 & 23.03 & 25.81 & 24.63 & 22.60 & 23.65 & 20.27 \\
\hline Renewals & 105.35 & 38.44 & 80.84 & 51.95 & 51.89 & 164.10 & 61.03 & 35.06 & 28.50 & 19.70 \\
\hline
\end{tabular}


and Foreign Government Use: 2\%.

In terms of the technical information of conventional licenses, we presented some interesting findings. For instance, we can point out that for the past 8 years the number of experimental equipment being used is around $40 \%$ of the total instrumentation, which is a clear increase from 2007 and 2008 when it was approximately 20\%. In addition, we can see that over these past ten years, $53 \%$ of the total authorized stations are mobile and $43 \%$ are fixed. Furthermore, these stations have great flexibility in terms of authorized frequencies and transmission power. In fact, since 2007 a total of 74,932 frequencies have been assigned, where the only radio band with 0 frequencies is the Tremendously High Frequency (THF) band, which ranges from 300 to $3000 \mathrm{GHz}$. On the other hand, the bands with the higher number of frequencies assigned are the Ultra High Frequency (UHF) and the Super High Frequency (SHF) with 34,251 and 15,010 assignations, respectively. As mentioned, this great flexibility is also true for the authorized power. Indeed, for this past ten years the transmitted power varied from very low (less than $1 \mathrm{~mW}$ ) to very high power levels (more than $1 \mathrm{GW}$ ). Moreover, most of the authorized power limits have been less than $1 \mathrm{~mW}$ in the past ten years $(24 \%)$ and the highest concentration of power levels is located between $100 \mathrm{~mW}$ to $1 \mathrm{KW}$ corresponding to $65 \%$ of assignments.

This flexibility in frequency assignment by the FCC can be further evidenced in the most common band for conventional experimental licenses: UHF. We observe that frequencies have been assigned to all the services ${ }^{3}$ in this band as shown in Table 10. Moreover, as shown in Fig.36, the service with the greatest number of assigned frequencies (around 3,500 since 2007) within the UHF band corresponds to the former high-band UHF TV (From 698 to $806 \mathrm{MHz}$ ). It is necessary to point out that this section of the UHF band was auctioned in March 2008 when bidders got full use after the transition to digital TV ${ }^{4}$. In addition, we can observe that other services such as the UHF business band $(450-470 \mathrm{MHz})$ and the ISM band (902-928MHz) have been very popular among experimental licensees. Thus, more than 1800 frequencies have been assigned by the Commission. To conclude this analysis of the UHF band, we observe that the services with the least amount assignments correspond to

\footnotetext{
${ }^{3}$ The details of the services in this band are exposed in Appendix B

${ }^{4}$ The companies currently using the band include: Verizon Wireless, U.S. Cellular, Cavalier Telephone, CenturyTel, AT\&T and Triad Broadcasting
} 
higher frequencies, where services such as pagers, aeronautical radio-navigation and amateur radio reside.

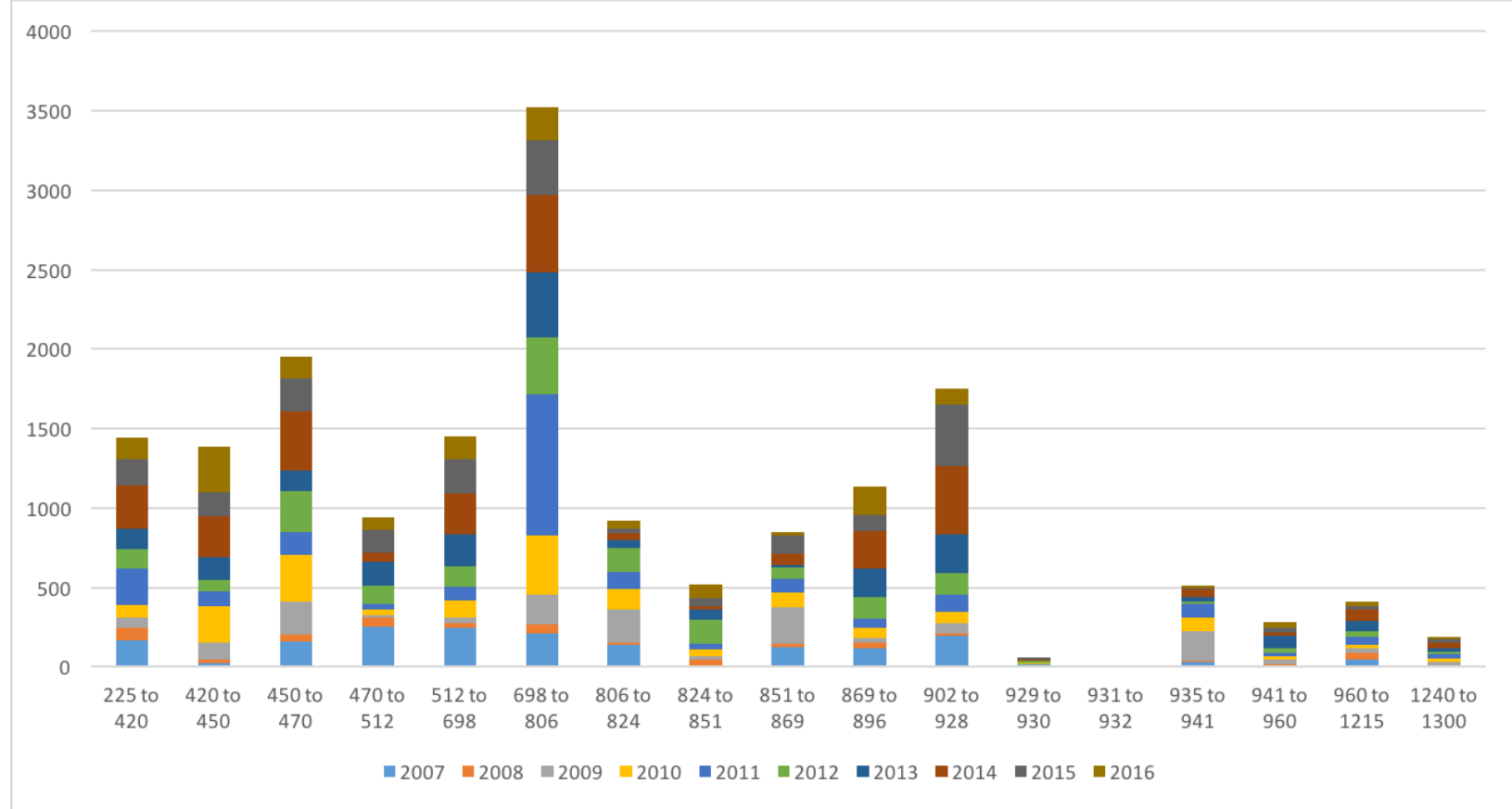

Figure 36: Distribution of Frequencies in the UHF Band 
Table 10: Distribution of Frequencies in the UHF Band

\begin{tabular}{|c|r|r|r|r|r|r|r|r|r|r|}
\hline Band $(\mathbf{M H z})$ & $\mathbf{2 0 0 7}$ & $\mathbf{2 0 0 8}$ & $\mathbf{2 0 0 9}$ & $\mathbf{2 0 1 0}$ & $\mathbf{2 0 1 1}$ & $\mathbf{2 0 1 2}$ & $\mathbf{2 0 1 3}$ & $\mathbf{2 0 1 4}$ & $\mathbf{2 0 1 5}$ & $\mathbf{2 0 1 6}$ \\
\hline $\mathbf{2 2 5}$ to $\mathbf{4 2 0}$ & 167 & 81 & 61 & 84 & 223 & 123 & 134 & 270 & 167 & 132 \\
\hline $\mathbf{4 2 0}$ to $\mathbf{4 5 0}$ & 23 & 25 & 105 & 228 & 96 & 73 & 144 & 258 & 147 & 285 \\
\hline $\mathbf{4 5 0}$ to $\mathbf{4 7 0}$ & 163 & 41 & 210 & 288 & 146 & 255 & 132 & 371 & 212 & 137 \\
\hline $\mathbf{4 7 0}$ to $\mathbf{5 1 2}$ & 254 & 60 & 9 & 36 & 38 & 118 & 147 & 56 & 143 & 79 \\
\hline $\mathbf{5 1 2}$ to $\mathbf{6 9 8}$ & 246 & 32 & 36 & 105 & 88 & 126 & 203 & 254 & 217 & 143 \\
\hline $\mathbf{6 9 8}$ to $\mathbf{8 0 6}$ & 209 & 56 & 186 & 374 & 892 & 358 & 410 & 485 & 341 & 212 \\
\hline $\mathbf{8 0 6}$ to $\mathbf{8 2 4}$ & 136 & 15 & 211 & 126 & 109 & 151 & 47 & 44 & 32 & 50 \\
\hline $\mathbf{8 2 4}$ to $\mathbf{8 5 1}$ & 13 & 33 & 21 & 46 & 35 & 149 & 66 & 20 & 49 & 88 \\
\hline $\mathbf{8 5 1}$ to $\mathbf{8 6 9}$ & 125 & 18 & 235 & 93 & 86 & 70 & 16 & 72 & 114 & 21 \\
\hline $\mathbf{8 6 9}$ to $\mathbf{8 9 6}$ & 118 & 36 & 31 & 63 & 53 & 138 & 177 & 240 & 98 & 178 \\
\hline $\mathbf{9 0 2}$ to $\mathbf{9 2 8}$ & 196 & 17 & 64 & 68 & 106 & 138 & 242 & 436 & 386 & 95 \\
\hline $\mathbf{9 2 9}$ to $\mathbf{9 3 0}$ & 15 & 0 & 0 & 6 & 0 & 15 & 0 & 10 & 11 & 0 \\
\hline $\mathbf{9 3 1}$ to $\mathbf{9 3 2}$ & 5 & 0 & 0 & 0 & 0 & 5 & 0 & 0 & 0 & 0 \\
\hline $\mathbf{9 3 5}$ to $\mathbf{9 4 1}$ & 29 & 8 & 188 & 84 & 85 & 15 & 33 & 46 & 12 & 13 \\
\hline $\mathbf{9 4 1}$ to $\mathbf{9 6 0}$ & 9 & 9 & 31 & 19 & 20 & 27 & 79 & 25 & 26 & 35 \\
\hline $\mathbf{9 6 0}$ to $\mathbf{1 2 1 5}$ & 44 & 42 & 32 & 21 & 53 & 30 & 68 & 69 & 23 & 28 \\
\hline $\mathbf{1 2 4 0}$ to $\mathbf{1 3 0 0}$ & 4 & 2 & 27 & 22 & 29 & 13 & 22 & 34 & 25 & 8 \\
\hline
\end{tabular}

\subsubsection{Special Temporal Authorizations}

For the special case of conventional licenses, STAs, 5,582 authorizations have been issued by the FCC since 2007. However, most of these licenses have been emitted in the past years; thus, we can see that the number of STAs has increased from 212 in 2007 to almost 1000 by the end of 2015, which represents an average increase of $18 \%$ per year. With regards to the authorized time we can point out that $47 \%$ of the applications are authorized for less than 30 days ( 1 month). Indeed, we observe that the majority of these licenses are either 
authorized for less than 3 days, $10 \%$, or less than a week, $52 \%$.

In the case of STAs, we showed that most of the equipment being used is categorized as non-experimental. Indeed, only $23 \%$ of the licensed equipment was experimental in this past ten years. In addition, in the same manner as conventional experimental licenses, STAs have great flexibility in terms of authorized power and frequency. Therefore, from the 56,201 frequencies assigned for STAs since 2007, the only frequencies that were not associated with authorizations are those belonging to the Ultra Low Frequency (ULF) band. Most of the frequencies were assigned to the UHF band with a total of 35,555 assignments (68\%). However, the bands with more significant increase correspond to the higher bands (SHF and EHF), which went from less than 500 in 2007 to more than 2500 by 2016. Within the authorized frequencies we can also observe the great power flexibility. In fact, it varies from very low (less than $1 \mathrm{~mW}$ ) to very high levels (more than $1 \mathrm{GW}$ ) throughout the past ten years. In this wide range of power levels, we see that the highest concentration is located between $100 \mathrm{~mW}$ to $1 \mathrm{KW}$.

Finally, without a doubt, one of the most interesting points about Special Temporary Authorizations is the detailed purpose of operation described in each license. From this analysis we can see that $73 \%$ of all STAs area assigned for televised events in the US ${ }^{5}$. Furthermore, we observed that these licenses are not only used for live transmissions but also for several other activities that provide event support. On the other hand, the remaining $27 \%$ of STAs are utilized in military, government and research projects. We can further observe that the main activities within this group are demonstrations, developing, analysis, and testing of equipment, wireless technologies or security standards.

\subsection{EXPERIMENTAL LICENSES AND FUTURE TECHNOLOGIES}

To conclude this work, we consider it very important to link the notion of experimental radio service with practical applications. In this light, in what follows, we will explore some examples of the implementation of experimental licenses and their potential impact on the

\footnotetext{
${ }^{5}$ Considering the applicants with the greatest number of authorized STAs per year
} 
development of new technologies, more specifically in the new cellular standard, 5G.

In previous cellular standards, $2 \mathrm{G}, 3 \mathrm{G}$ and $4 \mathrm{G}$, it is clear that most of the allocated spectrum belongs to bands below $3 \mathrm{GHz}$. Nevertheless, it is also a well-known fact that spectrum in these bands has become scarce. Thus, for the newer mobile generations, one of the biggest challenges is to find new potential "free" spectrum locations. One proposed approach in this quest is to exploit the available spectrum on higher bands, mainly above $3 \mathrm{GHz}$ [3]. Consequently, this could be traced as one of the reasons for the increment in the number of experimental license ${ }^{6}$ authorizations in these bands. We can indeed observe that the number of authorizations has a 5 times increase: from less than 1000 in 2007 to almost 5000 in 2016 (Fig. 37).

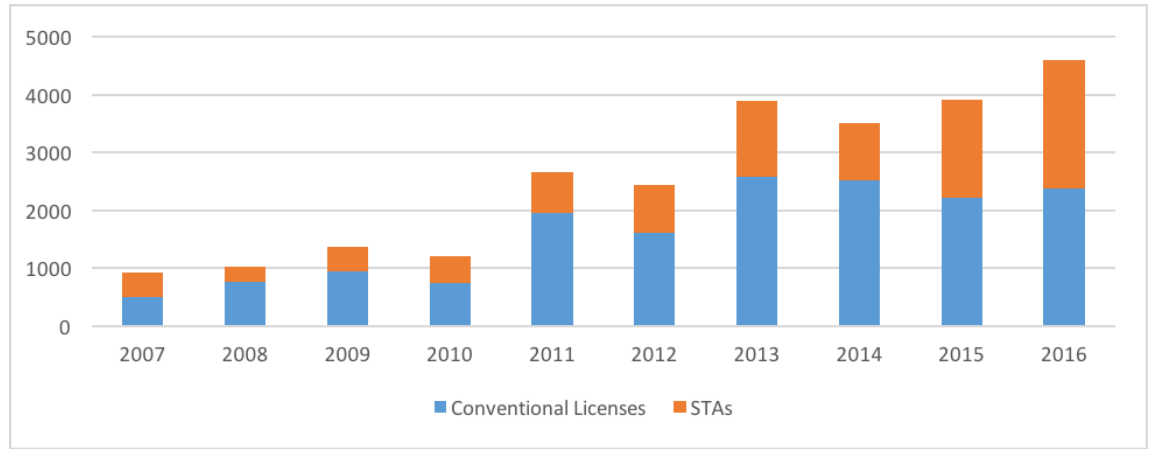

Figure 37: Number of Licenses Assigned in the 3 to $300 \mathrm{GHz}$ bands

\subsubsection{Experimental Authorizations}

In this section, we tie some examples of experimental authorizations, made by the FCC to different types of organizations, to the development of the Fifth Generation of cellular networks.

\footnotetext{
${ }^{6}$ Including Conventional Experimental Licenses and Special Temporary Authorizations
} 
7.2.1.1 Experimental Coverage: One key element in the development of any cellular standard is to understand the potential coverage of a given cell. In this light, in 2010 and 2012, the conventional experimental licenses with File Numbers: 0548-EX-PL-2010 and 0040EX-ML-2012, were issued to the University of Texas at Austin for a period of 24 months. These licenses authorized Dr. Theodore S Rappaport, leader of the project, to utilize 20 distributed frequencies with different power levels (see Table 11) for fixed stations to operate in New York City and Austin, Texas ${ }^{7}$.

The aforementioned licenses allowed to conduct extensive propagation measurements at $28 \mathrm{GHz}$ and $38 \mathrm{GHz}$ to gain insight on $\mathrm{AOA}^{8}, \mathrm{AOD}^{9}$, RMS delay spread, path loss, and building penetration and reflection characteristics for the design of future mm-wave cellular systems [17]. Furthermore, the study concluded that coverage is possible in high frequencies $(28$ and $38 \mathrm{GHz}) .{ }^{10}$ This work also exposes that using the data collected allows the development of statistical channel models for urban environments, and "are highly valuable for the development of $5 \mathrm{G}$ cellular communications at mm-wave bands in the coming decade" [17].

7.2.1.2 Equipment Testing Another well known key element in the design of a functional new standard is the development and testing of the proposed equipment and its characteristics. Indeed, we can observe that the FCC has already granted Special Temporary Authorizations for this type of testing. For instance, an STA with Callsign WK9XII was assigned to AT\&T Services, Inc. for indoor demonstration of equipment that would support potential fifth generation (5G) multi-gigabyte per second (Gbps) applications for fixed and mobile wireless communication networks. Furthermore, the purpose of operation detailed by AT\&T, lays out: "[a]pplicant seeks authority to begin conducting these demonstration to allow for trials before the 3rd Generation Partnership Project (3GPP) 5G standards are finalized in the 2018-2019 time period." This special authorization was granted for tests in the 27.5-28.5 GHz band, as presented in Table 12.

\footnotetext{
${ }^{7}$ All the technical information about the licenses was obtained and processes through the central database developed for this work.

${ }^{8}$ Angle of Arrival

${ }^{9}$ Angle of Departure

${ }^{10}$ Using base stations with a cell-radius of 200 meters
} 
Table 11: Authorized Frequencies License Number 0040-EX-ML-2012 (University of Texas)

\begin{tabular}{|c|c|c|}
\hline Frequency & Station & Power \\
\hline $27.50000000-28.50000000 \mathrm{GHz}$ & FX & $1.000000 \mathrm{~W} 61.090000 \mathrm{~W}$ \\
\hline 28.00000000- GHz & FX & $1.000000 \mathrm{~W} 61.090000 \mathrm{~W}$ \\
\hline $38.00000000-\mathrm{GHz}$ & FX & $1.000000 \mathrm{~W} 61.090000 \mathrm{~W}$ \\
\hline $60.00000000-\mathrm{GHz}$ & FX & 1.000000 W 193.200000 W \\
\hline $27.50000000-28.50000000 \mathrm{GHz}$ & FX & $1.000000 \mathrm{~W} 61.090000 \mathrm{~W}$ \\
\hline 28.00000000- GHz & FX & $1.000000 \mathrm{~W} 61.090000 \mathrm{~W}$ \\
\hline 38.00000000- GHz & FX & $1.000000 \mathrm{~W} 61.090000 \mathrm{~W}$ \\
\hline $60.00000000-\mathrm{GHz}$ & $\mathrm{FX}$ & $1.000000 \mathrm{~W} 193.200000 \mathrm{~W}$ \\
\hline $27.50000000-28.50000000 \mathrm{GHz}$ & $\mathrm{FX}$ & $1.000000 \mathrm{~W} 61.090000 \mathrm{~W}$ \\
\hline 28.00000000- GHz & FX & $1.000000 \mathrm{~W} 61.090000 \mathrm{~W}$ \\
\hline $38.00000000-\mathrm{GHz}$ & FX & $1.000000 \mathrm{~W} 61.090000 \mathrm{~W}$ \\
\hline $60.00000000-\mathrm{GHz}$ & FX & $1.000000 \mathrm{~W} 193.200000 \mathrm{~W}$ \\
\hline $27.50000000-28.50000000 \mathrm{GHz}$ & FX & $1.000000 \mathrm{~W} 61.090000 \mathrm{~W}$ \\
\hline 28.00000000- GHz & FX & $1.000000 \mathrm{~W} 61.090000 \mathrm{~W}$ \\
\hline 38.00000000- GHz & FX & $1.000000 \mathrm{~W} 61.090000 \mathrm{~W}$ \\
\hline $60.00000000-\mathrm{GHz}$ & FX & $1.000000 \mathrm{~W} 193.200000 \mathrm{~W}$ \\
\hline $27.50000000-28.50000000 \mathrm{GHz}$ & FX & $1.000000 \mathrm{~W} 61.090000 \mathrm{~W}$ \\
\hline 28.00000000- GHz & FX & $1.000000 \mathrm{~W} 61.090000 \mathrm{~W}$ \\
\hline $38.00000000-\mathrm{GHz}$ & FX & $1.000000 \mathrm{~W} 61.090000 \mathrm{~W}$ \\
\hline 60.00000000- GHz & $\mathrm{FX}$ & $1.000000 \mathrm{~W} 193.200000 \mathrm{~W}$ \\
\hline
\end{tabular}


Table 12: Authorized Frequencies STA WK9XII(AT\&T)

\begin{tabular}{|c|c|c|}
\hline Frequency & Station & Power \\
\hline $27500.00000000-28500.00000000 \mathrm{MHz}$ & $\mathrm{MO}$ & N/A $0.100000 \mathrm{~W}$ \\
\hline $27500.00000000-28500.00000000 \mathrm{MHz}$ & $\mathrm{FX}$ & N/A $1.000000 \mathrm{~W}$ \\
\hline
\end{tabular}

It is also interesting to point out that this experimental license anlaysis allows us to identify the type of equipment that will be utilized in this authorized STA. As included in Table 13, for the aforementioned experiment, two experimental Ericson transmitters will be utilized in fixed and mobile stations ${ }^{11}$.

Table 13: Authorized Equipment STA WK9XII(AT\&T)

\begin{tabular}{|c|c|c|c|c|}
\hline Station & Brand & Model & Number & Experimental \\
\hline FX MO & Ericsson & Experimental & 2 & Yes \\
\hline
\end{tabular}

7.2.1.3 Design and Development Finally, it is possible to observe that in absence of a $5 \mathrm{G}$ standard, tests are being done not only in the $28 \mathrm{GHz}$ band. In fact, the FCC issued the conventional license 0494-EX-PL-2016 in favor of Keysight Technologies, Inc. with a duration of 24 months. The purpose of this license is to not only test, but also design, develop and demonstrate $5 \mathrm{G}$ technologies at an indoor facility in the $71-76 \mathrm{GHz}$ band (Table 14 ).

Table 14: Authorized Frequencies License 0494-EX-PL-2016 (Keysight Technologies, Inc.)

\begin{tabular}{|c|c|c|}
\hline Frequency & Station & Power \\
\hline $71.00000000-76.00000000 \mathrm{GHz}$ & FX & $3.000000 \mathrm{~mW} 1.000000 \mathrm{~W}$ \\
\hline
\end{tabular}

\footnotetext{
${ }^{11}$ Information gathered directly from the Experimental License Database constructed for this thesis
} 


\subsection{CONCLUSIONS AND FUTURE WORK}

The analysis that we have performed has enabled us to explore the actual range of applicability and impact of the FCC's experimental licenses. Indeed, as a result of the amount of information that is publicly available, we have been able to construct a database that suits the purposes of our study.

Throughout this work, we have pointed out statistics on how different metrics have changed over the past ten years. For instance, we have observed how the number of assigned (granted) licenses has significantly increased during this period. Additionally, the delays associated with the licensing process have decreased from 160 days to 40 days in average. These outcomes represent positive opportunities for those seeking access to experimental licenses. Regarding the technical characteristics of the assigned licenses, we have evidenced multiple types of operational parameters and applications. In this work we have analyzed frequency and power independently; however, the diversity of the assigned licenses leaves room for pairing the aforementioned parameters and providing a more technical assessment of the impact of the experimental licenses.

In this light, our future work comprises a deeper technical analysis of the characteristics of these licenses and additional exploration of the impact that experimental licenses have in the advance of research on next generation technologies. We are also interested on delving

deeper on the actual licensing process. For this purpose, we are interested in developing a mechanisms to differentiate between delays regarding FCC and NTIA, when both entities are involved in the licensing process. Further, it is important to provide a more general assessment of the effectiveness of this process in the U.S. An avenue for reaching this objective is to compare the delays and other relevant metrics to those obtained for similar licenses in other countries. The future work with the database that we have constructed is not limited 
to the current ideas we expose. We expect this database to be a key tool for exploring additional data of interest as these are linked to other technologies in commercial as well as research areas. 


\section{APPENDIX A}

\section{SUMMARY PURPOSE OF OPERATION STAS}

\begin{tabular}{|c|c|c|c|}
\hline Year & Company & STAs & Purpose of Operation (Summary) \\
\hline \multirow{13}{*}{2007} & GLOBAL TESTING LABORATORIES, LLC & 17 & $\begin{array}{l}\text { RF Immunity test of commerical machine for } \\
\text { compliance with European EMC regulation }\end{array}$ \\
\hline & \multirow[t]{2}{*}{ ERICSSON INC } & \multirow[t]{2}{*}{17} & $\begin{array}{l}\text { Demonstration of UMTS/HSPA technology } \\
\text { for customers. }\end{array}$ \\
\hline & & & $\begin{array}{l}\text { Testing of interworking of various contigu- } \\
\text { ous cell site clusters in transmitting voice, } \\
\text { video, and data calls using UMTS technology } \\
\text { and equipment for Advanced Wireless Services } \\
\text { (AWS). }\end{array}$ \\
\hline & \multirow[t]{3}{*}{ BAE SYSTEMS } & \multirow[t]{3}{*}{15} & $\begin{array}{l}\text { Developing of imaging system that will involve } \\
\text { one-way transmission of data. }\end{array}$ \\
\hline & & & $\begin{array}{l}\text { Test various antennas and communications } \\
\text { systems for emergency responders. }\end{array}$ \\
\hline & & & $\begin{array}{l}\text { The testing for which authority is requested } \\
\text { in this STA Request will involve experiment } \\
\text { in data and video transmission. }\end{array}$ \\
\hline & \multirow{5}{*}{ THE BOEING COMPANY } & \multirow{5}{*}{13} & Equipment testing \\
\hline & & & Analyze communication's system performance \\
\hline & & & Feasibility study for a landing system. \\
\hline & & & $\begin{array}{l}\text { The purpose of this operation is to test the } \\
\text { feasability of using this equipment and to } \\
\text { gather data to be used in bidding for the U.S } \\
\text { Department of Homeland Security contract. }\end{array}$ \\
\hline & & & $\begin{array}{l}\text { To conduct VSWR acceptance testing on UHF } \\
\text { Cup Dipole antennae. See attached test de- } \\
\text { scription. }\end{array}$ \\
\hline & \multirow[t]{2}{*}{ HARRIS CORPORATION } & \multirow[t]{2}{*}{8} & $\begin{array}{l}\text { Demonstration of digital video broadcast } \\
\text { equipment at National Association of Broad- } \\
\text { casters Convention. in Las Vegas, Nevada. }\end{array}$ \\
\hline & & & $\begin{array}{l}\text { Development of new radio communications } \\
\text { equipment for use by military, government, } \\
\text { and public safety organizations, based on } \\
\text { emerging Wireless Metropolitan Area Net- } \\
\text { work technology. }\end{array}$ \\
\hline
\end{tabular}




\begin{tabular}{|c|c|c|c|}
\hline & & & $\begin{array}{l}\text { Testing in connection with development ef- } \\
\text { forts with the United States Army for the } \\
\text { Warfighter Information Network - Tactical } \\
\text { ("WIN-T") and Future Combat Systems } \\
\text { ("FCS") programs. }\end{array}$ \\
\hline \multirow{14}{*}{2008} & \multirow[t]{3}{*}{ BROADCAST SPORTS INC. } & \multirow[t]{3}{*}{45} & $\begin{array}{l}\text { Facilitate video production for airing of sports } \\
\text { shows (IRL, NASCAR, PGA, etc.) }\end{array}$ \\
\hline & & & $\begin{array}{l}\text { Coordinate video and audio production activ- } \\
\text { ities sports shows (IRL, NASCAR, PGA, etc.) }\end{array}$ \\
\hline & & & Test new equipment for sports transmissions \\
\hline & \multirow{3}{*}{ BROAD COMM, INC. } & \multirow{3}{*}{27} & Provide coverage of sports events \\
\hline & & & $\begin{array}{l}\text { Provide support for media coverage of the } \\
\text { Democratic National Convention }\end{array}$ \\
\hline & & & $\begin{array}{l}\text { Provide support for media coverage of the Re- } \\
\text { publican National Convention }\end{array}$ \\
\hline & \multirow{3}{*}{ THE BOEING COMPANY } & \multirow{3}{*}{17} & Equipment testing \\
\hline & & & Analyze communication's system performance \\
\hline & & & Feasibility study for a landing system. \\
\hline & \multirow[t]{3}{*}{ ERICSSON INC } & \multirow[t]{3}{*}{14} & $\begin{array}{l}\text { Demonstration of QuicLINK mobile radio } \\
\text { communications solution }\end{array}$ \\
\hline & & & $\begin{array}{l}\text { Demonstration of UMTS/HSPA and LTE } \\
\text { technology to prospective customers. }\end{array}$ \\
\hline & & & $\begin{array}{l}\text { Testing of interworking of various contigu- } \\
\text { ous cell site clusters in transmitting voice, } \\
\text { video, and data calls using UMTS technology } \\
\text { and equipment for Advanced Wireless Services } \\
\text { (AWS). }\end{array}$ \\
\hline & \multirow[t]{2}{*}{ QUALCOMM INC. } & \multirow[t]{2}{*}{13} & $\begin{array}{l}\text { Testing and demonstration of MediaFLO tech- } \\
\text { nology. }\end{array}$ \\
\hline & & & To demonstrate MediaFlo technology. \\
\hline \multirow{11}{*}{2009} & \multirow[t]{3}{*}{ BROADCAST SPORTS, INC. } & \multirow[t]{3}{*}{60} & $\begin{array}{l}\text { Facilitate video production for airing of sports } \\
\text { shows (IRL, NASCAR, PGA, etc.) }\end{array}$ \\
\hline & & & $\begin{array}{l}\text { Coordinate video and audio production activ- } \\
\text { ities sports shows (IRL, NASCAR, PGA, etc.) }\end{array}$ \\
\hline & & & Test new equipment for sports transmissions \\
\hline & \multirow{3}{*}{ BROAD COMM INC. } & \multirow{3}{*}{55} & Provide coverage of sports events \\
\hline & & & $\begin{array}{l}\text { Provide support for media coverage of the } \\
\text { Democratic National Convention }\end{array}$ \\
\hline & & & $\begin{array}{l}\text { Provide support for media coverage of the Re- } \\
\text { publican National Convention }\end{array}$ \\
\hline & \multirow[t]{3}{*}{ ERICSSON INC } & \multirow[t]{3}{*}{16} & $\begin{array}{l}\text { Demonstrate LTE performanc and applica- } \\
\text { tions }\end{array}$ \\
\hline & & & $\begin{array}{l}\text { Demonstration of satellite backhaul for a GSM } \\
\text { call system to potential Government cus- } \\
\text { tomers. }\end{array}$ \\
\hline & & & $\begin{array}{l}\text { Demonstration of the QuicLINK mobile radio } \\
\text { communications system. }\end{array}$ \\
\hline & \multirow[b]{2}{*}{ LOCKHEED MARTIN CORP. } & \multirow[b]{2}{*}{16} & $\begin{array}{l}\text { Demonstration of IPWireless products at } \\
\text { Lockheed Martin facility. }\end{array}$ \\
\hline & & & $\begin{array}{l}\text { Telemetry for Safety-of-Flight and operation } \\
\text { of an F35. }\end{array}$ \\
\hline
\end{tabular}




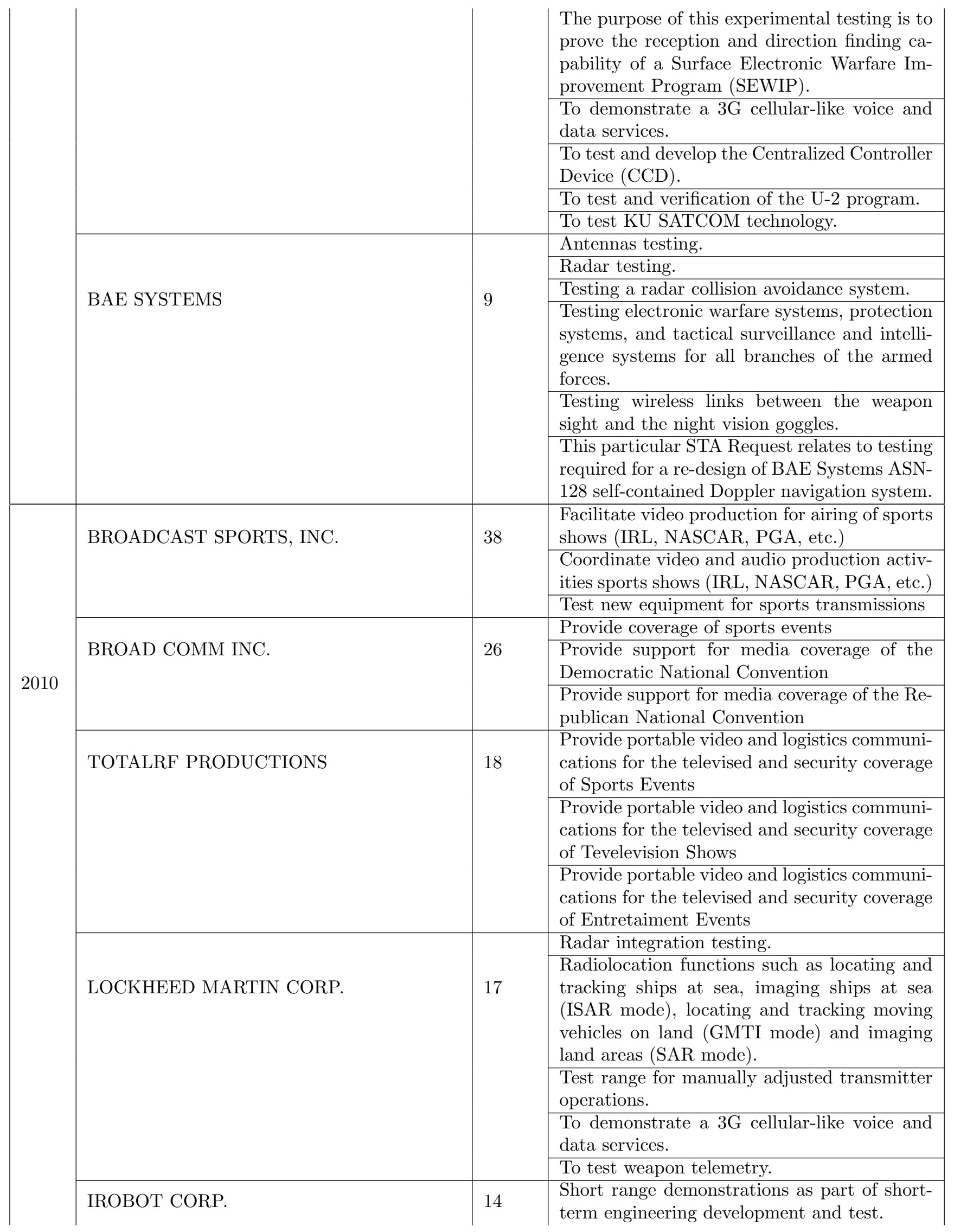




\begin{tabular}{|c|c|c|c|}
\hline & & & To demonstrate robot maneuverability \\
\hline \multirow{24}{*}{2011} & \multirow[t]{3}{*}{ BROADCAST SPORTS, INC. } & \multirow[t]{3}{*}{66} & $\begin{array}{l}\text { Facilitate video production for airing of sports } \\
\text { shows (IRL, NASCAR, PGA, etc.) }\end{array}$ \\
\hline & & & $\begin{array}{l}\text { Coordinate video and audio production activ- } \\
\text { ities sports shows (IRL, NASCAR, PGA, etc.) }\end{array}$ \\
\hline & & & Test new equipment for sports transmissions \\
\hline & \multirow[t]{3}{*}{ CP COMMUNICATIONS PA, LLC } & \multirow[t]{3}{*}{30} & $\begin{array}{l}\text { Provide portable audio at televised sports } \\
\text { events }\end{array}$ \\
\hline & & & $\begin{array}{l}\text { Provide portable audio at televised public } \\
\text { events }\end{array}$ \\
\hline & & & $\begin{array}{l}\text { Provide the US Marine Corp, security video, } \\
\text { audio and logistics communications at this } \\
\text { event. }\end{array}$ \\
\hline & \multirow[t]{4}{*}{ ALCATEL-LUCENT } & \multirow[t]{4}{*}{26} & $\begin{array}{l}\text { Build an LTE public safety customer evalu- } \\
\text { ation lab that will provide first responders } \\
\text { with infrastructure to evaluate applications } \\
\text { that will enhance their daily work experience. }\end{array}$ \\
\hline & & & APCO Demonstrations. \\
\hline & & & Equipment Demonstration \\
\hline & & & $\begin{array}{l}\text { To demonstrate wireless technologies to vari- } \\
\text { ous attendees }\end{array}$ \\
\hline & \multirow{5}{*}{ LOCKHEED MARTIN CORP. } & \multirow{5}{*}{24} & $\begin{array}{l}\text { Demonstration of a mobile communication } \\
\text { technology. }\end{array}$ \\
\hline & & & $\begin{array}{l}\text { Integration, testing, and demonstration of a } \\
\text { radar receiver technology upgrade. }\end{array}$ \\
\hline & & & $\begin{array}{l}\text { To demonstrate a } 3 \mathrm{G} \text { cellular-like voice and } \\
\text { data services. }\end{array}$ \\
\hline & & & $\begin{array}{l}\text { To demonstrate and verify the utility of a pri- } \\
\text { vate } 4 \mathrm{G} \text { cellular service. }\end{array}$ \\
\hline & & & $\begin{array}{l}\text { To evaluate EADS Interrogator performance. } \\
\text { To evaluate Ku-band satellite technology for } \\
\text { high data rate communication to rotary wing } \\
\text { platforms. }\end{array}$ \\
\hline & \multirow{5}{*}{ RAYTHEON NETWORK CENTRIC SYS. } & \multirow{5}{*}{18} & Intelligent Transportation System \\
\hline & & & $\begin{array}{l}\text { A ground mobile demonstration and evalua- } \\
\text { tion. }\end{array}$ \\
\hline & & & $\begin{array}{l}\text { Raytheon Network Centric Systems (NCS) } \\
\text { The goal of the project is to provide a } \\
\text { demonstrable D-RAPCON configuration for } \\
\text { ESC/Hanscom and User Community prior to } \\
\text { RFP. }\end{array}$ \\
\hline & & & $\begin{array}{l}\text { To demonstrate High Speed Data Gateway ra- } \\
\text { dio System for interoperability. }\end{array}$ \\
\hline & & & $\begin{array}{l}\text { To perform a demonstration of the TacLink } \\
\text { Mobile smartphone and its capabilities. }\end{array}$ \\
\hline & \multirow[t]{3}{*}{ BROADCAST SPORTS, INC. } & \multirow[t]{3}{*}{77} & $\begin{array}{l}\text { Facilitate video production for airing of sports } \\
\text { shows (IRL, NASCAR, PGA, etc.) }\end{array}$ \\
\hline & & & $\begin{array}{l}\text { Coordinate video and audio production activ- } \\
\text { ities sports shows (IRL, NASCAR, PGA, etc.) }\end{array}$ \\
\hline & & & Test new equipment for sports transmissions \\
\hline & CP COMMUNICATIONS PA, LLC & 50 & $\begin{array}{l}\text { Provide portable audio at televised sports } \\
\text { events }\end{array}$ \\
\hline
\end{tabular}




\begin{tabular}{|c|c|c|c|}
\hline & \multirow{5}{*}{ 3G WIRELESS, LLC } & \multirow{5}{*}{24} & \multirow{2}{*}{$\begin{array}{l}\text { Provide portable audio at televised public } \\
\text { events } \\
\text { Provide the US Marine Corp, security video, } \\
\text { audio and logistics communications at this } \\
\text { event. }\end{array}$} \\
\hline & & & \\
\hline & & & $\begin{array}{l}\text { Live HD video from inside the convention cen- } \\
\text { ter and deliver these feeds to Fox News. }\end{array}$ \\
\hline & & & $\begin{array}{l}\text { To provide on the spot video from various lo- } \\
\text { cations during televised events }\end{array}$ \\
\hline & & & $\begin{array}{l}\text { To provide remote wireless communication in } \\
\text { and around Times Square. }\end{array}$ \\
\hline & \multirow{7}{*}{ LOCKHEED MARTIN CORP. } & \multirow{7}{*}{17} & RF Evaluation purposes \\
\hline & & & Demonstration and use of Desert Hawk III. \\
\hline & & & $\begin{array}{l}\text { Demonstrate and verify the utility of a private } \\
4 \mathrm{G} \text { cellular service } \mathrm{f}\end{array}$ \\
\hline & & & $\begin{array}{l}\text { Verifying antenna propagation range perfor- } \\
\text { mance measurements. }\end{array}$ \\
\hline & & & $\begin{array}{l}\text { To demonstrate the remote operation of an } \\
\text { Intelligence, Surveillance and Reconnaissance } \\
\text { (ISR) }\end{array}$ \\
\hline & & & $\begin{array}{l}\text { To evaluate Ku-band satellite technology for } \\
\text { high data rate communication to rotary wing } \\
\text { platforms. }\end{array}$ \\
\hline & & & $\begin{array}{l}\text { Verification of performance of new radar tech- } \\
\text { nology for domestic border security for state } \\
\text { officials. }\end{array}$ \\
\hline & \multirow{3}{*}{ IROBOT CORP. } & \multirow{3}{*}{16} & Testing of robots (range, mobility, etc) \\
\hline & & & To demonstrate robot maneuverability \\
\hline & & & $\begin{array}{l}\text { To demonstrate the capabilities of robotic } \\
\text { technology }\end{array}$ \\
\hline \multirow{11}{*}{2013} & \multirow[t]{3}{*}{ BROADCAST SPORTS, INC. } & \multirow[t]{3}{*}{209} & $\begin{array}{l}\text { Facilitate video production for airing of sports } \\
\text { shows (IRL, NASCAR, PGA, etc.) }\end{array}$ \\
\hline & & & $\begin{array}{l}\text { Coordinate video and audio production activ- } \\
\text { ities sports shows (IRL, NASCAR, PGA, etc.) }\end{array}$ \\
\hline & & & Test new equipment for sports transmissions \\
\hline & \multirow[t]{3}{*}{ CP COMMUNICATIONS } & \multirow[t]{3}{*}{45} & $\begin{array}{l}\text { Provide portable audio at televised sports } \\
\text { events }\end{array}$ \\
\hline & & & $\begin{array}{l}\text { Provide portable audio at televised public } \\
\text { events }\end{array}$ \\
\hline & & & $\begin{array}{l}\text { Provide the US Marine Corp, security video, } \\
\text { audio and logistics communications at this } \\
\text { event. }\end{array}$ \\
\hline & \multirow{5}{*}{ THE BOEING COMPANY } & \multirow{5}{*}{29} & Aircraft Certification Testing \\
\hline & & & Development for new heliocopter at Mesa, AZ \\
\hline & & & Test Aircraft Communications \\
\hline & & & $\begin{array}{l}\text { To develop a platform agnostic sensor suite } \\
\text { and software package to demonstrate au- } \\
\text { tonomous approaches and landing for unpre- } \\
\text { pared landing sites using the Unmanned Little } \\
\text { Bird platform. }\end{array}$ \\
\hline & & & $\begin{array}{l}\text { To Verify Aircraft Communication Systems } \\
\text { performance after Depot Maintenance. Trans- } \\
\text { mit time not expected to exceed } 3 \text { hours per } \\
\text { test at longest. }\end{array}$ \\
\hline
\end{tabular}




\begin{tabular}{|c|c|c|c|}
\hline & \multirow{3}{*}{ 3G WIRELESS, LLC } & \multirow[t]{3}{*}{22} & $\begin{array}{l}\text { Live HD video from inside the convention cen- } \\
\text { ter and deliver these feeds to Fox News. }\end{array}$ \\
\hline & & & $\begin{array}{l}\text { To provide on the spot video from various lo- } \\
\text { cations during televised events }\end{array}$ \\
\hline & & & $\begin{array}{l}\text { To provide remote wireless communication in } \\
\text { and around Times Square. }\end{array}$ \\
\hline & SCREENED IMAGES, INC & 18 & $\begin{array}{l}\text { Demonstration of the functionality of a Man- } \\
\text { aged Access mobile radio communications sys- } \\
\text { tem. }\end{array}$ \\
\hline \multirow{17}{*}{2014} & \multirow[t]{3}{*}{ BROADCAST SPORTS, INC. } & \multirow[t]{3}{*}{198} & $\begin{array}{l}\text { Facilitate video production for airing of sports } \\
\text { shows (IRL, NASCAR, PGA, etc.) }\end{array}$ \\
\hline & & & $\begin{array}{l}\text { Coordinate video and audio production activ- } \\
\text { ities sports shows (IRL, NASCAR, PGA, etc.) }\end{array}$ \\
\hline & & & Test new equipment for sports transmissions \\
\hline & \multirow[t]{3}{*}{ CP COMMUNICATIONS } & \multirow[t]{3}{*}{48} & $\begin{array}{l}\text { Provide portable audio at televised sports } \\
\text { events }\end{array}$ \\
\hline & & & $\begin{array}{l}\text { Provide portable audio at televised public } \\
\text { events }\end{array}$ \\
\hline & & & $\begin{array}{l}\text { Provide the US Marine Corp, security video, } \\
\text { audio and logistics communications at this } \\
\text { event. }\end{array}$ \\
\hline & \multirow{4}{*}{ HARRIS CORP. } & \multirow{4}{*}{21} & $\begin{array}{l}\text { Demonstrations of a HF Wideband waveform } \\
\text { for various military groups. }\end{array}$ \\
\hline & & & $\begin{array}{l}\text { Continued testing of the transmission and re- } \\
\text { ception of voice and data communications to } \\
\text { replicate in theater tactical communication. }\end{array}$ \\
\hline & & & $\begin{array}{l}\text { Demonstration of wireless technologies related } \\
\text { to public safety }\end{array}$ \\
\hline & & & $\begin{array}{l}\text { Experimental testing to determine RF com- } \\
\text { patibility of military radio system to be de- } \\
\text { ployed by the US Army at common sites in- } \\
\text { theater. }\end{array}$ \\
\hline & \multirow[t]{3}{*}{ 3G WIRELESS, LLC } & \multirow[t]{3}{*}{20} & $\begin{array}{l}\text { Live HD video from inside the convention cen- } \\
\text { ter and deliver these feeds to Fox News. }\end{array}$ \\
\hline & & & $\begin{array}{l}\text { To provide on the spot video from various lo- } \\
\text { cations during televised events }\end{array}$ \\
\hline & & & $\begin{array}{l}\text { To provide remote wireless communication in } \\
\text { and around Times Square. }\end{array}$ \\
\hline & \multirow{4}{*}{ NORTHROP GRUMMAN SYS. CORP. } & \multirow{4}{*}{16} & $\begin{array}{l}\text { Conduct tests of an E-band transceiver for po- } \\
\text { tential RF backbone use. }\end{array}$ \\
\hline & & & $\begin{array}{l}\text { Demonstration of Advanced Extremely High } \\
\text { frequency (AEHF) satellite communications } \\
\text { capabilities using an Active Electronically } \\
\text { beamed array }\end{array}$ \\
\hline & & & $\begin{array}{l}\text { Demonstration of radar capabilities support- } \\
\text { ing Customs and Border Patrol operations. }\end{array}$ \\
\hline & & & $\begin{array}{l}\text { Operation of a trial } 700 \mathrm{MHz} \text { LTE network } \\
\text { for use in the development of solutions in- } \\
\text { tended to advance the FirstNet program and } \\
\text { the development of the FirstNet Nationwide } \\
\text { Network. }\end{array}$ \\
\hline
\end{tabular}




\begin{tabular}{|c|c|c|c|}
\hline & & & $\begin{array}{l}\text { Test commercial equipment for possible devel- } \\
\text { opment of remote control payload deployment } \\
\text { operations. }\end{array}$ \\
\hline & & & $\begin{array}{l}\text { Testing the STARlite SAR/GMTI Tactical } \\
\text { Radar System (STARlite) and TCDL air-to- } \\
\text { ground data equipment. }\end{array}$ \\
\hline & BROADCAST SPORTS INT. & 123 & $\begin{array}{l}\text { The purpose for this STA is to provide enough } \\
\text { available frequencies for communications to } \\
\text { cameras, utilities, producers, directors, emer- } \\
\text { gency and security personnel at elevised sports } \\
\text { event }\end{array}$ \\
\hline & & & $\begin{array}{l}\text { The purpose of this STA operation is to coor- } \\
\text { dinate wireless audio and video transmission } \\
\text { for televised sporting event. }\end{array}$ \\
\hline & & & $\begin{array}{l}\text { To coordinate wireless audio and video trans- } \\
\text { mission for televised sporting event. }\end{array}$ \\
\hline & & & $\begin{array}{l}\text { To provide wireless return video to all talent } \\
\text { and camera personnel at the sporting event. }\end{array}$ \\
\hline 2015 & CP COMMUNICATIONS & 93 & $\begin{array}{l}\text { Provide portable audio at televised sports } \\
\text { events }\end{array}$ \\
\hline & & & $\begin{array}{l}\text { Provide portable audio at televised public } \\
\text { events }\end{array}$ \\
\hline & & & $\begin{array}{l}\text { Provide the US Marine Corp, security video, } \\
\text { audio and logistics communications at this } \\
\text { event. }\end{array}$ \\
\hline & BROADCAST SPORTS, INC. & 65 & $\begin{array}{l}\text { Facilitate video production for airing of sports } \\
\text { shows (IRL, NASCAR, PGA, etc.) }\end{array}$ \\
\hline & & & $\begin{array}{l}\text { Coordinate video and audio production activ- } \\
\text { ities sports shows (IRL, NASCAR, PGA, etc.) }\end{array}$ \\
\hline & & & Test new equipment for sports transmissions \\
\hline & 3G WIRELESS, LLC & 37 & $\begin{array}{l}\text { Live HD video from inside the convention cen- } \\
\text { ter and deliver these feeds to Fox News. }\end{array}$ \\
\hline & & & $\begin{array}{l}\text { To provide on the spot video from various lo- } \\
\text { cations during televised events }\end{array}$ \\
\hline & & & $\begin{array}{l}\text { To provide remote wireless communication in } \\
\text { and around Times Square. }\end{array}$ \\
\hline & & 35 & Mexsat Initial System Test (IST) \\
\hline & & & Network integration testing. \\
\hline & & & $\begin{array}{l}\text { Satellite telemetry and Command RF Func- } \\
\text { tional Check at the launch site facility and in } \\
\text { the fairing. }\end{array}$ \\
\hline & THE BOEING COMPANY & & $\begin{array}{l}\text { Testing of CDL communication equipment } \\
\text { to validate links properly transmit necessary } \\
\text { data. }\end{array}$ \\
\hline & & & $\begin{array}{l}\text { The device will be used in a control laboratory } \\
\text { environment for research/development testing } \\
\text { of RFID tags }\end{array}$ \\
\hline & & & $\begin{array}{l}\text { The purpose of the altimeter system is to pro- } \\
\text { vide altitude data that will be used to navi- } \\
\text { gate and land the Unmanned Aircraft Systems } \\
\text { (UAS). }\end{array}$ \\
\hline & & & $\begin{array}{l}\text { To demonstrate and test a new unmanned sys- } \\
\text { tem to potential military customers. }\end{array}$ \\
\hline & & & To evaluate the airplane system. \\
\hline
\end{tabular}




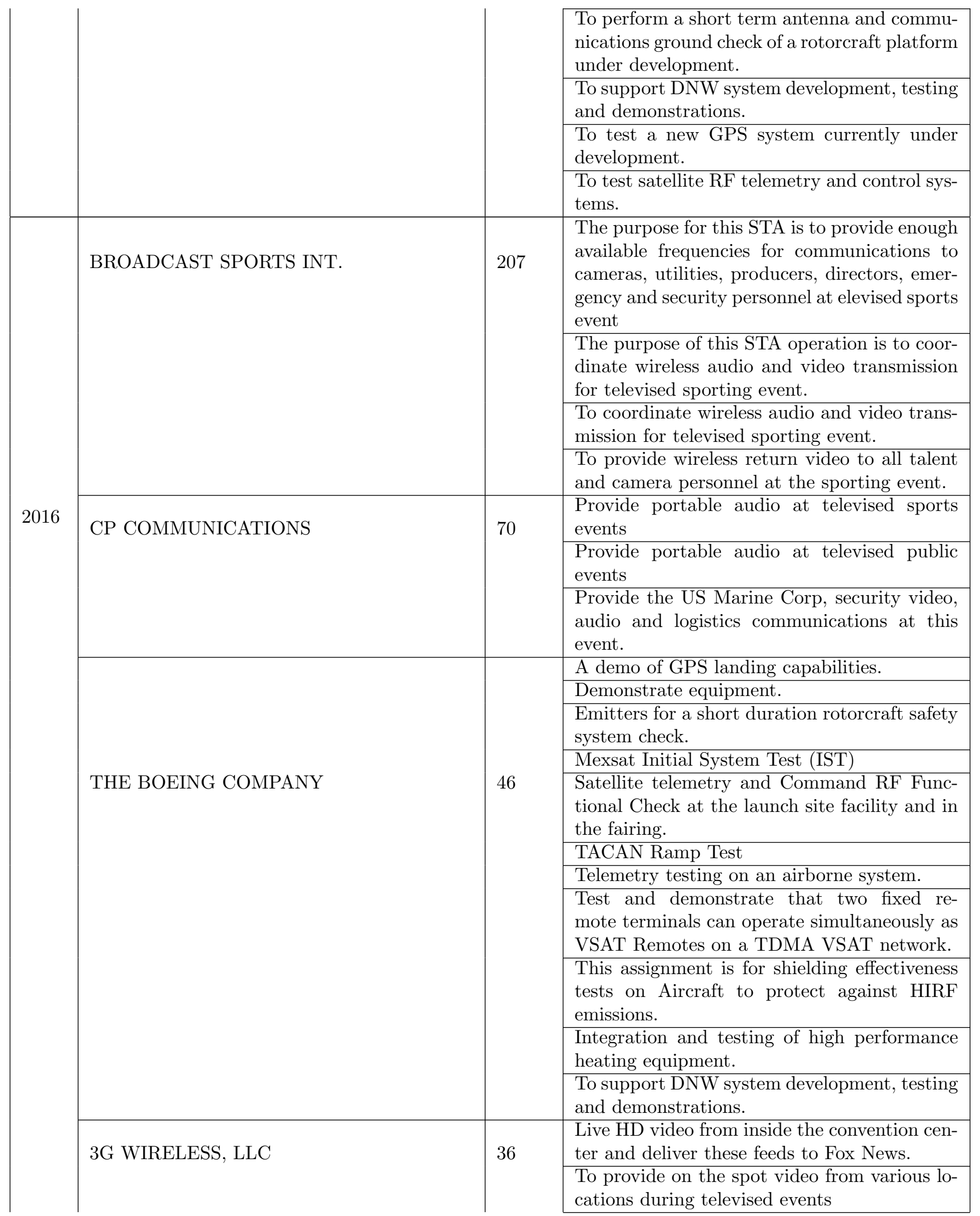




\begin{tabular}{|l|l|l|} 
& & $\begin{array}{l}\text { To provide remote wireless communication in } \\
\text { and around Times Square. }\end{array}$ \\
\hline \multirow{3}{*}{ BROAD COMM INC. } & \multirow{2}{*}{28} & $\begin{array}{l}\text { Provide logistical support for sports events } \\
\text { Test a new video capture system }\end{array}$ \\
\cline { 3 - 4 } & & $\begin{array}{l}\text { The purpose is to accommodate the use of } \\
\text { portable cameras at televised events }\end{array}$ \\
& & $\begin{array}{l}\text { Proveide Coverage for televised sports events } \\
\text { Transmit two channels of audio to spectators } \\
\text { using special receivers }\end{array}$ \\
\hline
\end{tabular}


APPENDIX B

UHF BAND DISTRIBUTION 


\begin{tabular}{|l|l|}
\hline Band $(\mathrm{MHz})$ & \\
\hline 225 to 420 & Government use \\
\hline 420 to 450 & Government radiolocation and amateur radio \\
\hline 450 to 470 & UHF business band, General Mobile Radio Service, and Family Radio Service \\
\hline 470 to 512 & Low-band TV channels \\
\hline 512 to 698 & Medium-band TV channels \\
\hline 698 to 806 & Formerly high-band UHF TV \\
\hline 806 to 824 & Public safety and commercial \\
\hline 824 to 851 & Cellular A \& B franchises \\
\hline 851 to 869 & Public safety and commercial \\
\hline 869 to 896 & Cellular A \& B franchises, BTS \\
\hline 902 to 928 & ISM band, amateur radio \\
\hline 929 to 930 & Pagers \\
\hline 931 to 932 & Pagers \\
\hline 935 to 941 & Commercial 2-way radio \\
\hline 941 to 960 & Mixed studio-transmitter links \\
\hline 960 to 1215 & Aeronautical radionavigation \\
\hline 1240 to 1300 & Amateur radio \\
\hline
\end{tabular}




\section{BIBLIOGRAPHY}

[1] Memorandum opinion and order and further notice of proposed rulemaking:. Promoting Expanded Opportunities for Radio Experimentation and Market Trials under Part 5 of the Commissions Rules and Streamlining Other Related Rules, 2015.

[2] Ranveer Chandra, Thomas Moscibroda, Paramvir Bahl, Rohan Murty, George Nychis, and Xiaohui Wang. A campus-wide testbed over the tv white spaces. ACM SIGMOBILE Mobile Computing and Communications Review, 15(3):2-9, 2011.

[3] Shanzhi Chen and Jian Zhao. The requirements, challenges, and technologies for $5 \mathrm{~g}$ of terrestrial mobile telecommunication. IEEE Communications Magazine, 52(5):36-43, 2014.

[4] Federal Communications Commission. Conditions for use of outdoor test ranges for $\mathrm{rf}$ immunity testing. Technical report, 071996.

[5] Federal Communications Commission. Part 5: Experimental radio service. Code of Federal Regulations Title, 47, 2013.

[6] Federal Communications Commission. Promoting expanded opportunities for radio experimentation and market trials under part 5 of the commissions rules and streamlining other related rules. Report and Order FCC 13-15, 2013.

[7] The National Association for Amateur Radio. Fcc adopts sweeping changes to experimental radio service, 2013.

[8] Federal Communications Commission Spectrum Policy Task Force. Report of the unlicensed devices and experimental licenses working group, 2002.

[9] ITU-T. Nomenclature of the frequency and wavelength bands used in telecommunications. Technical report, 082015.

[10] Taeyoung Kim, Jeongho Park, Ji-Yun Seol, Suryong Jeong, Jaeweon Cho, and Wonil Roh. Tens of gbps support with mmwave beamforming systems for next generation communications. In 2013 IEEE Global Communications Conference (GLOBECOM), pages 3685-3690. IEEE, 2013. 
[11] George R MacCartney, Junhong Zhang, Shuai Nie, and Theodore S Rappaport. Path loss models for $5 \mathrm{~g}$ millimeter wave propagation channels in urban microcells. In 2013 IEEE Global Communications Conference (GLOBECOM), pages 3948-3953. IEEE, 2013.

[12] Shuai Nie, George R MacCartney, Shu Sun, and Theodore S Rappaport. 72 ghz millimeter wave indoor measurements for wireless and backhaul communications. In PIMRC, pages 2429-2433, 2013.

[13] Office of Engineering and Technology. Experimental licensing system generic search, 2016.

[14] Federal Communications Commission Office of Engineering Technology. Federal Communications Commission (FCC) Experimental Licensing System (External) Users Manual. Federal Communications Commission, 445 12th Street SW, Washington, DC 20554, 3 edition, 2008.

[15] Inc Open Signal. The State of LTE (February 2016). Technical report, 022016.

[16] Przemyslaw Pawelczak, Keith Nolan, Linda Doyle, Ser Wah Oh, and Danijela Cabric. Cognitive radio: Ten years of experimentation and development. IEEE Communications Magazine, 49(3):90-100, 2011.

[17] Theodore S Rappaport, Shu Sun, Rimma Mayzus, Hang Zhao, Yaniv Azar, Kevin Wang, George N Wong, Jocelyn K Schulz, Mathew Samimi, and Felix Gutierrez. Millimeter wave mobile communications for 5g cellular: It will work! IEEE access, 1:335-349, 2013.

[18] Paul Struhsaker (TRIAS Research). 5g leaps forward, what you need to know about 5g standards, spectrum and ecosystems, 2016.

[19] Wonil Roh, Ji-Yun Seol, Jeongho Park, Byunghwan Lee, Jaekon Lee, Yungsoo Kim, Jaeweon Cho, Kyungwhoon Cheun, and Farshid Aryanfar. Millimeter-wave beamforming as an enabling technology for $5 \mathrm{~g}$ cellular communications: theoretical feasibility and prototype results. IEEE Communications Magazine, 52(2):106-113, 2014.

[20] Shu Sun and Theodore S Rappaport. Multi-beam antenna combining for 28 ghz cellular link improvement in urban environments. In 2013 IEEE Global Communications Conference (GLOBECOM), pages 3754-3759. IEEE, 2013.

[21] International Telecommunications Union. Description of amateur and experimental operation between 415 and $526.5 \mathrm{khz}$ in some countries. Technical report, 112011. 